NBER WORKING PAPER SERIES

\title{
PRODUCTIVITY, EXTERNAL BALANCE AND \\ EXCHANGE RATES: EVIDENCE ON THE TRANSMISSION MECHANISM AMONG G7 COUNTRIES
}

\author{
Giancarlo Corsetti \\ Luca Dedola \\ Sylvain Leduc \\ Working Paper 12483 \\ http://www.nber.org/papers/w12483
}

\author{
NATIONAL BUREAU OF ECONOMIC RESEARCH \\ 1050 Massachusetts Avenue \\ Cambridge, MA 02138
}

August 2006

Prepared for the 2006 ISOM in Tallin. We thank our discussants Susanto Basu and Robert Kollmann, as well as seminar participants at the ECB and ISOM, for comments. We are grateful to Javier Rupay for help with the data. Corsetti's work on this paper is part of the Pierre Werner Chair Programme on Monetary Union, at the Robert Schuman Centre of the European University Institute. The views expressed here are those of the authors and do not necessarily reflect the positions of the ECB, the Board of Governors of the Federal Reserve System, or any other institutions with which the authors are affiliated. The views expressed herein are those of the author(s) and do not necessarily reflect the views of the National Bureau of Economic Research.

C2006 by Giancarlo Corsetti, Luca Dedola and Sylvain Leduc. All rights reserved. Short sections of text, not to exceed two paragraphs, may be quoted without explicit permission provided that full credit, including (C) notice, is given to the source. 
Productivity, External Balance and Exchange Rates: Evidence on the Transmission Mechanism Among G7 Countries

Giancarlo Corsetti, Luca Dedola and Sylvain Leduc

NBER Working Paper No. 12483

August 2006

JEL No. F32, F41, F42

\begin{abstract}
$\underline{\text { ABSTRACT }}$
This paper investigates the international transmission of productivity shocks in a sample of five G7 countries. For each country, using long-run restrictions, we identify shocks that increase permanently domestic labor productivity in manufacturing (our measure of tradables) relative to an aggregate of other industrial countries including the rest of the G7. We find that, consistent with standard theory, these shocks raise relative consumption, deteriorate net exports, and raise the relative price of nontradables --- in full accord with the Harrod-Balassa-Samuelson hypothesis. Moreover, the deterioration of the external account is fairly persistent, especially for the US. The response of the real exchange rate and (our proxy for) the terms of trade differs across countries: while both relative prices depreciate in Italy and the UK (smaller and more open economies), they appreciate in the US and Japan (the largest and least open economies in our sample); results are however inconclusive for Germany. These findings question a common view in the literature, that a country's terms of trade fall when its output grows, thus providing a mechanism to contain differences in national wealth when productivity levels do not converge. They enhance our understanding of important episodes such as the strong real appreciation of the dollar as the US productivity growth accelerated in the second half of the 1990s. They also provide an empirical contribution to the current debate on the adjustment of the US current account position. Contrary to widespread presumptions, productivity growth in the US tradable sector does not necessarily improve the US trade deficit, nor deteriorate the US terms of trade, at least in the short and medium run.
\end{abstract}

Giancarlo Corsetti

European University Institute

Badia Fiesolana

Via dei Roccettini 9

I-50016 San Domenico di Fiesole (FI)

Florence

ITALY

giancarlo.corsetti@iue.it
Luca Dedola

General Econ. Research Division

European Central Bank

Postfach 160319

D- 60066 Frankfurt am Main

GERMANY

luca.dedola@ecb.int

Sylvain Leduc

Board of Governors of the Federal Reserve

System

20th and C streets NW, Mail Stop 23

Washington, DC 20551

sylvain.leduc@frb.gov 


\section{Introduction}

A widespread view of the transmission mechanism holds that a productivity increase in the traded goods sector of a country should simultaneously lower the international relative price of domestic tradables (i.e. it should worsen the country's terms of trade) and raise the relative price of domestic nontradables - as predicted by to the Harrod-Balassa-Samuelson (henceforth HBS) hypothesis. A host of theoretical and quantitative models built by academics and researchers in policy institutions subscribe to this view, with far reaching implications at both theoretical and policy levels. Namely, international spillovers of productivity shocks are acknowledged to be unambiguously positive: foreign consumers benefits from an increase in the traded goods' production in the domestic country via reduced import prices (e.g. Corsetti and Pesenti [2001]). For this very reason, divergences in productivity levels across countries supposedly have a contained effect on relative national wealth. ${ }^{1}$ Moreover, terms of trade movements purportedly reduce the consumption risk of asymmetric productivity shocks: even if international asset markets do not provide complete insurance, relative price movements systematically reduce the wedge between domestic and foreign wealth induced by fluctuations in relative productivity. ${ }^{2}$ To the extent that international price movements insure consumption against production risk, the scope for welfare gains through international policy coordination may be quite limited (e.g. Obstfeld and Rogoff [2002]).

However, according to standard general equilibrium open-economy models, the macroeconomic effects and the international transmission of technology shocks need not be identical across economies that differ in structural characteristics such as openness and trade elasticities, as well as the degree of shock persistence. Depending on these features, country-specific gains in productivity are not necessarily associated with a (short-run) deterioration in the international relative prices of a country's output and consumption. For instance, the above conventional wisdom is unable to account for important episodes such as the US strong dollar and the US terms of trade appreciation

\footnotetext{
${ }^{1}$ Acemoglu and Ventura [2003] argue that, because of offsetting terms of trade movements, the world distribution of wealth can be stationary even in the absence of technological spillovers - i.e. if technical progress remains confined to a single country.

${ }^{2}$ To emphasize this point, Cole and Obstfeld [1991] point out that, with unitary elasticity of substitution between domestic and foreign goods and no home bias, international consumption risk sharing can be achieved without any international trade in assets.
} 
in the second half of the 1990s, which accompanied the productivity boom in this country (see Corsetti and Pesenti [1999]).

As the international transmission mechanism is at the core of theoretical modelling and policymaking alike, it is somewhat surprising to find limited empirical work on these issues. Taking a step towards addressing this gap in the literature, this paper analyzes the international transmission of productivity shocks in manufacturing among industrial countries. The countries in our sample - Germany, Italy, Japan, the UK and US - differ in size and degree of openness. ${ }^{3}$ For each country, we run structural VARs, identifying productivity shocks in manufacturing using long-run restrictions as in Galí [1999], Francis and Ramey [2003], and Christiano, Eichenbaum and Vigfusson [2004]. We emphasize two features of our study. First, we focus on productivity shocks to the tradable sector, rather than to the economy as a whole, because the theory's predictions are starker for the former than for the latter. Specifically, the effects of economy-wide productivity shocks on the domestic and international relative prices depend heavily on the distribution of the shock across sectors, making any inference on the international transmission exceedingly difficult. As the bulk of exports in industrialized countries consists of manufactured products, we look at manufacturing as a natural proxy for the tradable sector. Second, whereas previous studies mostly focused on the link between productivity and real exchange rates, motivated by the HBS hypothesis, we place significant emphasis on the joint dynamics of net trade and international relative prices (including the price of tradables). Our analysis incorporates three measures of international relative prices between each country and an aggregate of OECD economies, namely, a CPI-based, a PPI-based and an export-deflator-based real exchange rate - the latter being constructed to proxy for the terms of trade. ${ }^{4}$

Overall, our baseline VAR results square well with standard models' predictions on the international transmission along many dimensions: as a general pattern, positive productivity shocks in each of the countries in our sample raise domestic manufacturing output and aggregate consumption relative to an aggregate of other industrial countries. In response to such shocks, the trade balance worsens, its deterioration being persistent over time; the price of domestic tradables in terms of nontradables - proxied in most cases by

\footnotetext{
${ }^{3}$ We could not include France and Canada in our analysis because of the results of unit root tests on relevant variables - see section 4 .

${ }^{4}$ As discussed in the text, we build this proxy because bilateral import and export prices are unavailable for most countries in our sample.
} 
the PPI relative to the services CPI - falls, in full accord with the HBS hypothesis.

Most interestingly, we find that the real exchange rate's response to productivity shocks is heterogenous across countries. In the case of the US and Japan - the two largest and least open economies in our sample - productivity gains lead to a short-run appreciation in all our three measures of the international relative prices. The price response is instead not significant for Germany, at least in our baseline specification. In the case of the UK and Italy - the smaller and more open economies in our sample - we detect permanent depreciations.

It is worth emphasizing that, while the sign of the international price response differs across countries, in each economy all prices move in the same direction. Namely, the response of the CPI-based real exchange rate has the same sign as the response of the PPI-based and export-deflatorbased real exchange rates (or terms of trade). Together with our finding that nontradables prices always appreciate in response to productivity shocks to manufacturing, this result suggests that real exchange rate movements are dominated by movements in the terms of trade (proxied by our exportdeflator-based exchange rates), rather than by the HBS effect. ${ }^{5}$

We verify the robustness of our results along different dimensions, particularly by modelling in levels (rather than first differences) all the variables for which unit-root tests give contrasting results. For the US and Japan, our results are unchanged under this alternative specification. However, we detect short-run real exchange rate appreciation for Germany - possibly in line with the other large countries' results - and for the UK, while the response of the real exchange rate becomes insignificant for Italy. We also verify that our results are reasonably stable over different subsamples and across specifications where one country's productivity growth is not entered as a differential with respect to the rest of the OECD economies, but in absolute terms. Finally, using the model developed in Corsetti, Dedola and Leduc [2006], we carry out some Monte Carlo experiments to assess the performance of our identification strategy on simulated time series data, obtaining

\footnotetext{
${ }^{5}$ While the textbook version of the HBS hypothesis is often phrased in reference to a real appreciation of the exchange rate, we emphasize that such version is not correct when countries are specialized in the production of different tradable goods. In this case, whether or not the increase in the relative price of nontradables across countries also transpires into an appreciation of the real exchange rate depends on the sign and relative strength of the terms of trade movement.
} 
fairly encouraging results.

In the large countries in our sample, a productivity-driven macroeconomic expansion is initially associated with stronger international prices of domestic tradables prices, and a trade deficit. This characterization of cyclical expansions is reminiscent of models attributing international business cycle movements to demand shocks — such as the Mundell-Fleming-Dornbusch (MFD) model. Specifically, in the MFD model with flexible exchange rate, a real ('IS') demand boom raising output and employment, also increases imports and appreciates the currency in real terms (hence net exports are 'crowded out'). Overall, consumption and output booms are associated with a stronger currency and an external deficit. In the MFD theoretical framework, demand shocks are driven by exogenous policy measures (fiscal policy) and/or exogenous swings in the 'autonomous' component of consumption and investment spending — often motivated, but not modelled, in terms of changing expectations about future income or productivity.

In dynamic general equilibrium models, however, productivity shocks do affect relative prices and wealth, thus shaping consumption and investment demand. Early international real business cycle models have stressed the importance of intertemporal considerations for demand dynamics. For instance, Backus et al. [1995] shows that a persistent country-specific shock to productivity in an economy with investment leads to a current account deficit, as domestic agents raise their consumption with permanent income as well as invest in domestic technologies. Recent quantitative and analytical literature on the international business cycle has increasingly recognized the need to reconsider the dynamics of international prices as well. With incomplete markets, it is now well understood that pronounced wealth effects drive the response of domestic absorption (demand) to persistent productivity shocks. This response may be strong enough to cause a real appreciation, at least in the short run. Our results provide an empirical contribution to this literature.

Specifically, our overall findings for the US and Japan question the transmission mechanism embedded in some popular DSGE models of the international economy. Our results suggest that price movements may magnify the consumption risk of productivity fluctuations, as countries with larger tradable supplies also enjoy favorable terms of trade movements. By the same token, they suggest that the sign of the international spillovers from domestic productivity shocks be negative, at least in the short run.

To appreciate the importance of our findings for policy analysis, consider 
the recent debate on the adjustment process associated with an hypothetical reversal of the US current account. In a series of papers, Obstfeld and Rogoff [2004, 2005] argue that a drastic correction of the US external balance would entail a large real depreciation of the dollar. Yet, productivity differentials in the tradable sector between the US and the rest of the world would somewhat smooth out the adjustment: a higher supply of tradable would improve US net exports, via a worsening of the terms of trade, while containing the overall rate of real depreciation via the HBS effect.

Our empirical results challenge this view in at least two respects. First, our evidence suggests that the terms of trade movements in the short and medium run are the opposite of what is postulated by Obstfeld and Rogoff [2004]: our measures of the US international price of tradables appreciate with productivity gains in the US domestic tradable sector. ${ }^{6}$ Second, we find that, for a prolonged period of time, productivity gains do not improve the trade balance. Once the dynamic response of absorption to productivity gains in the traded good sector is taken into account, the short- to mediumrun effect on the US net trade is negative. By the same token, consider the claim that productivity growth in the rest of the world would unconditionally hamper the US external correction, unless it is concentrated in the nontraded good sector. ${ }^{7}$ Contrary to this claim, our VAR results suggest that productivity growth in most industrial countries, especially in Japan and Europe, is likely to raise global demand for US products in the medium run, even when productivity gains are concentrated in the manufacturing sector. The effect on the US trade balance would clearly be positive - in accord to standard models' predictions, that higher growth and productivity in Europe and Japan would help correcting current global imbalances.

The paper is organized as follows. Section 2 reviews the international transmission mechanism in standard theoretical and quantitative models, identifying alternative views and empirical predictions. Section 3 describes the data and the empirical methodology. Section 4 presents and analyzes in detail our main results. Section 5 discusses whether our identified impulse

\footnotetext{
${ }^{6}$ This result also holds when in our US VAR model, we specify the terms of trade as the relative price of exports in terms of overall US imports.

7 "We dispel some common misconception about what kind of shifts are needed to help close the US current account imbalances. Faster growth abroad helps only if it is relatively concentrated in nontradable goods; faster productivity growth in foreign tradable goods is more likely to exacerbate the US adjustment problem." (Obstfeld and Rogoff, [2004], abstract).
} 
responses correctly reproduce the international transmission in Monte Carlo experiments. Section 6 concludes, deriving policy implications. Appendix 1 describes the data in detail, Appendix 2 specifies the model used in the Monte Carlo experiments in Section 5.

\section{Productivity, international prices and the current account: a theoretical perspective}

A common view of the international transmission of country-specific productivity growth is that a higher supply of domestic tradables is absorbed by international markets at a lower price. In this section, we reconsider the theoretical underpinning of such a view. Specifically, we argue that the international transmission mechanism envisaged by standard theory generates a much richer macroeconomic and relative price dynamics. To do so, we will initially refer to well-known general equilibrium models of the international economy including both nontradables and country-specific tradables (e.g., Obstfeld and Rogoff [2000]); we will also briefly discuss recent models allowing for firms' entry and market dynamics.

\subsection{The international transmission mechanism with high consumption-risk insurance.}

According to standard theory, productivity gains in the tradable sector raise the price of non-tradables relative to tradables - as predicted by HBS and change the country's terms of trade. The overall response of the real exchange rate will depend on the relative magnitude of the movements in these prices: the HBS effect tends to appreciate the real exchange rate; if the terms of trade worsens, this tends to depreciate it. What does the sign and magnitude of the terms of trade response depend on?

A key role is played by the structure of international asset markets and the degree of international consumption insurance. When models are developed under the assumption of complete risk sharing, this assumption implies an important restriction on terms of trade and real exchange rate movements. As is well known, efficient consumption-risk insurance implies that the ratio of marginal utility of consumption across two countries is proportional to the bilateral real exchange rate between these countries. In other 
words, domestic consumption rises relative to foreign consumption only if its relative price - the real exchange rate - is depreciating. To see the implications of this condition for the international transmission mechanism, recall that positive productivity shocks to tradables increases the price of home nontradables through the HBS effect: ceteris paribus, this leads to a real appreciation. Thus, for domestic consumption to rise, the terms of trade must worsen enough to more than offset the nontradable price increase, causing an overall depreciation of the real exchange rate. ${ }^{8}$ An important implication is that models assuming a high degree of consumption insurance necessarily subscribe to the conventional wisdom about the international transmission mechanism as stated above, that a higher domestic supply of tradable lowers their international price (e.g., see Obstfeld and Rogoff [2000]).

It follows that terms of trade depreciation in response to positive productivity shocks is predicted by models assuming incomplete markets, yet implying allocations that are close to the first best - i.e. predicting a counterfactual positive and high correlation between relative consumption and the real exchange rate. This is an important lesson from influential contributions which have contrasted complete-market and incomplete-market models, showing examples where the models are remarkably close to each other as regards the equilibrium allocations and the transmission mechanism (see Cole and Obstfeld [1991], Baxter and Crucini [1995] and Chari, Kehoe, McGrattan [2002], and the discussion in Corsetti, Dedola and Leduc [2004]).

\subsection{The international transmission mechanism with low consumption-risk insurance}

When markets are incomplete, however, it is no longer true that relative consumption can increase only in the presence of real depreciation. Productivity gains drive a wedge between domestic and foreign wealth: if this (endogenous) wedge is large, productivity shocks cause substantial asymmetric effects on domestic demand relative to foreign demand. With large movements in relative domestic absorption, the terms of trade response can even change sign relative to the complete market allocation; by the same token, a rise in

\footnotetext{
${ }^{8}$ It is easy to verify that a similar argument goes through also in models without nontradables, but home bias in consumption. In this case, the real exchange rate and the terms of trade move in the same direction. Then, a productivity shock raising domestic consumption cannot but depreciate both international prices.
} 
relative consumption is not necessarily associated with real exchange rate depreciation, but can be accompanied by real appreciation - consistent with a large body of evidence after Backus and Smith [1993], Kollmann [1995] and Ravn [2001]. With incomplete markets, the international transmission mechanism thus depends on a key set of structural parameters, including the persistence of shocks and trade elasticities.

\subsubsection{Dynamic response to persistent shocks}

Consider first the case in which productivity innovations are very persistent and/or anticipated. The macroeconomic dynamic response to these shocks is in part consistent with the above conventional wisdom about the international transmission. Namely, in the long run, the terms of trade unambiguously depreciate relative to the initial equilibrium, as new capital is installed and becomes productive, and productivity is at its new, higher levels; correspondingly, the trade balance improves. In the short run, however, because of inefficient consumption risk insurance, relative domestic wealth and absorption increase markedly in anticipation of future output gains. A strong response in domestic absorption raises demand for domestic tradables relative to supply, opening a trade deficit. Under some conditions, the short-term surge in absorption can actually cause an equilibrium temporary appreciation of the terms of trade.

In related work (Corsetti, Dedola and Leduc [2006]), we analyze the above transmission mechanism in a standard DSGE model with traded and nontraded goods, and internationally incomplete asset markets, in which productivity shocks, though falling short of having a unit root, are somehow more persistent than what it is usually assumed in business cycle models. We show that the model can indeed generate terms of trade and real exchange rate appreciation in response to those very persistent productivity shocks to tradables, under the following conditions. First, the economy has a sufficiently high degree of home bias in absorption - calibrated in line with the US economy - so that the response in spending to a shock raising wealth falls to a large extent on domestically produced goods (the economy is relatively closed to trade). Second, the long-run price elasticity of domestic tradables is relatively high — close to the (mainly panel) estimates by trade economists, see e.g. Eaton and Kortum [2002]. This is because the higher the price elasticity, the smaller the long-run fall in the international price of domestic goods required to accommodate an increase in their supply. 
With a high elasticity, the effects of adverse relative price movements on the international value of domestic output and domestic wealth are contained. Third, agents can only borrow and lend in international markets.

Under these conditions, standard DSGE open economy models predict that the dynamic response of the terms of trade to long-lasting productivity innovations consists in short-run appreciation, followed by depreciation in the long run. Observe that terms of trade spillovers are positive in the long run, but negative in the short run, when the upsurge in domestic absorption driven by expectations of future productivity gains (and financed in international capital markets) raises the international price of domestic tradables, hurting foreign consumers. These results obtain by assuming shocks that are very persistent yet stationary. A fortiori, similar results obtain if shocks are permanent, or are anticipated, as shown in our Monte Carlo experiments in Section 5 .

\subsubsection{The role of price elasticities}

A variety of aggregate, time-series estimates pick up a very low price elasticity of imports (e.g., see Hooper et al. [1995]). Combined with a realistic degree of home bias in absorption, a low price elasticity of imports has important general equilibrium implications. Namely, wealth effects from terms of trade movements can be so strong that productivity gains raise, rather than lowering, the international price of a country's tradable output. An intuitive explanation (discussed at length in Corsetti, Dedola, and Leduc [2004]) is as follows. Provided that domestic consumers and firms are the largest buyers of domestic goods (home bias is strong), an increase in the global demand for these goods is possible only if domestic private income and absorption rise enough. A fall in the terms of trade however tends to reduce domestic wealth and income, as the selling price of domestic tradables determines the value of domestic output. If income effects from a low price elasticity are strong enough, a terms of trade deterioration would cause a shortfall in the global demand for domestic goods. Then, an increase in domestic supply must be associated with an equilibrium appreciation in the terms of trade.

Different from the analysis in the previous subsection, if the elasticity remains sufficiently low in the long run, the response of the terms of trade needs not change sign over time - i.e. there is no long-run depreciation. The terms of trade appreciate and domestic absorption booms on impact, opening a real and nominal trade deficit (if the appreciation is not too large). Welfare 
implications are starker. With a low elasticity, spillovers are unambiguously negative at all time horizons, and for any degree of shock persistence. Strong wealth effects imply that a country can capture most of the domestic gains in productivity in both the short and the long run, independently of the possibility of intertemporal trade. In contrast, with high elasticity and persistent shocks, terms of trade movements tend to create positive (albeit small) spillovers in the long run.

\subsection{Adjustment at the extensive margin}

Further doubts on the common view of international transmission of technology shocks are raised by the recent macroeconomic literature on firm dynamics and endogenous goods variety, which allows for firms' adjustment at both the intensive margin (i.e., changing the scale of production of a given set of goods) and the extensive margin (i.e., via the introduction of new goods). ${ }^{9}$ For instance, the international business cycle model by Ghironi and Melitz [2006] predicts that the terms of trade appreciate in response to an increase in (labor) productivity. In this model, however, productivity shocks reduce symmetrically both the marginal costs of producing goods, and the sunk cost of setting up new firms. Corsetti, Martin and Pesenti [2004] relax this assumption, showing that the terms of trade response to productivity differ radically depending on which costs is affected: the terms of trade appreciate following a drop in entry costs, but depreciate if technology innovations make good manufacturing cheaper. Cross-country evidence consistent with these effects is provided by Acemoglu and Ventura [2003] as well as by Debaere and Lee [2004]. ${ }^{10}$

A policy-relevant issue raised by this class of model is that, when the supply of goods varieties is endogenous, international spillovers depend not only on the movements of the terms of trade (an appreciation hurts foreign consumers), but also on the welfare implications of a changing array of goods available to consumers (an increase in varieties benefits foreign consumers). International welfare effects are not directly related to relative price movements: if the consumers' love for goods variety is high enough, international

\footnotetext{
${ }^{9} \mathrm{~A}$ theoretical attempt to build a model encompassing a discussion of both elasticities and creation of new goods is provided by Ruhl [2003].

${ }^{10}$ Also in this class of models the intensity as well as the direction of international price movements depend on the degree of international consumption risk sharing - as well as on the elasticity of labor supply (see Corsetti, Martin and Pesenti [2004]).
} 
spillovers of productivity shocks may be positive even when the terms of trade move against the Foreign country.

\section{Estimating the effects of a permanent tech- nology shock to manufacturing}

In this section, we present our strategy for identifying the effects of permanent shocks to technology in the manufacturing sector for the US, Japan, Germany, the UK, and Italy vis-à-vis an aggregate of the other G7 countries and three other OECD countries (Australia, Sweden and Ireland) for which we were able to obtain quarterly data on hourly labor productivity. We focus on time series evidence and use VAR methods, extending work by Galí [1999], Francis and Ramey [2003] and Christiano, Eichenbaum and Vigfusson [2004] — where technology shocks are identified via long-run restrictions to an open-economy context. Namely, we adopt the identifying assumption that the only type of shock which affects the long-run level of average labor productivity in manufacturing is a permanent shock to technology. Our work is thus related to a number of recent contributions which have investigated the effects of technology shocks identified using long-run restrictions in a closed-economy framework. This literature uses the basic insight from the stochastic growth model, that only technology shocks should have a permanent effect on labor productivity, to identify economy-wide technology shocks in the data. ${ }^{11}$

As discussed below, we use reduced-form time series methods in conjunction with our identifying assumption to estimate the effects of a permanent shock to technology. As argued by Christiano et al. [2004], an advantage of this approach is that we do not need to resort to the set of assumptions usually required to construct measures of technology shocks based on Solow residuals, including corrections for labor hoarding, capital utilization, and

\footnotetext{
${ }^{11}$ See Shapiro and Watson [1988], among others. Some open-economy papers, following Blanchard and Quah [1989], use long-run restrictions derived in the context of the traditional aggregate demand and aggregate supply framework. For instance, Clarida and Galí [1994] identify supply shocks by assuming that demand and monetary shocks do not have long-run effects on relative output levels across countries. While monetary shocks satisfy this assumption in most models, fiscal or preference shocks do not, since they can have long-run effects on output (and hours) in the stochastic growth model. A survey of the closed economy literature using long-run restrictions is Galí and Rabanal [2005].
} 
time-varying markups. ${ }^{12}$ On the other hand, we are fully aware that there exist models in which our identifying assumption may not be verified. An obvious instance is the case of endogenous growth models where all shocks affect productivity in the long run. Another possibility is that of an otherwise standard two-sector model, when there are permanent shocks in both the manufacturing and the other (nontradable goods) sector. To be as sure as possible that we have actually identified technology shocks in the manufacturing sector, our baseline specification includes the relative price of manufactured goods in terms of consumer services, as a proxy for the relative price of domestic tradables in terms of nontradables. This price should fall in response to a technology shock which is specific to the tradable sector. ${ }^{13}$

We examine the effects of technology shocks to the manufacturing sector (our proxy for traded goods), identified with long run restrictions, on the real exchange rate, the terms of trade, net exports and relative consumption and output - we leave a detailed description of the data sources to the data appendix. Over the period 1973 to 2004, we estimate several specifications of the following structural VAR model

$$
\left[\begin{array}{c}
\Delta x_{j, t} \\
\Delta y_{j, t}
\end{array}\right]=\left[\begin{array}{ll}
C^{x z}(L) & C^{x m}(L) \\
C^{y z}(L) & C^{y m}(L)
\end{array}\right]\left[\begin{array}{c}
\varepsilon_{j t}^{z} \\
\varepsilon_{j t}^{m}
\end{array}\right]
$$

Here $x_{j, t}$ denotes the variable that is assumed to respond in the long run exclusively to permanent technology shocks: in all our specifications, this variable is the (log of the) quarterly labor productivity in manufacturing, measured in deviation from quarterly labor productivity in manufacturing in the "rest of the world" (hereafter ROW). All ROW's variables are specific to country $j$ and built as an aggregate of a large sample of other countries (excluding country $j$ ) weighted according to their respective (time-varying) GDP shares at PPP values. ${ }^{14}$ This set of countries comprises six of the

\footnotetext{
${ }^{12}$ This is the approach followed by Basu, Fernald and Kimball [2006]. For yet another alternative based on sign restricitions, see Dedola and Neri [2004].

${ }^{13}$ In Corsetti, Dedola and Leduc [2004] we used (annual) TFP data for the US obtaining very similar results to those reported below. As argued by Chang and Hong [2002], the use of TFP provides a further check on the identification strategy, as it amounts to controlling for long-run effects on labor productivity brought about by changes in the long-run capital labor ratio by other permanent shocks, e.g. capital tax-rate shocks (see Uhlig [2003]). Unfortunately, we could not extend the analysis in Corsetti et al [2004] to the other countries because of lack of data on sectoral TFP.

${ }^{14}$ We use GDP shares as trade weights were not available for all countries going back to 1970.
} 
G7 countries (thus including Canada and France), plus Australia, Ireland and Sweden. ${ }^{15}$ The vector $y_{j, t}$ is $5 \times 1$ and always includes (the log of) a country-specific index of manufacturing production and aggregate consumption relative to the same variable for the ROW, the country's ratio of nominal net export over GDP and (the log of) the relative domestic producer price index over the domestic consumer price index (of services, when available) in country $j$. The last variable in $y_{j, t}$ is a measure of international relative prices vis-à-vis ROW:

$$
R E R_{i}=\frac{P_{i}}{S P_{i}^{*}}
$$

where the price indexes $P_{i}$ and $P_{i}^{*}$ are alternatively (the log) of the CPI, PPI and export-deflator, and $S P_{i}^{*}$ is also built as a PPP GDP-weighted aggregate of the countries included in ROW. ${ }^{16}$

Finally, $C(L)$ is a polynomial in the lag operator; $\varepsilon_{j t}^{z}$ denotes the technology shock to manufacturing specific to country $j$, and $\varepsilon_{j t}^{m}$ the other structural, non-technology shocks. Although not necessary for identification, implicit in our benchmark specification is the assumption that all the variables other than productivity also have a unit root. Lacking any strong theoretical apriori on the stationarity of the variables included in the VARs, we resorted to standard unit root tests. In our sample, the assumption of nonstationarity is consistently not rejected in the data, but for Japanese net exports — tests' results are shown in Tables A1 through A5. ${ }^{17}$ However, following the suggestions in Christiano, Eichenbaum and Vigfusson [2004], whenever

\footnotetext{
${ }^{15}$ These 10 countries add up to roughly half of world GDP at PPP values, so they represent a substantial sample of the global economy. Moreover, trade flows among them also amount to over a half of their respective total trade, on average. For instance, the US trade share with the other 9 countries in our sample is around 60 percent of US total trade.

${ }^{16}$ This is meant to capture the following well-known decomposition of the CPI-based real exchange rate between a first component due to the relative price of tradables across countries, and a second component due to the relative price of tradables in terms of nontradables within countries (see Engel, 1999):

$$
R E R=\frac{P}{S P^{*}}=\frac{P_{T}}{S P_{T}^{*}}\left(\frac{P_{T}^{*}}{P_{N}^{*}}\right)\left(\frac{P_{N}}{P_{T}}\right) .
$$

${ }^{17}$ We run both the Phillips and Perron [1988] and Elliot, Rothenberg, Stock [1996] GLSmodified Dickey-Fuller tests, allowing the level of variables to have alternatively a constant term or also a deterministic trend.
} 
there is some evidence against a unit root, we also estimate specifications of the VARs with the corresponding variable (such as the real exchange rates or net exports) in levels, rather than growth rates.

Together with the usual assumption that the structural shocks $\varepsilon_{t}$ are uncorrelated and have unitary variance, positing that $C^{x m}(1)=0$ is enough to identify $\varepsilon_{t}^{z}$. This restricts the unit root in the variable $x_{t}$ to originate solely in the technology shock. In practice, in order to estimate impulse responses to the technology shock we follow the Bayesian approach for just-identified systems discussed in Doan (1992). For each country, we begin by estimating the following 4th-order reduced form VAR:

$$
Z_{j, t}=\alpha+B_{j}(L) Z_{j, t-1}+u_{j, t}, E u_{j, t} u_{j, t}^{\prime}=\Sigma_{j},
$$

where $Z_{j, t}=\left[\begin{array}{c}\Delta x_{j, t} \\ \Delta y_{j, t}\end{array}\right]$, and $u_{t}$ is the one-step-ahead forecast error in $Z_{j, t}$. Also, $\Sigma_{j}$ is a positive definite matrix. It is well-known that positing a non informative prior of the Normal-Wishart family and a Gaussian likelihood implies that the posterior for parameters of the reduced form VAR above is also Normal-Wishart (see Uhlig [2001] for a formal derivation), whose parameters including $\Sigma$ can be estimated by OLS applied to each equation. The structural economic shocks, $\varepsilon_{j t}$, are related to $u_{j t}$ by the following relation (dropping the subscript $j$ ):

$$
u_{t}=A_{0}^{-1} \varepsilon_{t}, E \varepsilon_{t} \varepsilon_{t}^{\prime}=I .
$$

As in (1), without loss of generality, we suppose that $\varepsilon_{t}^{z}$ is the first element of $\varepsilon_{t}$, and $B(L)=A_{0}^{-1} C(L)^{-1}$. The assumption that $C^{x m}(1)=0$ implies that the first column of $A_{0}^{-1}$, depicting the effects of a technology shock on the variables in the VAR, is uniquely defined by:

$$
A_{0}^{-1}=\widetilde{B}(1)\left[\operatorname{chol}\left(\widetilde{B}(1)^{-1} \Sigma \widetilde{B}(1)^{-1^{\prime}}\right)\right]^{-1}, \widetilde{B}(1)=[I-B(1)] .
$$

Therefore, for each draw from the known posterior of the reduced-form VAR we can compute a unique $A_{0}^{-1}$ and the associated impulse responses. ${ }^{18}$

\footnotetext{
${ }^{18}$ Results below are based on 1000 draws.
} 


\section{The international transmission of perma- nent productivity shocks to tradables pro- duction}

In this and the next section, we report our results for five G7 countries (US, Japan, Germany, UK, Italy) in our sample. Our data are displayed in appendix 1, Figures A1-A5. We consider the sample period 1973-2004, corresponding to the international monetary system after the collapse of Bretton Woods (and the longest period for which we have data). While we initially included all the G7 countries in our analysis, we were forced to drop France and Canada from the analysis because for these countries unit-root tests rejected the hypothesis of nonstationarity in the measure of labor productivity differential with the ROW. ${ }^{19}$ In what follows, we report results based on our baseline specification, in which all variables are in growth rates. In the following subsection, we will conduct sensitivity analysis.

\subsection{Baseline specification}

Figures 1 through 5 display the impulse response functions for our baseline difference specification, along with 68 percent pointwise posterior confidence intervals. For instance, Figure 1 displays the response of US relative productivity, manufacturing output $\left(\mathrm{Y}^{-\mathrm{Y}^{*}}\right)$, and aggregate consumption $\left(\mathrm{C}-\mathrm{C}^{*}\right)$, all in log differential with ROW, along with nominal net trade over GDP $(\mathrm{NX} / \mathrm{Y})$, the PPI relative to the services CPI, and our three alternative international relative prices (RER), based on the CPI, the PPI and the export deflator. Each figure shows the OLS estimates (the black solid line), the median (the red solid line) and the 16th and 84th percentiles (the blue dashed lines) of the posterior distribution.

Starting with the US, our main results are as follows. First, the median impact effect of the shock on relative manufacturing output and aggregate consumption is slightly negative but statistically insignificant in the short run; both variables however converge to a permanently higher level after three years. Second, the long-run increase in both these variables is of the order of 0.5 percent, against a permanent increase of 1.5 percent in the pro-

\footnotetext{
${ }^{19}$ Precisely, in the case of France (Canada) both the Phillips-Perron and the GLS DickeyFuller tests rejected the null of nonstationarity at the 1 (10) percent confidence level.
} 
ductivity differential. Note that the rise in relative consumption and productivity are estimated with higher precision than the rise in output. Third, the technology shock leads to a prolonged, statistically significant fall in both net exports and the relative price of domestic tradables. The latter corresponds to a Balassa-Samuelson effect, according to the conventional wisdom about the relative price implications of productivity gains in manufacturing. Note that this result provides some support to the identification scheme underlying our analysis, against the possibility of productivity innovations more concentrated in others sectors (which are less likely to cause a significant increase in the price of nontradables). ${ }^{20}$

The fall in net export may be surprising, in light of some applied and policy literature postulating that a productivity increase in tradables should bring about an improvement in net trade. Against this presumption, our empirical results suggest that the deterioration in net trade peaks after about three years, standing at roughly 0.15 percentage points of nominal GDP, and persist in the long-run. While this very persistent effect reflects the assumption — strongly supported by unit root tests - that the net-tradeto-GDP ratio is nonstationary, it is by no means a mechanical implication of that assumption. ${ }^{21}$

Fourth, the CPI-based RER temporarily appreciates (an increase is an appreciation) in the aftermath of the shock, and then goes back to its previous long-run level. Notably, together with the response of relative consumption, the response of the CPI-based RER is at odds with the condition for efficient consumption risk sharing - but consistent with the evidence in Backus and Smith [1993]. Finally, the other two measures of international relative prices display the same pattern as the CPI-based RER. As these two measures are built using PPIs (i.e. price indexes including a larger share of tradables than the CPI) and export deflators (including only the price of traded goods), our results suggest that the RER appreciation reflects more than the classical Balassa-Samuelson effect: it also captures important terms of trade effects, as well as deviations from the law of one price (LOP) for manufacturing goods.

\footnotetext{
${ }^{20}$ Moreover, if our identification scheme was picking just an (offsetting) measurement error in manufacturing labor productivity and the PPI, it would be quite far-fetched that this measurement error be also positively correlated with very persistent increase in relative aggregate consumption and deterioration of net exports.

${ }^{21}$ See Engel and Rogers [2005] for further evidence on the nonstationary behavior of US net trade.
} 
In Figures 2 through 5, we report the same set of impulse responses for Japan, Germany, the UK and Italy, respectively. Relative to the US, these countries display similar patterns overall, but also some important differences. For all countries, a positive shock increases the consumption differential after a few quarters; it decreases both the nominal net trade relative to GDP as well as the relative price of manufacturing in terms of services/overall CPI - with the exception of Japan, where the latter variable initially rises, albeit insignificantly. The initial positive response of relative manufacturing output translates into a permanent increase in Japan, the UK and Italy, but it is significant only in Japan, where it levels off at around 1.5 percent. Relative output instead displays a permanent and significant fall in Germany. ${ }^{22}$ Conversely, relative consumption increases permanently in all four countries by around 0.5 percent, albeit insignificantly in Japan. The deterioration of net exports over GDP is stronger in the UK and Germany, where it is also permanent; in Italy this variable displays a similar qualitative behavior but is significantly negative only for a couple of quarters one year after the shock. As in the US case, these permanent effects reflect the assumption that the net-trade-to-GDP ratio is nonstationary, in line with results from unit root tests. In Japan net exports - modelled as stationary — reach a minimum 8-10 quarters after the shock, and then slowly revert to their baseline value. Finally the relative price of manufactured goods in terms of services falls permanently in all countries, although significantly so only in Germany and Italy.

Strikingly different patterns emerge as regards international pricing. As for the US, also in Japan all measures of international relative prices, including the CPI-based RER, significantly appreciate in the first few quarters after the shock. Conversely, international relative prices depreciate permanently in the case of Italy and the UK - for these countries, our results are close to the conventional view of the international transmission mechanism. The response of international prices is small and insignificant in the case of

\footnotetext{
${ }^{22}$ This result for Germany does not sit well with the assumption that the identified shock is a positive technology shock. However, alternative interpretations run into even more serious problems with other variables' responses. Similarly to the case of a measurement error in labor productivity discussed above, attributing the estimated responses to an increase in labor taxes, though consistent with the productivity increase and the output drop, could hardly be reconciled with the positive wealth effect implied by both consumption and net exports responses. Moreover, it would also be at odds with the large fall in the domestic relative price of manufactured goods.
} 
Germany. Note that, as for the US, in each country in our sample, our three measures of relative prices display the same behavior despite the different weights of tradable goods in the corresponding price indexes. This result lends support to the hypothesis that terms-of-trade movements and deviations from the law of one price play a crucial role in driving the CPI-based real exchange rate dynamics in the aftermath of the productivity shock.

Our baseline results on the international transmission of productivity shocks to manufacturing can be summarized as follows. First, we find that a positive shock leads to an increase of domestic consumption above foreign consumption, and worsens the trade balance.

Second, with the exception of Japan, where this effect turns out to be insignificant, productivity gains in manufacturing lower the PPI relative to the (services) CPI. As the latter index includes a much larger share of nontraded goods, this is evidence in support of the HBS hypothesis: in response to sector-specific productivity gains, nontraded good prices appreciate relative to tradables.

Third, the real exchange rate response is heterogenous across countries. However, in each individual country our three measures of the real exchange rate move in very similar ways - despite the different degree of tradability of the goods included in the corresponding price indexes (CPI, PPI or export deflator). In the case of the US and Japan - the two largest and least open countries in our sample - productivity gains lead to a short-run appreciation in all our measures of the real exchange rate. In our baseline specification, the response is instead not significant for Germany. In the case of the UK and Italy - the smaller and more open economies in our sample - , we detect permanent depreciations. So, while we find evidence of a Balassa-Samuelson increase in the domestic relative price of nontradables in all countries, the CPI-based real exchange rate seem to be driven by a country's terms of trade, as proxied by our export-deflator based real exchange rate.

\subsection{Sensitivity analysis}

In this subsection, we investigate the sensitivity of our analysis along three dimensions. First, we allow some variables to enter the VAR specifications in levels, possibly with deterministic trends; second we verify subsample stability; third, we re-estimate the VAR models with labor productivity growth in each country, not measured in deviations from 'ROW'. Robustness along a further dimension, the choice of variables included in the VARs, was obtained 
in part as a by-product of the above analysis, in part through alternative specifications of the model, e.g. including a different international relative price - the PPI- instead of the CPI based real exchange rate. These alternative specifications did not have any significant impact on our results. ${ }^{23}$

\subsubsection{Results with level specifications}

It is well-known that VAR's with long-run restrictions may be sensitive to mistakenly modelling stationary series as nonstationary because of the ensuing specification error due to overdifferencing (see Christiano et al. [2004]). Since unit-root tests yield conflicting results regarding the nonstationarity of some of our series, we run additional VARs with these variables in levels, detrending them when appropriate. Note that, by construction, this entails a zero long-run response of these variables. Specifically, our unit root tests give conflicting results for at least one measure of international relative prices in all countries, and for net exports over GDP in the case of the UK and Italy. This latter variable is stationary in Japan and nonstationary in the US and Germany according to all tests considered. ${ }^{24}$

The results of our sensitivity analysis are reported in Figures 6 through 10 with the same variables' mnemonics and format as before. Namely, each figure shows the OLS estimates (the black solid line), the median (the red solid line) and the 16th and 84th percentiles (the blue dashed lines) of the pointwise posterior distribution. For the case of US and Japan, Figures 6 and 7 make it clear that our baseline results are not sensitive to alternative assumptions about the stationarity of international relative prices. In these figures we assume that all our measures of international prices are stationary around a deterministic trend: as in the case of Figures 1 and 2, all these relative prices appreciate significantly in the short run in response to a positive technology shock.

However, some baseline results turn out to be sensitive to the level specification for Germany, the UK, and Italy. Although the responses of con-

\footnotetext{
${ }^{23}$ We also estimated specifications of the model including other domestic and international variables, like total and non-residential investment, and aggregate GDP, obtaining broadly similar results to those discussed in the text.

${ }^{24}$ For these latter two variables, besides the Phillips-Perron and GLS Dickey-Fuller tests, we also run KPSS tests (see Kwiatkowski et al., [1992]). The null of stationarity was rejected at least at the 5 percent level, even when we included a deterministic trend in the variables' level specification.
} 
sumption and output differentials, as well as that of the relative price of nontradables are generally unchanged, we detect differences in the behavior of international relative prices. Figures 8 and 9 show that all measures of international relative prices markedly appreciate in the short run in the case of Germany and the UK. Conversely, the responses of international relative prices in Italy - shown in Figure 10 - turn out to be small and not significantly different from zero. Finally, modelling net exports in levels for the UK (Figure 9) or Italy (Figure 10) does not change the sign of their responses, as they continue to deteriorate after a few quarters, albeit not significantly. ${ }^{25}$

These results robustly suggest that the international transmission of productivity shocks is at odds with the conventional wisdom - that higher supply leads to terms of trade depreciation — in the cases of the US and Japan. This conventional wisdom is instead verified for Italy - although the response of the international prices and net exports may be small. For Germany and the UK, results vary depending on the assumptions about stationarity of the real exchange rate.

\subsubsection{Subsample stability}

In this subsection we briefly discuss subsample stability, focusing on the benchmark specification. Stock and Watson [2005], among others, have argued that the world economy has become less volatile after the 1970s the "great moderation" — and that this resulted in a structural change in VAR's. Moreover, one can observe that the first years in our sample were characterized by the transition from the Bretton-Woods regime of fixed exchange rates, to the current regime of floating rates. Finally, the beginning of the 21st century has witnessed several changes in the global economy, with the rapid growth of large emerging market countries such as China and India, the launch of the European common currency, and the emergence of large current account imbalances across the world. This subsection assesses the robustness of our conclusions to the possibility of subsample instability due to these changes.

Panels A and B of Figure 11 - referred to the US - display the estimated impulse responses of the variables in our baseline system, for the pre-1999Q1

\footnotetext{
${ }^{25}$ We also run a specification for Germany with also the detrended consumption differential in level, given that the Phillips-Perron test without a constant rejected a unit root in this variable at the 5 percent level. Since results are very similar results to those displayed in Figure 8 we do not report them in this version of the paper.
} 
and post-1978Q4 sample periods, respectively. As before, each figure shows the OLS estimates (the black solid line), the median (the red solid line) and the 16th and 84th percentiles (the blue dashed lines) of the pointwise distribution in the indicated subsample. To save on space, we do not show the results for the other countries, as these substantially confirm our findings for the US.

The key results are as follows. First, the qualitative patterns of all variables responses are broadly similar across periods, and in full accord to our estimates for the full sample. The US net exports deteriorate persistently and international relative prices appreciate on impact in both subsamples. Second, both the median and OLS estimates for each sample period would lie well within the 68 percent confidence intervals in the full sample. This is consistent with the view that the responses in the subperiods are the same as they are for the full sample. However, the estimated effects of technology appear somehow less significant, perhaps due to the loss of degrees of freedom entailed by reducing the number of observations. Overall, this evidence is consistent with the view that the responses in the subperiods are the same as they are for the full sample and there is no break in the international transmission of tradable technology shocks.

\subsubsection{Absolute vs relative productivity shocks}

We conclude this section by briefly discussing what happens if we identify permanent shocks to the absolute level of a country's labor productivity, rather than to its productivity differential relative to the rest of the world. ${ }^{26}$ The important difference is that the former shock can diffuse to productivity levels in other countries in the long-run. We do so despite our empirical findings that labor productivity differentials are non-stationary - a result in line with the Ricardian idea of perfect specialization in tradables entertained in most standard DSGE open-economy models. These findings notwithstanding, it could be argued that technological diffusion should bring all countries on the same production frontier in the long run. If this view is correct, long-run differentials in measured productivity should be attributed to factors other than technology, e.g. taxes. In this respect, it is worth noting that the closed economy literature from which we borrow our identification strategy is concerned only with shocks affecting the absolute level of produc-

\footnotetext{
${ }^{26}$ We thank our discussant Susanto Basu for suggesting to pursue this robustness check.
} 
tivity in a specific country. In what follows, we assess the robustness of our conclusions to the possibility of misspecification due to defining productivity in deviations from other countries.

Figure 12 - referred to the US - displays the estimated impulse responses of the variables in our system in first differences, where the only departure from our baseline specification above is that labor productivity in the rest of the world is not subtracted from its US counterpart. In accord with the international focus of our analysis, the other variables are defined exactly as before. As in the previous figures, each chart shows the OLS estimates (the black solid line), the median (the red solid line) and the 16th and 84th percentiles (the blue dashed lines) of the pointwise distribution in the subsample. As the results for all the other countries substantially confirm our findings for the US, to save on space, we only show the results for this country.

The key results are as follows. First, the qualitative and quantitative patterns of all variables responses are in full accord with our baseline estimates in Figure 1. Relative output and consumption display a permanent increase, while US net exports deteriorate persistently and international relative prices significantly appreciate in the first few quarters; the PPI falls permanently in terms of CPI services. Second, both the median and OLS estimates would lie well within the 68 percent confidence intervals in the baseline specification in Figure 1. This is consistent with the view that the responses are the same as for the specifications with productivity differentials, and that we are truly identifying shocks that permanently affect US productivity both in absolute level and relative to the rest of the world. ${ }^{27}$

\footnotetext{
${ }^{27}$ For the US, we also estimated a system with quantity variables not in deviations from the rest of the world, and terms of trade and real exchange rates defined vis-à-vis a broader set of countries, from the OECD Economic Outlook database. Again we find broadly similar results to those reported in Figure 12.

In addition, our findings are further corroborated by Bems, Dedola and Smets [2006] — who also find that, in line with the predictions in Backus, Kehoe and Kydland [1995], shocks that permanently increase US labor productivity in the overall business sector bring about a deterioration of net trade - and by Enders a Mueller [2006] — who in addition find that these shocks appreciate both the terms of trade and the real exchange rate.
} 


\section{Do identified impulse responses correctly reproduce the international transmission?}

In this section we examine whether our identification strategy is able to detect the true effect of a positive technology shock on the terms of trade and the real exchange rate, when this effect can be either an appreciation or a depreciation. We pursue this goal by drawing on recent VAR literature, whose aim is to assess the ability of a given set of identifying restrictions to recover the true impulse responses when applied to data simulated using stochastic general equilibrium models. ${ }^{28}$ In line with this literature we run the following experiment. First, we simulate time series from a standard DSGE model with traded and non-traded goods similar to that of Stockman and Tesar [1995], except that we assume incomplete asset markets. Second, for each realized set of time series, we estimate a reduced form VAR with 4 lags with the same variables as in our baseline specification in Section 4, and apply the identification scheme described in Section 3 above to estimate the effects of technology shocks.

We emphasize that the aim of our exercise is not to provide a broad assessment of the general properties of long-run restrictions with simulated data from models which are estimated from actual macroeconomic data - thus giving a complete description of the latter (see e.g. Christiano, Eichenbaum and Vigfusson [2006]). Such an ambitious goal is clearly beyond the scope of this paper. More modestly, we ask whether the set of model's conditional moments (impulse responses) computed by applying VARs with long-run restrictions to simulated data does a good job in detecting different patterns of the international transmission, when simulated data are produced by calibrated open-economy models which satisfy our identifying assumption that labor productivity in manufacturing has a unit root because of a nonstationary technology shock. In particular, we ask whether the VARs' impulse responses change in the same way as the theoretical impulse responses across models entailing different transmission mechanisms. This is a prerequisite for impulse responses from identified VARs from the data to be useful in providing guidance in choosing across different open-economy models.

The artificial economies we use are characterized by home bias in do-

\footnotetext{
${ }^{28}$ See, among others, Erceg, Guerrieri and Gust [2003], Chari, Kehoe and McGrattan [2004], Giannone, Reichlin and Sala [2006], and Christiano, Eichenbaum and Vigfusson $[2006]$.
} 
mestic spending on tradables and by the presence of distribution services produced with the intensive use of local inputs; our models therefore generates realistic departures from purchasing power parity. We describe the main building blocks of the model in Appendix 2; a more detailed analysis of the model's properties can be found in Corsetti, Dedola, and Leduc [2006]. As discussed in Section 2, the international transmission of productivity shocks to tradables - especially the response of the terms of trade and the exchange rates - can vary significantly, depending on shock persistence and price elasticities. To be consistent with our identification procedure, we assume that productivity shocks to tradables follow a unit root process in all our experiments. We then simulate our model under two alternative parameterizations of the trade elasticities, giving rise to different transmission mechanisms of technology shocks to tradables. Namely we set the trade elasticity equal to 1 and 4, respectively. The value of 1 entails a transmission consistent with the conventional view described in Section 2.1, and is quite common in contributions subscribing to that view (e.g. Obstfeld and Rogoff [2000]). The second, higher value for the trade elasticity, equal to 4, is in line with the estimates typically used by international trade studies; with this value the international transmission follows the pattern described in Section 2.2.1. The values of all the other parameters of the model are constant across experiments; Appendix 2 describes the model's calibration in detail. In order to avoid stochastic singularity problems when estimating the VARs, in the simulations we add other shocks hitting the economy, namely persistent shocks to productivity in the nontradable sector in each country and taste shocks to the utility function, as in Stockman and Tesar [1995]. All shocks' innovations have the same standard deviation, set to 0.7 percent.

We simulate 100 datasets of 128 time periods for our two alternative parameterizations. As in our empirical VARs, each simulated dataset includes the following variables: relative labor productivity and output in the tradable sector, aggregate relative consumption (all in log differential with ROW, namely the other country), along with net trade over GDP and the relative price of tradables over nontradables, and the terms of trade (the relative price of exports in terms of imports).

Figures 13 and 14 report the result from applying long-run restrictions to simulated data from the economy with trade elasticity equal to 4 and 1 , respectively. In each chart, we report the theoretical response (the red line) and the average response estimated by the VAR across all simulations (the black line). Following Christiano, Eichenbaum, and Vigfusson [2006], 
we also report two sets of confidence intervals. The first interval, represented by the dotted green lines, denotes the true degree of sampling uncertainty, measured by a 68 percent error band around the estimated impulse response functions across the 100 simulated datasets. The second confidence interval, corresponding to the dotted blue lines, is computed by estimating the VAR and computing confidence intervals for each simulated dataset using the procedure described in Section 3, and then averaging the upper and lower bands over these 100 simulations.

Consider first the theoretical responses — the solid red lines — under the alternative parameterizations. In both parameterizations, a productivity improvement in the tradable sector leads to a rise in relative labor productivity, relative output, and relative consumption, to a fall in the relative price of tradables to nontradables, and to a deterioration of net exports. However, the response of international relative prices differ noticeably across experiments. Because a permanent productivity shock induces sizeable wealth effects that raise Home demand for domestic products, the terms of trade persistently appreciate following the shock when the price elasticity is relatively high (Figure 13) — the real exchange rate, not reported in the figure, moves together with the terms of trade. Conversely, international prices depreciate on impact when the price elasticity is set to1 (Figure 14).

Turning to the estimated impulse responses, it is clear that our identification procedure captures fairly well the qualitative features of the different transmission mechanisms. In both parameterizations, the estimated impulse responses uncover the correct sign of each variable's response; the VAR average impulse response is in most cases close to the true impulse response. In both experiments, the VAR correctly predicts a permanent increase in relative labor productivity, relative output, and relative consumption. More strikingly, the VAR distinguishes to a large extent the differences in the transmission mechanism across experiments. It correctly uncovers an appreciation (depreciation) of the terms of trade in Figure 13 (Figure 14). Notably, in the case of the high trade elasticity, it detects that the appreciation of the terms of trade is persistent but not permanent. However, the VAR has some difficulty uncovering with precision the theoretical response of the relative price of nontradables. For this variable, the VAR displays some bias toward zero - this being the only instance in which the true impulse response falls outside of the estimated confidence bands. Finally, note that, as apparent from Figures 13 and 14, the procedure adopted in Section 3 to compute confidence bands (corresponding to the dotted blue lines), is fairly conservative 
- as it typically encompasses the true degree of sampling uncertainty (corresponding to the dotted green lines). These results therefore suggest that an econometrician using our procedure would be unlikely to infer incorrectly that a response is significant when the true response is not.

To sum up, the experiments discussed in this section suggest that, if the identifying assumption that the only source of unit root in labor productivity in manufacturing is correct, our empirical findings are unlikely to be driven by some bias inherent in our approach. We view this result as supporting our approach — our methodology appears to lead to a correct inference of the international transmission of technology shocks to tradables.

\section{Discussion and implications for open-economy modelling and policy analysis}

In this paper, we provide empirical evidence on the international transmission of productivity shocks among G7 countries. Relative to the literature, our contribution is novel in at least two respects. First, it applies time series methods with minimal identifying assumptions to international data. Second, we jointly study the dynamics of the international transmission and international relative prices, distinguishing between the relative price of nontradables, the real exchange rate and the terms of trade.

Our main result is that the international transmission of productivity shocks in manufacturing — which we identify with the tradable sector squares quite well with the main predictions of standard general equilibrium models of the international economy, discussed in Section 2.

First, productivity gains in manufacturing lower the PPI relative to the (services) CPI in all countries. As the latter index includes a much larger share of nontraded goods, this is evidence in support of the Harrod-BalassaSamuelson hypothesis.

However, the response of international prices is not identical across countries, but appears to vary across economies with different size and degree of openness. Namely, both the real exchange rate and the terms of trade appreciate in the largest and less open economies - the US and Japan in contrast with a conventional view of the international transmission. Conversely, international relative prices depreciate in a small open economy such as Italy — similar results for the UK turn out to depend on assuming non- 
stationarity of the real exchange rate. Results for Germany are inconclusive.

The results for the US and Japan challenge a popular view of the core transmission mechanism in DSGE models of the international economy. They suggest that price movements may raise the international consumption risk of productivity fluctuations, as countries with larger supplies will also rip further gains from favorable terms of trade movements; by the same token, the sign of the spillovers from productivity shocks may be negative, with relevant policy implications. Namely, our results help understand the dynamics of the US terms of trade and real exchange rate when this country experienced a persistent increase in productivity growth in the second half of the 1990s - whereas both the relative price of US exports and the US real exchange rate appreciated together. In this respect, the terms of trade dynamics unveiled by our empirical analysis run counter to the view that favorable price movements contain national wealth differences when countries experience (persistent) productivity growth differentials. In such circumstances, market forces may provide much less automatic stabilization of consumption and real income across borders than commonly believed. Finally, our evidence suggests that terms of trade movements in the short and medium run are the opposite of what is postulated by many observers, e.g. Obstfeld and Rogoff [2004], who build world-wide adjustment scenarios following a reduction of the US current account deficit. Our measures of the US international price of tradables instead appreciate on impact with productivity gains in the US domestic tradable sector.

Second, as a general pattern, positive shocks raise total domestic consumption and manufacturing output relative to their foreign counterpart, and worsen the trade balance. The negative response of net exports is stronger in the case of our three largest countries; it is insignificant only in some specifications of the empirical model for Italy and the UK. The finding that the external account response is persistently negative is especially relevant for the case of the US. Our results are at odds with the view expressed in recent policy contributions, that productivity growth in US manufacturing could lead to an early and relevant improvement in the US external trade balance. According to our VAR evidence, other things equal, the dynamics of domestic demand in response to productivity shocks is not likely to contribute to a US current account reversal at least in the short and medium run. Instead, our results lend support to the standard policy view that productivity growth in the rest of the (industrial) world could help reduce the US current account deficit, even when relatively concentrated in the production of tradables. 


\section{Appendix 1 Data description and sources}

\section{United States}

Labor productivity: Index of output per hour of all persons in manufacturing sector, seasonally adjusted, $1992=100$ (Bank of International Settlements and Dept. of Labor).

Manufacturing output: Index of industrial production in manufacturing, seasonally adjusted, $2000=100$ (Federal Reserve Board)

Consumption: Private final consumption expenditure, volume in national currency, seasonally adjusted (OECD, Economic Outlook Database).

Nominal GDP: Gross domestic product, value, market prices in national currency, seasonally adjusted (OECD, Economic Outlook Database)

Net exports:Net exports of goods \& services, value in national currency, seasonally adjusted (OECD, Economic Outlook Database)

PPI index: Producer price index of manufactured products, seasonally adjusted, $2000=100$ (OECD, Main Economic Indicators Database)

CPI total: Consumer price index all items, seasonally adjusted, $2000=100$ (OECD, Main Economic Indicators Database)

CPI services: Consumer price index for services less energy services, seasonally adjusted; 1982-84 = 100, monthly converted to quarterly averages (BLS)

Export deflator: Exports of goods and services, deflator, seasonally adjusted, national accounts basis; $2000=100$ (OECD, Economic Outlook Database)

CPI-based real exchange rate: Index of ratio of US CPI (total) to aggregate CPI (total) of 9 OECD countries, all in current US dollars, weighted with GDP shares at annual PPP values, 1970q1 = 100 (authors calculations based on OECD, Economic Outlook Database)

PPI-based real exchange rate: Index of ratio of US PPI (manufacturing) to aggregate PPI (manufacturing) of 9 OECD countries, all in current US dollars, weighted with GDP shares at annual PPP values, 1971q1 = 100 (authors calculations based on OECD, Economic Outlook Database)

Terms of trade: Index of ratio of US export deflator (goods and services) to aggregate export deflator (goods and services) of 9 OECD countries, all in current US dollars, weighted with GDP shares at annual PPP values, 1970q1 
$=100$ (authors calculations based on OECD, Economic Outlook Database)

\section{Japan}

Labor productivity: Index of output per hour of all persons in manufacturing, obtained as ratio of industrial production to total hours worked in manufacturing, $2000=100$ (OECD, Main Economic Indicators).

Manufacturing output: Index of industrial production in manufacturing, seasonally adjusted, $2000=100$ (Federal Reserve Board)

Consumption: Private final consumption expenditure, volume in national currency, seasonally adjusted (OECD, Economic Outlook Database).

Nominal GDP: Gross domestic product, value, market prices in national currency, seasonally adjusted (OECD, Economic Outlook Database)

Net exports:Net exports of goods \& services, value in national currency, seasonally adjusted (OECD, Economic Outlook Database)

PPI index: Producer price index of manufactured products, seasonally adjusted, $2000=100$ (OECD, Main Economic Indicators Database)

CPI total: Consumer price index all items, seasonally adjusted, $2000=100$ (OECD, Main Economic Indicators Database)

CPI services: Consumer price index for services less rents, seasonally adjusted; $2000=100$ (OECD, Main Economic Indicators Database)

Export deflator: Exports of goods and services, deflator, seasonally adjusted, national accounts basis; $2000=100$ (OECD, Economic Outlook Database)

CPI-based real exchange rate: Index of ratio of Japanese CPI (total) to aggregate CPI (total) of 9 OECD countries, all in current US dollars, weighted with GDP shares at annual PPP values, 1970q1 = 100 (authors calculations based on OECD, Economic Outlook Database)

PPI-based real exchange rate: Index of ratio of Japanese PPI (manufacturing) to aggregate PPI (manufacturing) of 9 OECD countries, all in current US dollars, weighted with GDP shares at annual PPP values, 1971q1 $=100$ (authors calculations based on OECD, Economic Outlook Database)

Terms of trade: Index of ratio of Japanese export deflator (goods and services) to aggregate export deflator (goods and services) of 9 OECD coun- 
tries, all in current US dollars, weighted with GDP shares at annual PPP values, 1970q1 = 100 (authors calculations based on OECD, Economic Outlook Database)

\section{Germany}

Before 1991, all series were obtained on the basis of West Germany growth rates applied to level variables of unified Germany.

Labor productivity: Monthly index of output per hour of all persons in manufacturing and mining, seasonally adjusted, $2000=100$ (Bank of International Settlements).

All other series are from the same sources as Japanese series, but for CPI services which is not available.

\section{United Kingdom}

Labor productivity: (a) From 1970 to 1995:q1, quarterly index of output per hour of all persons in manufacturing, seasonally adjusted, $1990=100$ (Bank of International Settlements); (b) from 1995:q1 to 2004q4 , quarterly index of output per person in manufacturing, seasonally adjusted, $2002=100$ (Bank of International Settlements), divided by the quarterly index of average hours worked per person in manufacturing (from Eurostat and ). The series were joined by using growth rates over overlapping periods.

All other series were from the same sources as Japanese series, but for CPI services which was not available.

\section{Italy}

Labor productivity: Hourly labor productivity in manufacturing, seasonally adjusted, in 1995 national currency (Bank of International Settlements). A missing value in 1999q1 was filled by interpolation with output in manufacturing.

All other series were from the same sources as Japanese series, but for PPI from 1970 to 1980 which is the monthly price index of domestical finished manufactures, $1980=100$ (BIS). The MEI and BIS monthly series were 
joined by using growth rates over overlapping periods and then converted by quarterly averaging.

\section{Rest of the world}

For each country the rest of the world comprises the other six G7 countries (alternatively US, Japan, Germany, UK, Italy, France, Canada) plus Australia, Sweden and Ireland. This choice was dictated by data availability regarding hourly productivity in manufacturing.

Individual country's variables were aggregated by first taking quarterly growth rates to remove national basis effects; then cross-country average growth rates were computed with weights based on each country's GDP share in the 9-country aggregate calculated at annual purchasing power parity (PPP) values. Average growth rates were then cumulated starting from the initial base year to obtain levels.

Annual PPP based GDP shares are from the IMF's World Economic Outlook Database from 1980; before 1980 they were computed directly on the basis of annual GDP at PPP values form OECD's Economic Outlook Database.

Labor productivity: Aggregate of country-specific indexes of output per hour of all persons in manufacturing sector, seasonally adjusted, 1970q1 = 100 (authors calculations based on national statistical sources)

Manufacturing output: Aggregate of country-specific indexes of industrial production, manufacturing, seasonally adjusted, 1970q1 = 100 (authors calculations based on national statistical sources)

Consumption: Aggregate of country-specific private final consumption expenditure, volumes in national currency, seasonally adjusted, 1970q1 $=100$ (authors calculations based on OECD, Economic Outlook Database).

\section{Appendix 2 Model description}

Our world economy consists of two countries of equal size, as before denoted $\mathrm{H}$ and $\mathrm{F}$, each specialized in the production of an intermediate, perfectly tradable good. In addition, each country produces a nontradable good. This good is either consumed or used to make intermediate tradable goods $\mathrm{H}$ and 
F available to domestic consumers. In what follows, we describe our setup focusing on the Home country, with the understanding that similar expressions also characterize the Foreign economy - whereas starred variables refer to Foreign firms and households.

\section{The Firms' Problem}

Firms producing Home tradables $(\mathrm{H})$ and Home nontradables $(\mathrm{N})$ are perfectly competitive and employ a technology that combines domestic labor and capital inputs, according to the following Cobb-Douglas functions:

$$
\begin{aligned}
& Y_{\mathrm{H}}=Z_{\mathrm{H}} K_{\mathrm{H}}^{1-\xi} L_{\mathrm{H}}^{\xi} \\
& Y_{\mathrm{N}}=Z_{\mathrm{N}} K_{\mathrm{N}}^{1-\zeta} L_{\mathrm{N}}^{\zeta},
\end{aligned}
$$

where $Z_{\mathrm{H}}$ and $Z_{\mathrm{N}}$ are exogenous random disturbances, independent across sectors and countries. Consistent with our empirical methodology, we assume that $Z_{\mathrm{H}}$ follows a unit root process. In turn, $Z_{\mathrm{N}}$ follows an $\operatorname{AR}(1)$ process with autocorrelation coefficient equal to 0.95. We assume that capital and labor are freely mobile across sectors. The problem of these firms is standard: they hire labor and capital from households to maximize their profits:

$$
\begin{aligned}
& \pi_{\mathrm{H}}=\bar{P}_{\mathrm{H}, t} Y_{\mathrm{H}, t}-W_{t} L_{\mathrm{H}, t}-R_{t} K_{\mathrm{H}, t} \\
& \pi_{\mathrm{N}}=P_{\mathrm{N}, t} Y_{\mathrm{N}, t}-W_{t} L_{\mathrm{N}, t}-R_{t} K_{\mathrm{N}, t},
\end{aligned}
$$

where $\bar{P}_{\mathrm{H}, t}$ is the wholesale price of the Home traded good and $P_{\mathrm{N}, t}$ is the price of the nontraded good. $W_{t}$ denote the wage rate, while $R_{t}$ represents the capital rental rate.

Firms in the distribution sector are also perfectly competitive. They buy tradable goods and distribute them to consumers using nontraded goods as the only input in production. We assume that bringing one unit of traded goods to Home (Foreign) consumers requires $\eta$ units of the Home (Foreign) nontraded goods.

\section{The Household's Problem}

Preferences The representative Home agent in the model maximizes the expected value of her lifetime utility, given by:

$$
E\left\{\sum_{t=0}^{\infty} U\left[C_{t}, \ell_{t}\right] \exp \left[\sum_{\tau=0}^{t-1}-\nu\left(U\left[C_{t}, \ell_{t}\right]\right)\right]\right\}
$$


where instantaneous utility $U$ is a function of a consumption index, $C$, and leisure, $(1-\ell)$. Foreign agents' preferences are symmetrically defined. It can be shown that, for all parameter values used in the quantitative analysis below, these preferences guarantee the presence of a locally unique symmetric steady state, independent of initial conditions. ${ }^{29}$

The full consumption basket, $C_{t}$, in each country is defined by the following CES aggregator

$$
C_{t} \equiv\left[a_{\mathrm{T}}^{1-\phi} C_{\mathrm{T}, t}^{\phi}+a_{\mathrm{N}}^{1-\phi} C_{\mathrm{N}, t}\right]^{\frac{1}{\phi}}, \quad \phi<1,
$$

where $a_{\mathrm{T}}$ and $a_{\mathrm{N}}$ are the weights on the consumption of traded and nontraded goods, respectively and $\frac{1}{1-\phi}$ is the constant elasticity of substitution between $C_{\mathrm{N}, t}$ and $C_{\mathrm{T}, t}$. The consumption index of traded goods $C_{\mathrm{T}, t}$ including both domestically produced goods $C_{\mathrm{H}}$ and goods produced abroad $C_{\mathrm{F}}$, is given by

$$
C=C_{\mathrm{T}}=\left[a_{\mathrm{H}}^{1-\rho} C_{\mathrm{H}}^{\rho}+a_{\mathrm{F}}^{1-\rho} C_{\mathrm{F}}^{\rho}\right]^{\frac{1}{\rho}}, \quad \rho<1 .
$$

Price indexes A notable feature of our specification is that, because of distribution costs, there is a wedge between the producer price and the consumer price of each good. Let $\bar{P}_{\mathrm{H}, t}$ and $P_{\mathrm{H}, t}$ denote the price of the Home traded good at the producer and consumer level, respectively. Let $P_{\mathrm{N}, t}$ denote the price of the nontraded good that is necessary to distribute the tradable one. With competitive firms in the distribution sector, the consumer price of the traded good is simply

$$
P_{\mathrm{H}, t}=\bar{P}_{\mathrm{H}, t}+\eta P_{\mathrm{N}, t} .
$$

We hereafter write the utility-based CPIs:

$$
P_{t}=\left[a_{\mathrm{T}} P_{\mathrm{T}, t}^{\frac{\phi}{\phi-1}}+a_{\mathrm{N}} P_{\mathrm{N}, t}^{\frac{\phi}{\phi-1}}\right]^{\frac{\phi-1}{\phi}} .
$$

whereas the price index of tradables is given by

$$
P=\left[a_{\mathrm{H}} P_{\mathrm{H}}^{\frac{\rho}{\rho-1}}+\left(1-a_{\mathrm{H}}\right) P_{\mathrm{F}}^{\frac{\rho}{\rho-1}}\right]^{\frac{\rho-1}{\rho}} .
$$

\footnotetext{
${ }^{29} \mathrm{~A}$ unique invariant distribution of wealth under these preferences will allow us to use standard numerical techniques to solve the model around a stable nonstochastic steady state when only a non-contingent bond is traded internationally (see Obstfeld [1990], Mendoza [1991], and Schmitt-Grohe and Uribe [2001]).
} 
Foreign prices, denoted with an asterisk and expressed in the same currency as Home prices, are similarly defined. We take the price of Home aggregate consumption $P_{t}$ to be the numeraire.

Budget constraints and asset markets We assume that international asset markets are incomplete. Home and Foreign agents can only hold an international bond, $B_{\mathrm{H}}$, which pays in units of Home aggregate consumption and is zero in net supply. Agents derive income from working, $W_{t} \ell_{t}$, from renting capital to firms, $R_{t} K_{t}$, and from interest payments, $\left(1+r_{t}\right) B_{\mathrm{H}, t}$, where $r_{t}$ is the real bond's yield, paid at the beginning of period $t$ but known at time $t-1$. The individual flow budget constraint for the representative agent in the Home country is therefore: ${ }^{30}$

$$
\begin{gathered}
P_{\mathrm{H}, t} C_{\mathrm{H}, t}+P_{\mathrm{F}, t} C_{\mathrm{F}, t}+P_{\mathrm{N}, t} C_{\mathrm{N}, t}+B_{\mathrm{H}, t+1}+\bar{P}_{\mathrm{H}, t} I_{\mathrm{H}, t} \leq \\
W_{t} \ell_{t}+R_{t} K_{t}+\left(1+r_{t}\right) B_{\mathrm{H}, t} .
\end{gathered}
$$

We assume that investment is carried out in Home tradable goods and that the capital stock, $K$, can be freely reallocated between the traded $\left(K_{\mathrm{H}}\right)$ and nontraded $\left(K_{\mathrm{N}}\right)$ sectors: ${ }^{31}$

$$
K=K_{\mathrm{H}}+K_{\mathrm{N}} .
$$

As opposed to consumption goods, we assume that investment goods do not require distribution services. The price of investment is therefore equal to the wholesale price of the domestic traded good, $\bar{P}_{\mathrm{H}, t}$. The law of motion for the aggregate capital stock is given by:

$$
K_{t+1}=I_{\mathrm{H}, t}+(1-\delta) K_{t}
$$

The household's problem then consists of maximizing lifetime utility, defined by (B.1), subject to the constraints (B.5) and (B.6).

\footnotetext{
${ }^{30} B_{\mathrm{H}, t}$ denotes the Home agent's bonds accumulated during period $t-1$ and carried over into period $t$.

${ }^{31}$ We also conduct sensitivity analysis on our specification of the investment process, below.
} 


\section{Model calibration}

Note that we assume symmetry across countries. We assume a utility function of the form:

$$
U\left[C_{t}, \ell_{t}\right]=\frac{\left[\left(\varkappa_{t} C_{t}\right)^{\alpha}\left(1-\ell_{t}\right)^{1-\alpha}\right]^{1-\sigma}-1}{1-\sigma}, \quad 0<\alpha<1, \quad \sigma>0,
$$

where $\varkappa_{t}$ is a taste shock assumed to follow an AR(1) process with autocorrelation coefficient equal to 0.95 and standard deviation set to 0.7 percent. We set $\alpha$ so that in steady state, one third of the time endowment is spent working; $\sigma$ (risk aversion) is set equal to 2. Following Schmitt-Grohe and Uribe [2001], we assume that the endogenous discount factor depends on the taste shock, the average per capita level of consumption, $C_{t}$, and hours worked, $\ell_{t}$, and has the following form:

$$
\nu\left(U\left[C_{t}, \ell_{t}\right]\right)=\left\{\begin{array}{cc}
\ln \left(1+\psi\left[\left(C_{t}\right)^{\alpha}\left(1-\ell_{t}\right)^{1-\alpha}\right]\right) & \sigma \neq 1 \\
\ln \left(1+\psi\left[\alpha \ln \left(C_{t}\right)+(1-\alpha) \ln \left(1-\ell_{t}\right)\right]\right) & \sigma=1
\end{array},\right.
$$

whereas $\psi$ is chosen such that the steady-state real interest rate is 1 percent per quarter. This parameter also determines the speed of convergence to the unique nonstochastic steady state.

Because of the presence of a distribution sector in our model, the trade elasticity is given by $\omega(1-\mu)$. Following the calibration in Burstein, Neves and Rebelo [2003], we set distribution costs to 50 percent. We then set the elasticity of substitution $\omega$ to either 2 or 8 , implying a trade elasticity of 1 and 4 , respectively.

The value of $\phi$ is selected based on the available estimates for the elasticity of substitution between traded and nontraded goods. We use the estimate by Mendoza [1991] referred to a sample of industrialized countries and set that elasticity equal to 0.74. Stockman and Tesar [1995] estimate a lower elasticity (0.44), but their sample includes both developed and developing countries.

As regards the weights of domestic and foreign tradables in the tradables consumption basket $\left(C_{\mathrm{T}}\right), a_{\mathrm{H}}$ and $a_{\mathrm{F}}$ (normalized to $a_{\mathrm{H}}+a_{\mathrm{F}}=1$ ) are chosen such that imports are 5 percent of aggregate output in steady state. This corresponds to the average ratio of U.S. imports from Europe, Canada and Japan to U.S. GDP between 1960 and 2002. The weights of traded and nontraded goods, $a_{\mathrm{T}}$ and $a_{\mathrm{N}}$, are chosen as to match the share of nontradables in the U.S. consumption basket. Over the period 1967-2002, this share is 
equal to 53 percent on average. Consistently, Stockman and Tesar [1995] suggest that the share of nontradables in the consumption basket of the seven largest OECD countries is roughly 50 percent. Finally, we calibrate $\xi$ and $\zeta$, the labor shares in the production of tradables and nontradables, based on the work of Stockman and Tesar [1995]. We set the depreciation rate of capital equal to 2.5 percent quarterly. 


\section{References}

[1] Acemoglu, Daron, and Jaume Ventura [2003]. "The World Income Distribution," Quarterly Journal of Economics, 117 (2), 659-94.

[2] Backus, David K., Patrick J. Kehoe, and Finn E. Kydland [1995]. "International Business Cycles: Theory and Evidence," in Thomas F. Cooley (ed.) Frontiers of Business Cycle Research, Princeton University Press, Princeton, 331-56.

[3] Backus, David K., and Gregor W. Smith, [1993]. "Consumption and Real Exchange Rates in Dynamic Economies with Non-traded Goods," Journal of International Economics 35, 297-316.

[4] Basu, Susanto, John G. Fernald, and Miles S. Kimball. "Are Technology Improvements Contractionary?" American Economic Review forthcoming.

[5] Baxter, Marianne, and Mario J. Crucini [1995]. "Business Cycles and the Asset Structure of Foreign Trade," International Economic Review $36,821-54$.

[6] Bems, Rudolfs, Luca Dedola and Frank Smets [2006]. "US external imbalances: The role of technology and policy," mimeo, European Central Bank.

[7] Blanchard Olivier J. and Danny Quah [1989]. "The Dynamic Effects of Aggregate Demand and Supply Disturbances," American Economic Review 19, 655-73.

[8] Burstein, Ariel T., João Neves, and Sergio Rebelo [2003]. "Distribution Costs and Real Exchange Rate Dynamics During Exchange-Rate-Based Stabilizations," Journal of Monetary Economics, September, 1189-1214.

[9] Chang, Yongsung, and Jay H. Hong [2002]. "On the Employment Effect of Technology: Evidence from U.S. Manufacturing for 1958-1996," mimeo, University of Pennsylvania.

[10] Chari, V.V., Patrick J. Kehoe, and Ellen McGrattan [2002]. "Can Sticky Prices Generate Volatile and Persistent Real Exchange Rates?," Review of Economic Studies 69, 633-63. 
[11] Chari, V. V., P. J. Kehoe and E. McGrattan [2004], "Are Structural VARs Useful Guides for Developing Business Cycle Theories", mimeo, Federal Reserve Bank of Minneapolis.

[12] Christiano, Lawrence J., Martin Eichenbaum and Robert Vigfusson [2004], "What Happens After a Technology Shock?,"mimeo, Northwestern University.

[13] Christiano, Lawrence J., Martin Eichenbaum and Robert Vigfusson [2006], "Assessing Structural VARs," forthcoming NBER Macroannuals.

[14] Clarida, Richard, and Jordi Galí [1994]. "Sources of Real Exchange Rate Fluctuations: How Important Are Nominal Shocks?" CarnegieRochester Series in Public Policy 41, 1-56

[15] Cole, Harold L., and Maurice Obstfeld [1991]. "Commodity Trade and International Risk Sharing: How Much Do Finacial Markets Matter?" Journal of Monetary Economics 28, 3-24.

[16] Cooley, F., T. and M. Dwyer [1998], "Business cycle analysis without much theory. A look at structural VARs", Journal of Econometrics, Vol. $83,57-88$.

[17] Corsetti Giancarlo and Paolo Pesenti, [1999], "Stability, Asymmetry, and Discontinuity: The Launch of European Monetary Union", Brookings Papers on Economic Activity, 2, 295-372

[18] Corsetti, Giancarlo, and Paolo Pesenti [2001]. "Welfare and Macroeconomic Interdependence," Quarterly Journal of Economics, 116 (2), 421446.

[19] Corsetti Giancarlo, Luca Dedola and Sylvain Leduc [2004], "International Risk-Sharing and the Transmission of Productivity Shocks," European Central Bank Working Paper No. 305.

[20] Corsetti Giancarlo, Luca Dedola and Sylvain Leduc [2006], "International Risk-Sharing and the Transmission of Productivity Shocks," revised, European University Institute. 
[21] Corsetti, Giancarlo, Philippe Martin and Paolo Pesenti [2004]. "Productivity, aggregate demand and real exchange rate: lessons from a general equilibrium analysis of the 'Home Market Effect'." mimeo, European University Institute

[22] Debaere, Peter, and Hongshik Lee [2003]. "The Real-Side Determinants of Countries' Terms of Trade: A Panel Data Analysis," mimeo, University of Texas, Austin.

[23] Dedola, Luca and Stefano Neri [2004]. "What does a technology shock do: A VAR analysis with model-based sign restrictions," CEPR Discussion Paper No. 4537, forthcoming Journal of Monetary Economics.

[24] Doan, T. [1992]. "RATS User's Guide," Estima.

[25] Eaton, Jonathan and Samuel Kortum [2002]. "Technology, Geography and Trade," Econometrica 70(5), 1741-79.

[26] Enders, Zeno and Gernot Mueller [2006]. "S-curve redux: On the international transmission of technology shocks," mimeo, European University Institute.

[27] Engel, Charles [1999]. "Accounting for Real Exchange Rate Changes," Journal of Political Economy 107, 507-38.

[28] Engel, Charles and John Rogers [2005]. "The U.S. Current Account Deficit and the Expected Share of World Output," forthcoming Journal of Monetary Economics.

[29] Erceg, Christopher J., Luca Guerrieri, and Christopher Gust [2004], "Can long run restrictions identify technology shocks?", forthcoming Journal of the European Economic Association.

[30] Elliott, Graham, Thomas J. Rothenberg and James H. Stock [1996]. "Efficient Tests for an Autoregressive Unit Root," Econometrica 64, 813-836.

[31] Francis, Neville, and Valerie A. Ramey [2003]. "Is the Technology-Driven Real Business Cycle Hypothesis Dead? Shocks and Aggregate Fluctuations Revisited," mimeo, University of California, San Diego. 
[32] Galí, Jordi [1999]. "Technology, Employment and the Business Cycle: Do Technology Shocks Explain Aggregate Fluctuations?" American Economic Review 89, 249-71.

[33] Galí, J. and P. Rabanal [2004], "Technology shocks and aggregate fluctuations: How well does the RBC model fit postwar U.S. data?", NBER Macroeconomic annuals.

[34] Giannone, D., Reichlin, L. and L. Sala [2006], "VARs, common factors and the empirical validation of equilibrium business cycle models", Journal of Econometrics, 132 (1), 257-279.

[35] Ghironi, Fabio and Marc Melitz [2005]. "International Trade and Macroeconomics Dynamics with Heterogenous Firms." Quarterly Journal of Economics, 865-915.

[36] Hooper, Peter, Karen Johnson and Jaime Marquez [2000]. "Trade elasticities for the G-7 countries." Princeton Studies in International Economics No. 87.

[37] Kollmann, Robert [1995]. "Consumption, Real Exchange Rates and the Structure of International Asset Markets," Journal of International Money and Finance 55, 29-57.

[38] Kwiatkowski, Denis, Peter C. B. Phillips, Peter Schmidt \& Yongcheol Shin [1992]. "Testing the Null Hypothesis of Stationary against the Alternative of a Unit Root," Journal of Econometrics, 54, 159- 178.

[39] MacKinnon, James G. [1991]. "Critical Values for Cointegration Tests," Chapter 13 in R. F. Engle and C. W. J. Granger (eds.), Long-run Economic Relationships: Readings in Cointegration, Oxford: Oxford University Press.

[40] Obstfeld, Maurice, and Kenneth Rogoff [2000]. "New Directions for Stochastic Open Economy Models." Journal of International Economics 50 (1), February, 117-153.

[41] Obstfeld, Maurice, and Kenneth Rogoff [2002]. "Global implications of self-oriented national monetary rules," Quarterly Journal of Economics $117,503-36$. 
[42] Obstfeld, M. and K. Rogoff [2004]. "The Unsustainable US Current Account Position Revisited", NBER Working Paper No 10869.

[43] Obstfeld, M. and K. Rogoff [2005]. "Global Current Account Imbalances and Exchange Rate Adjustments", Brookings Papers on Economics.

[44] Phillips, P.C.B. and P. Perron [1988]. "Testing for a Unit Root in Time Series Regression," Biometrika, 75, 335-346.

[45] Ravn, Morten [2001]. "Consumption Dynamics and Real Exchange Rates," mimeo, London Business School.

[46] Ruhl, Kim J. [2003]. "Solving the Elasticity Puzzle in International Economics," mimeo, University of Minnesota.

[47] Shapiro, Matthew D., and Mark Watson [1988]. "Sources of Business Cycle Fluctuations," NBER Macroeconomics Annual 1998, Cambridge, MA: MIT Press.

[48] Stockman, Alan C., and Linda Tesar [1995]. "Tastes and Technology in a Two-Country Model of the Business Cycle: Explaining International Comovements," American Economic Review 83, 473-86.

[49] Stock, James and Mark Watson [2005]. "Understanding changes in International Business Cycle Dynamics," Journal of European Economic Association, 3(5), 968-1006.

[50] Uhlig, H. [2001], "What are the effects of monetary policy on output? Results from an agnostic identification procedure", Tilburg University, Center for Economic Research Discussion Paper, No. 28, forthcoming Journal of Monetary Economics.

[51] Uhlig, H. [2003], "Do technology shocks lead to a fall in total hours worked?", Journal of the European Economic Association, Vol. 2, No. $2-3,361-371$ 
FIGURE 1 - US BASELINE SPECIFICATION
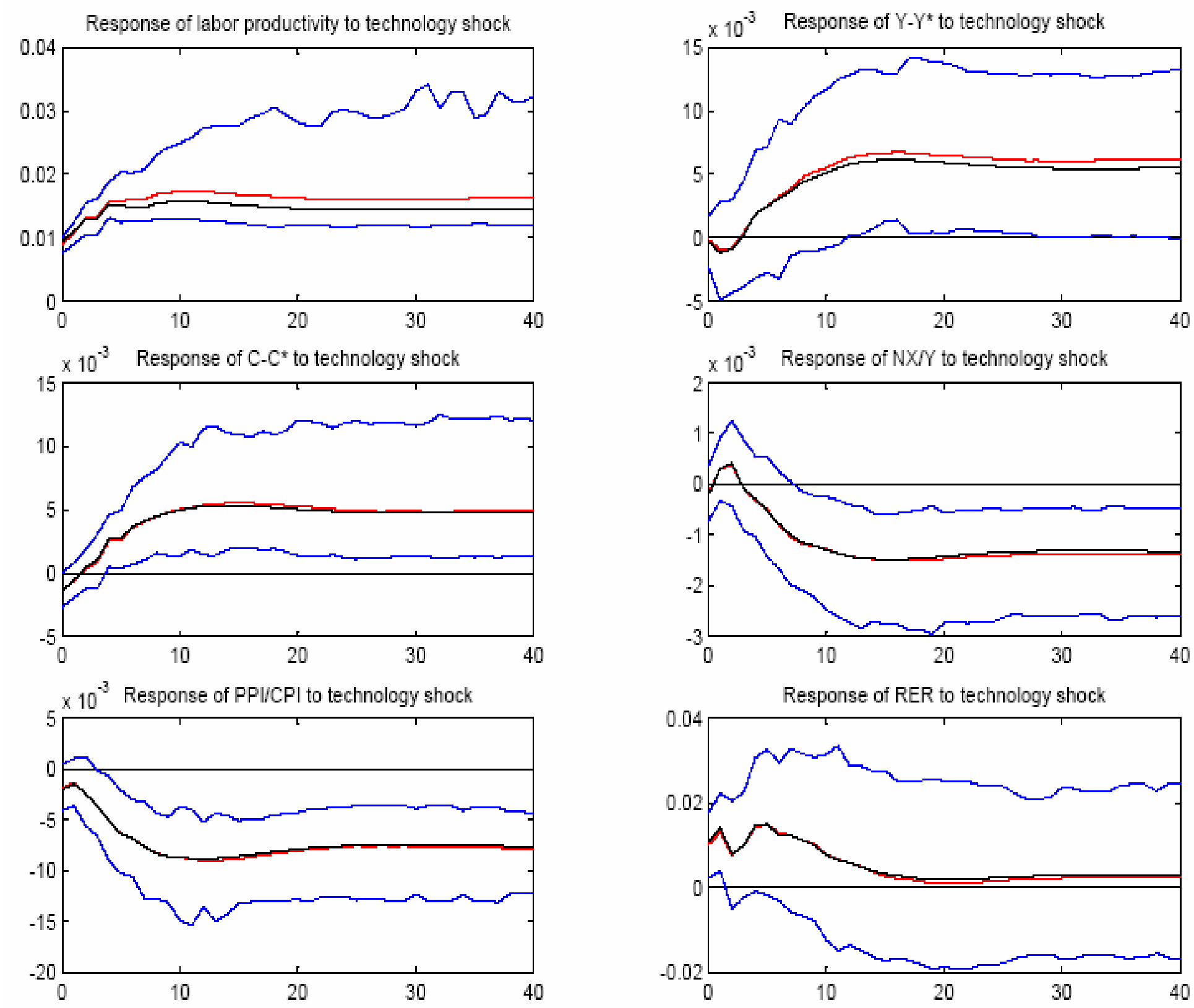

Response of RER (PPI) to technology shock

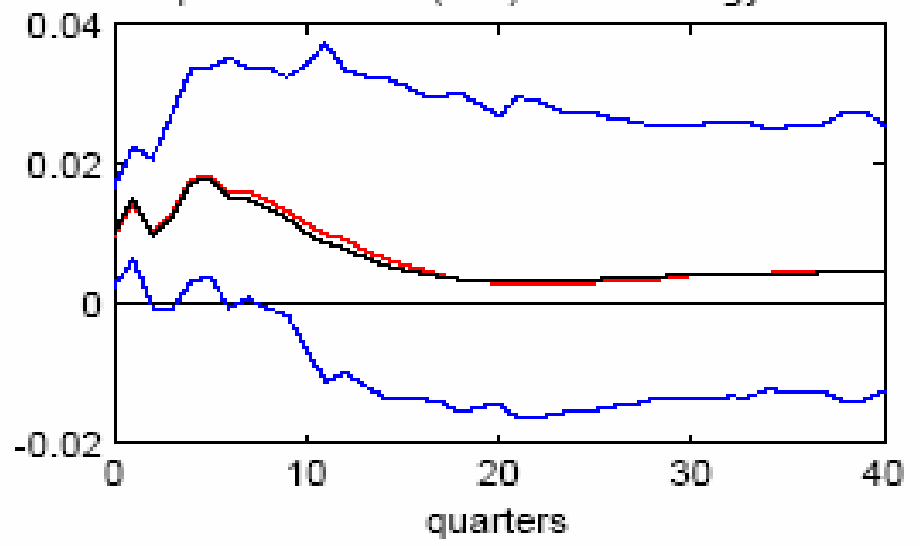

Response of RER (EXP DEF) to technology shock

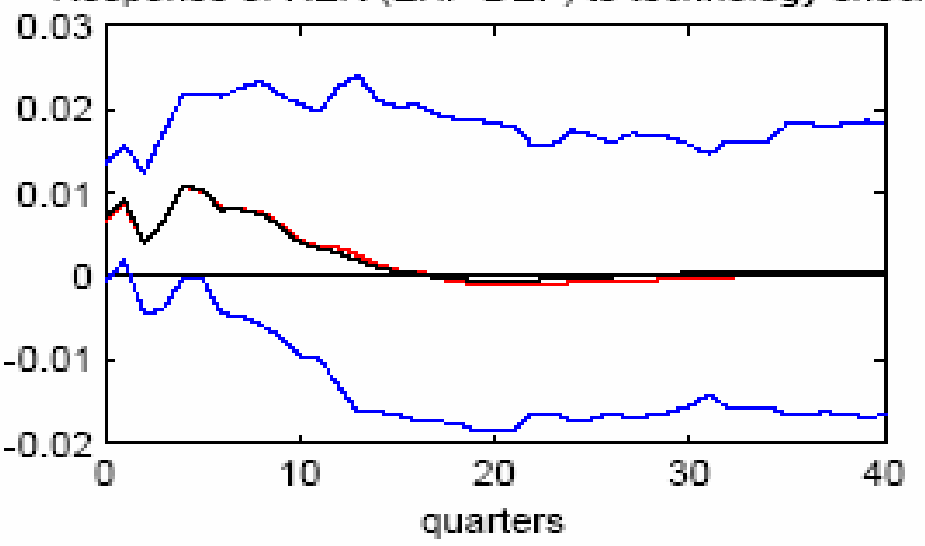




\section{FIGURE 2 - JAPAN BASELINE SPECIFICATION}
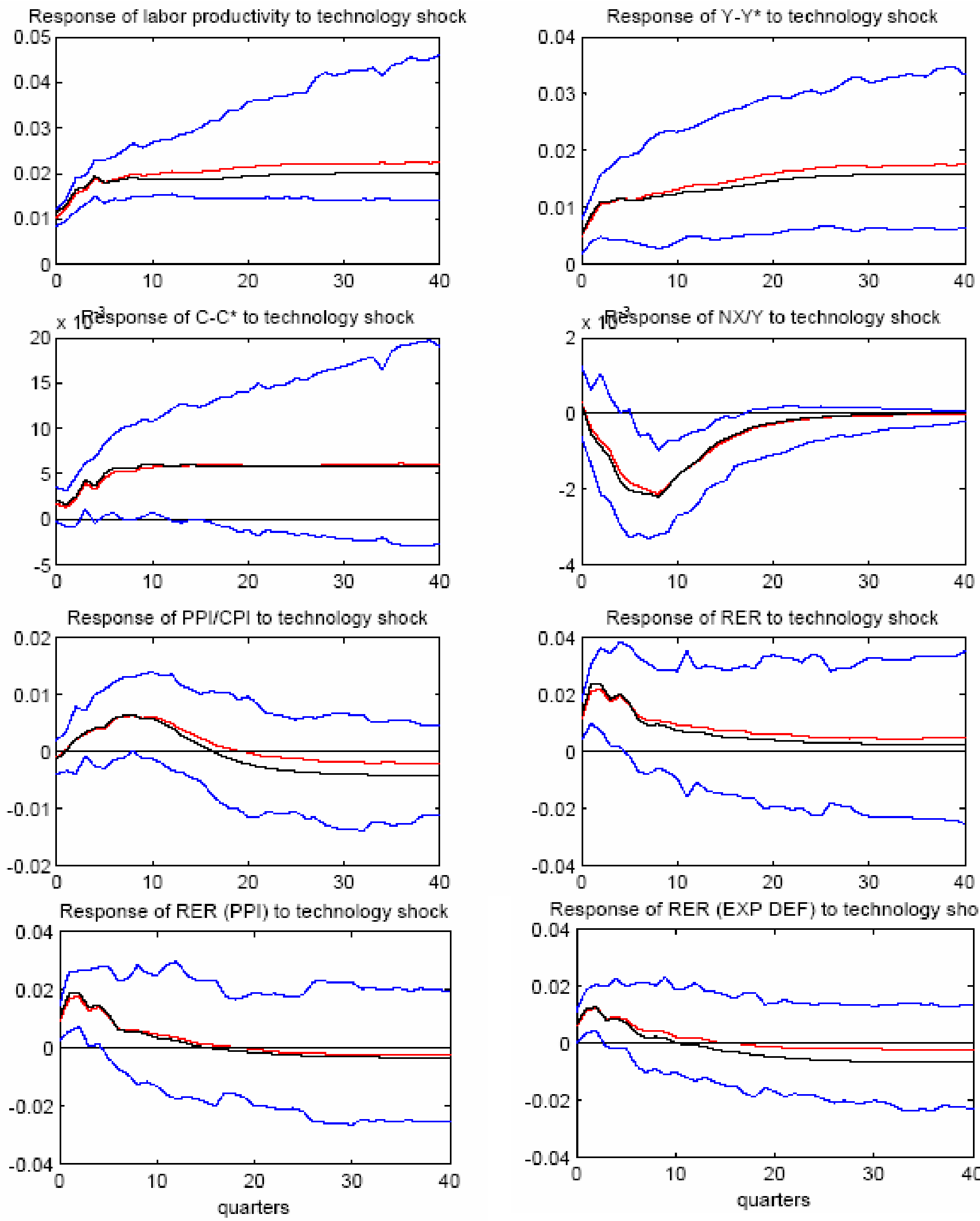

Response of RER (EXP DEF) to technology shock

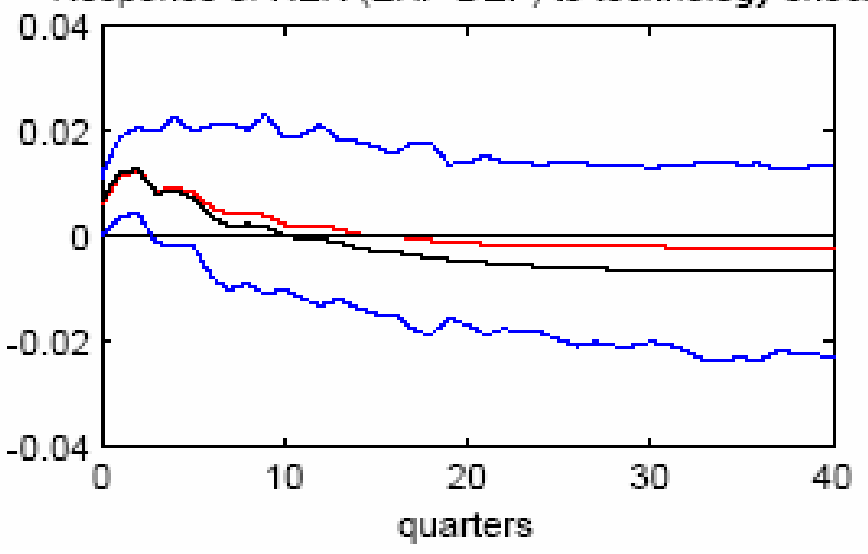


FIGURE 3 - GERMANY BASELINE SPECIFICATION

Response of labor productivity to technology shock
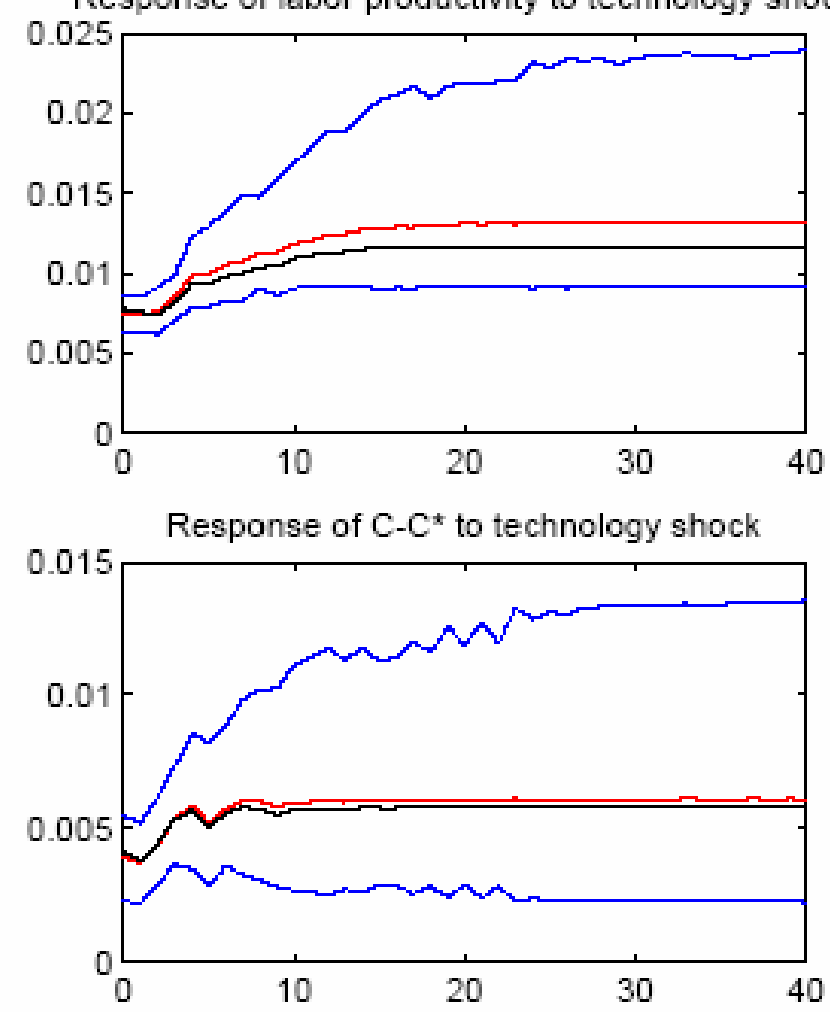

$x$ Rigsiponse of PPI/CPI to technology shock

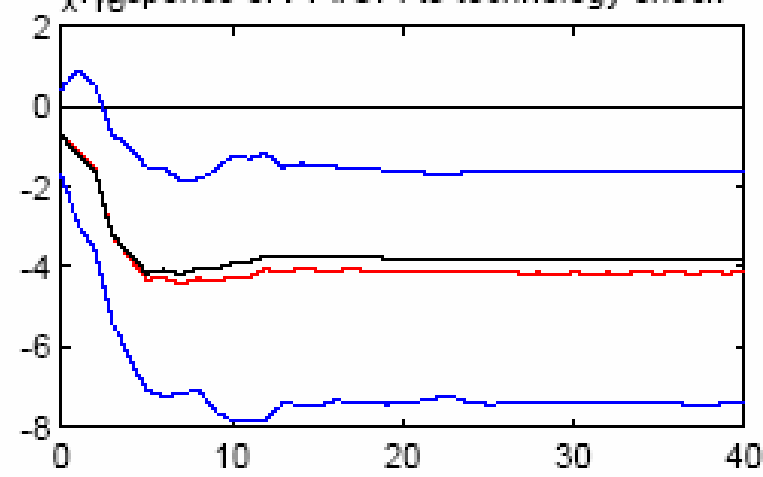

Response of RER (PPI) to technology shock

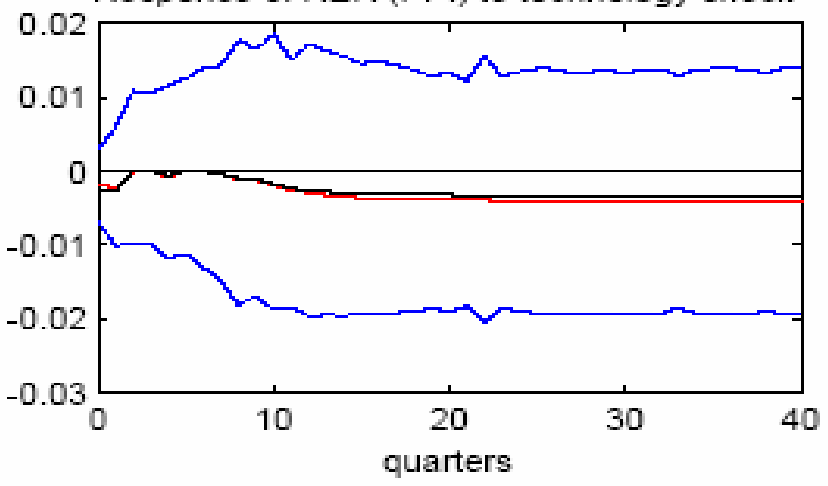

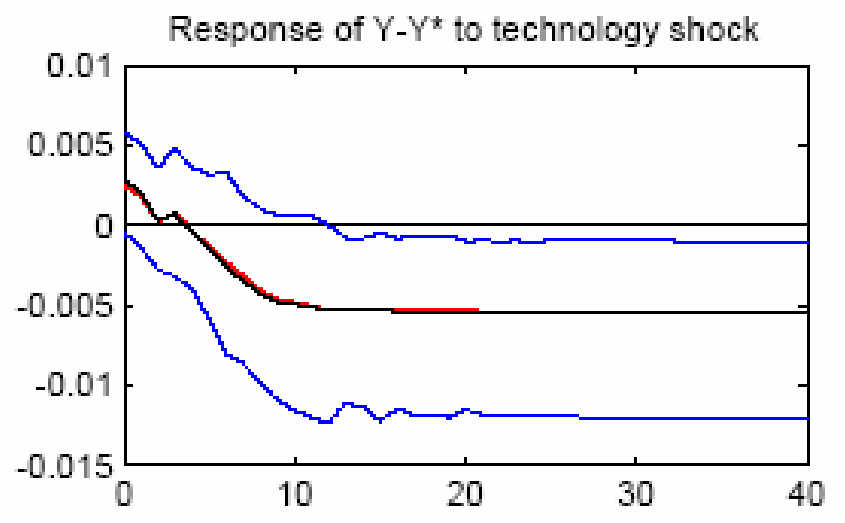
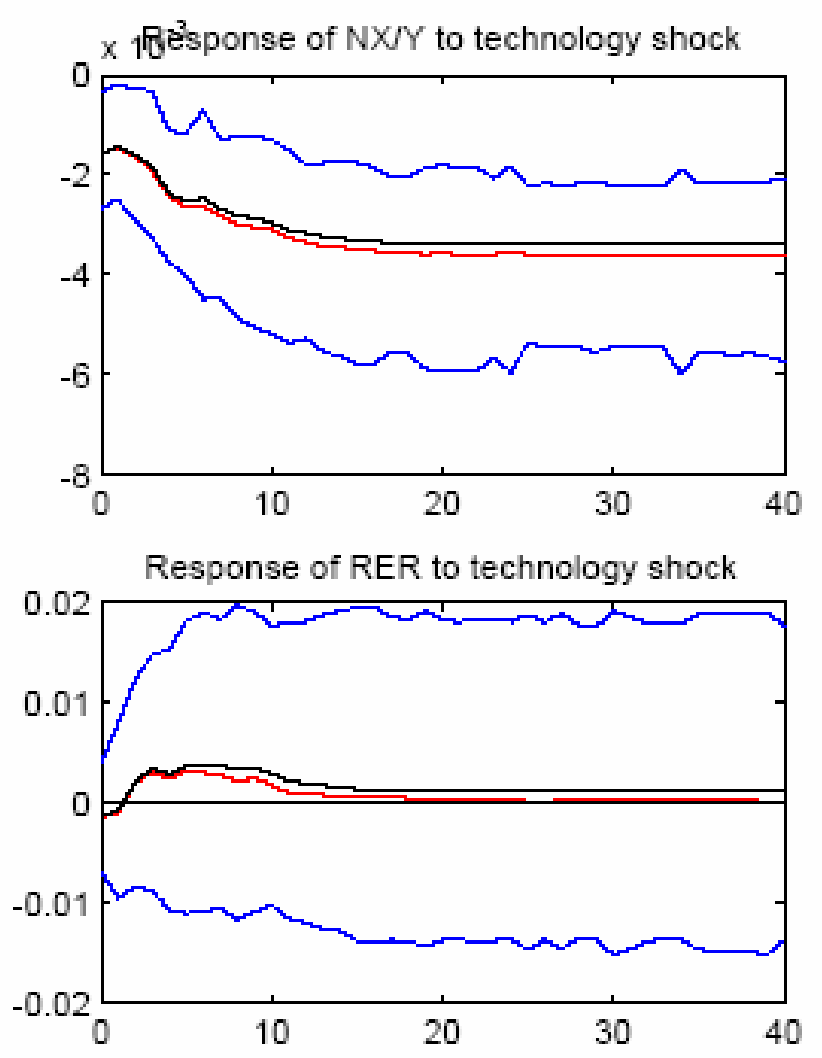

Response of RER (EXP DEF) to technology shock

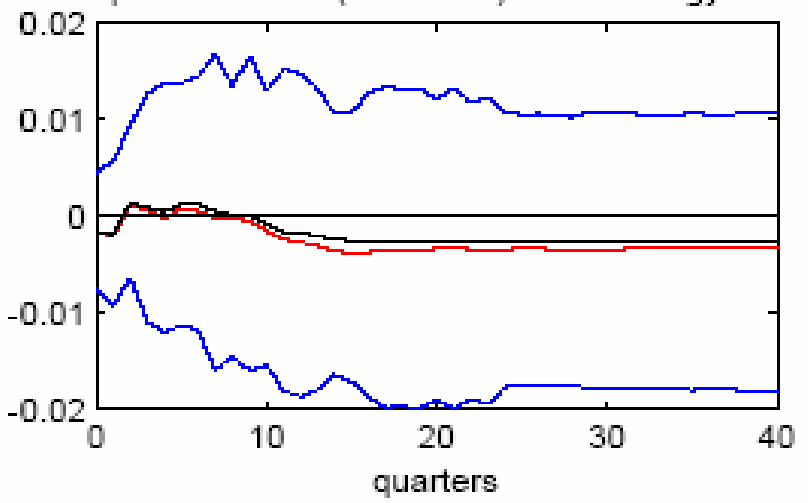


FIGURE 4 - UK BASELINE SPECIFICATION

Response of labor productivity to technology shock

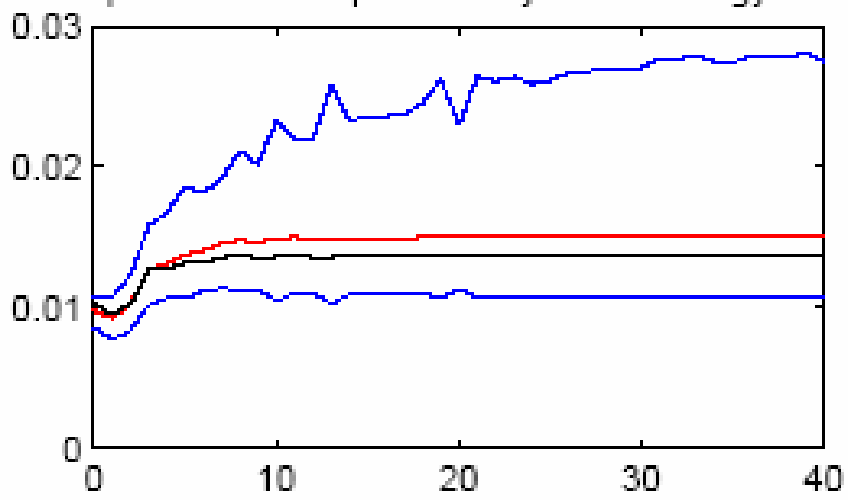

Response of $\mathrm{C}-\mathrm{C}^{\star}$ to technology shock
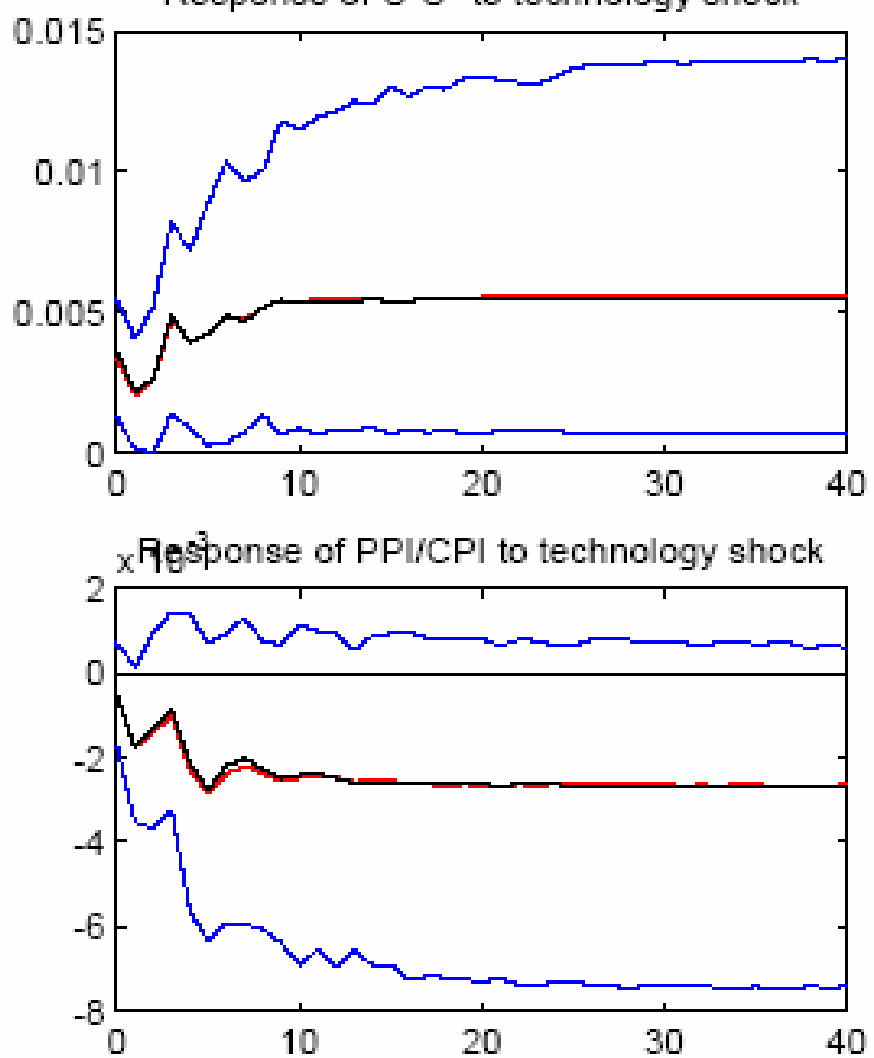

Response of RER (PPI) to technology shock

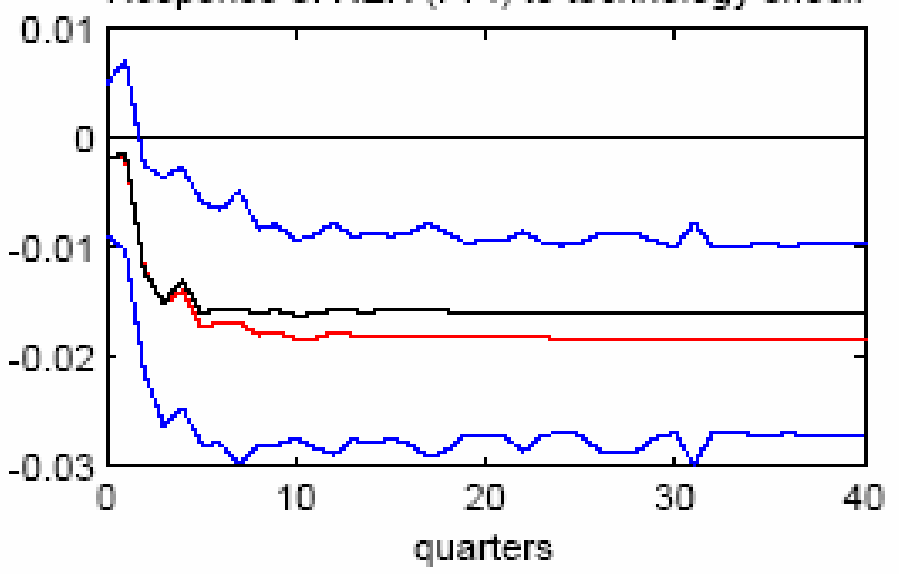

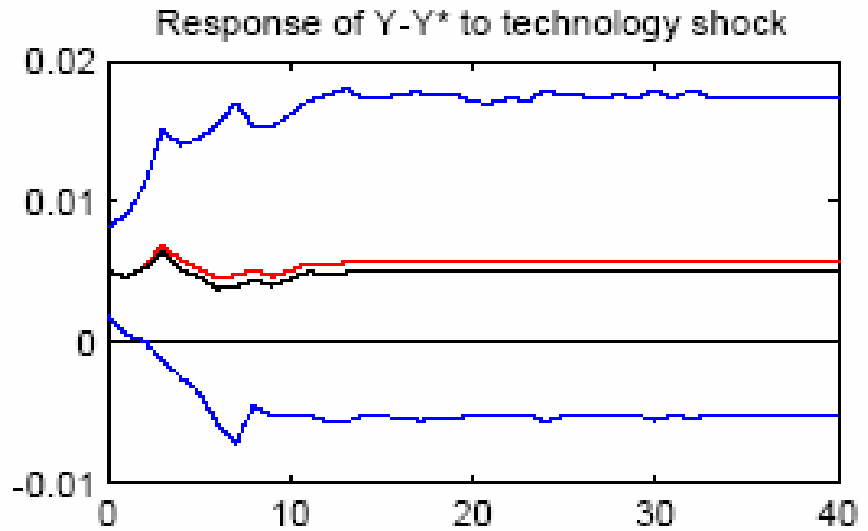
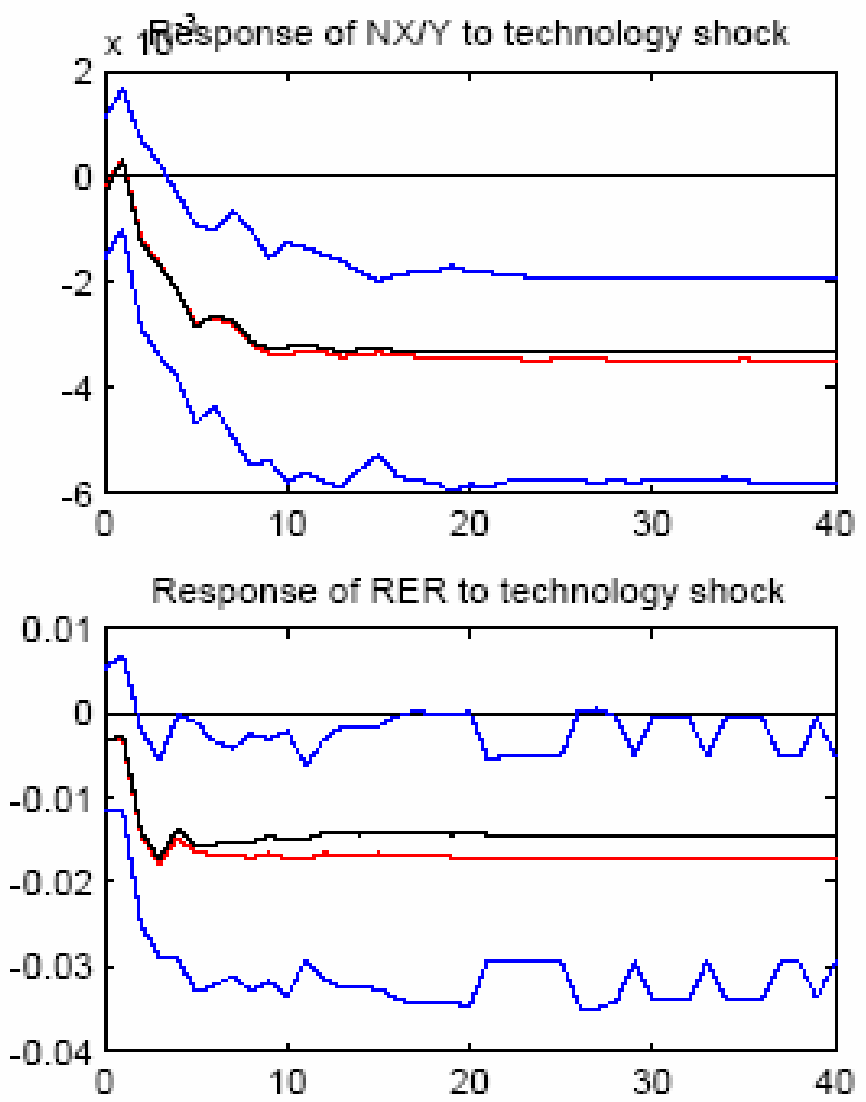

Response of RER (EXP DEF) to technology shock

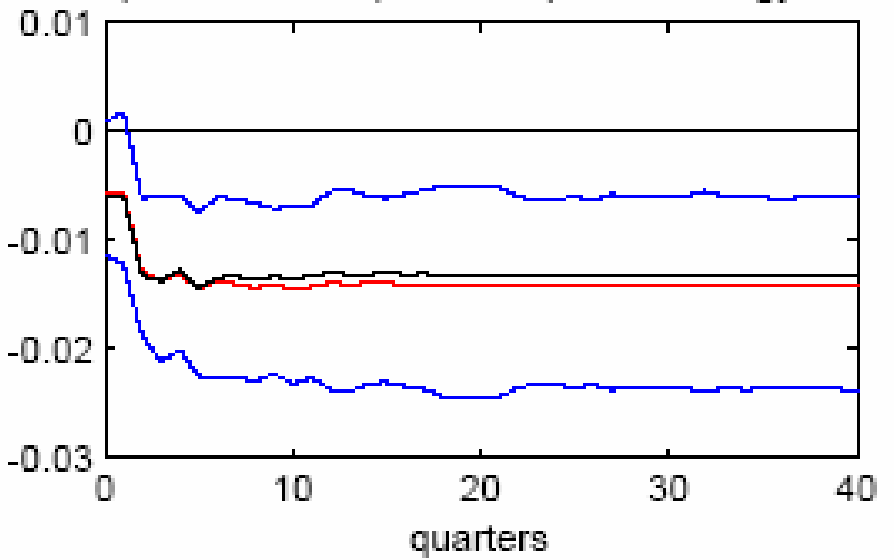




\section{FIGURE 5 - ITALY BASELINE SPECIFICATION}

Response of labor productivity to technology shock
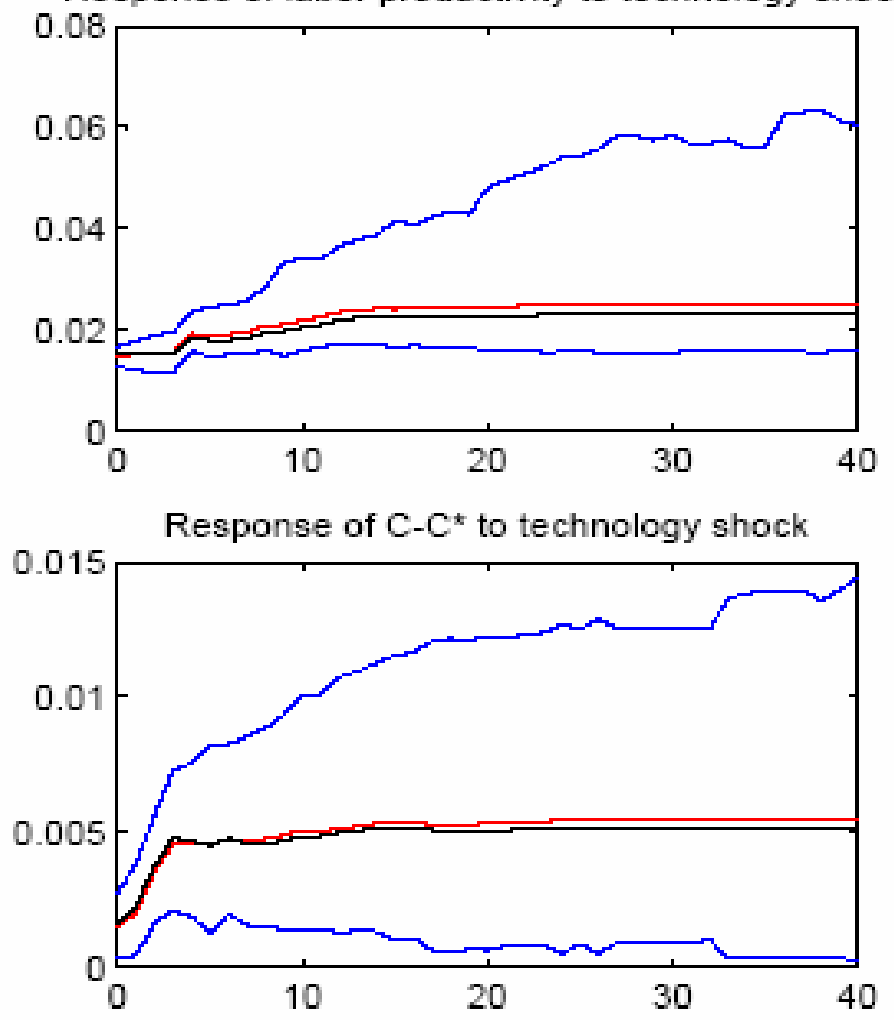

Response of PPI/CPI to technology shock
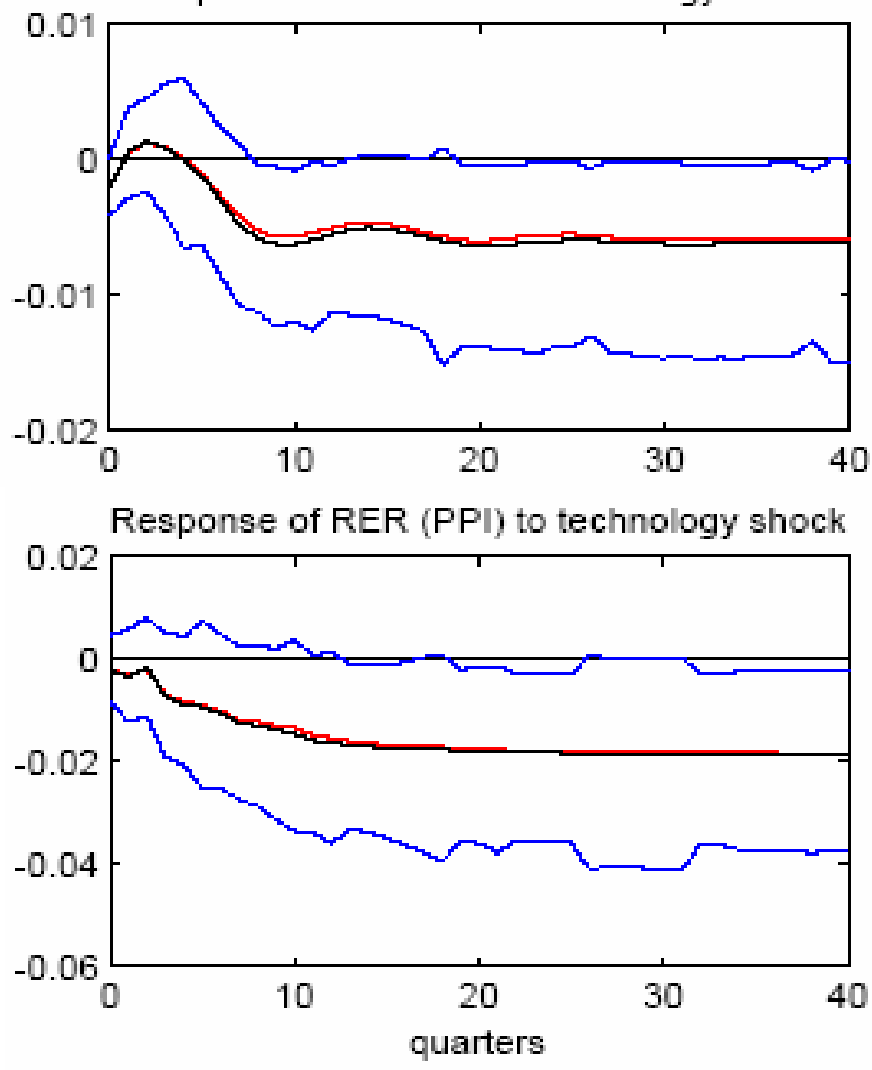
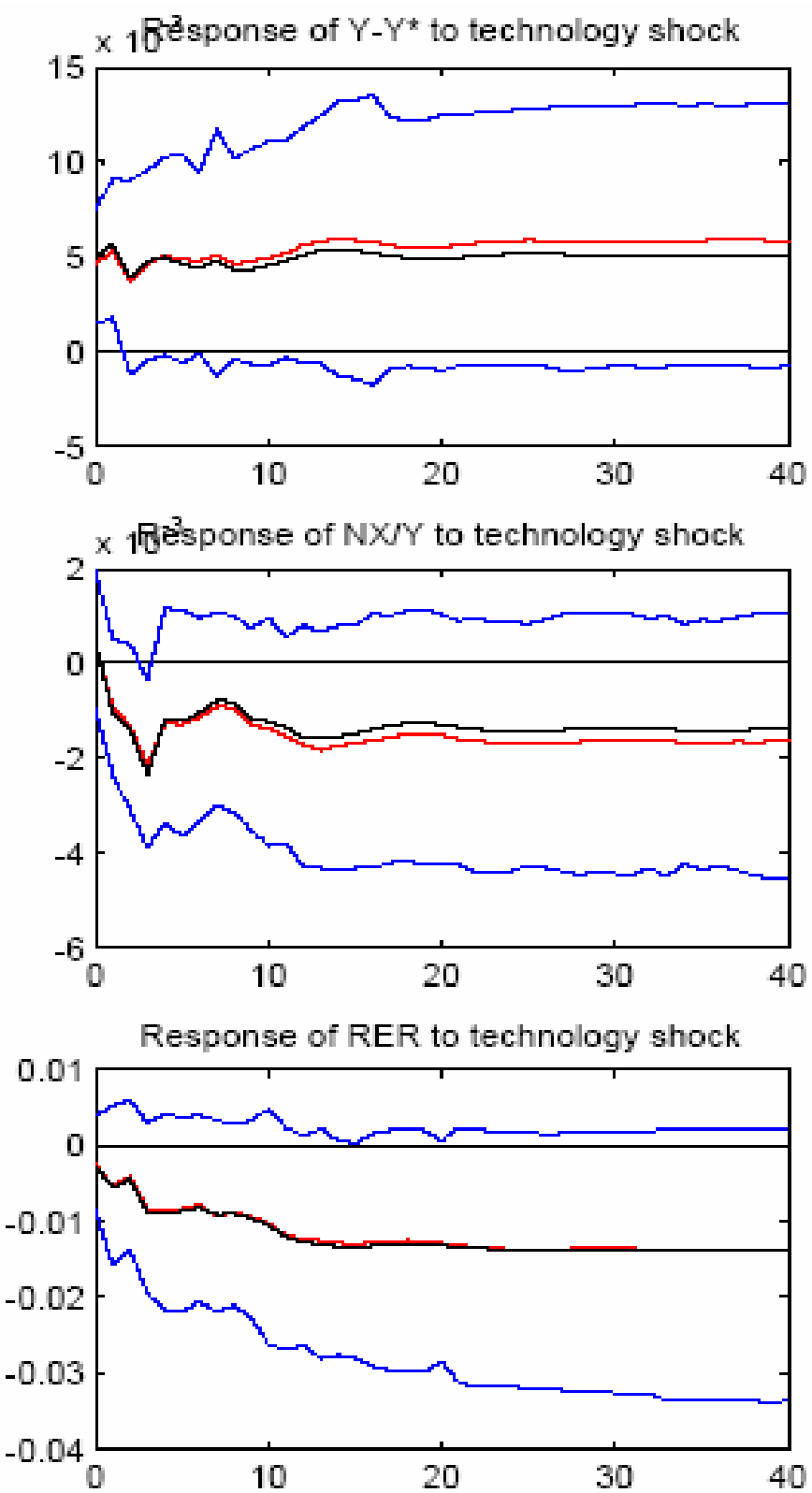

Response of RER (EXP DEF) to technology shock

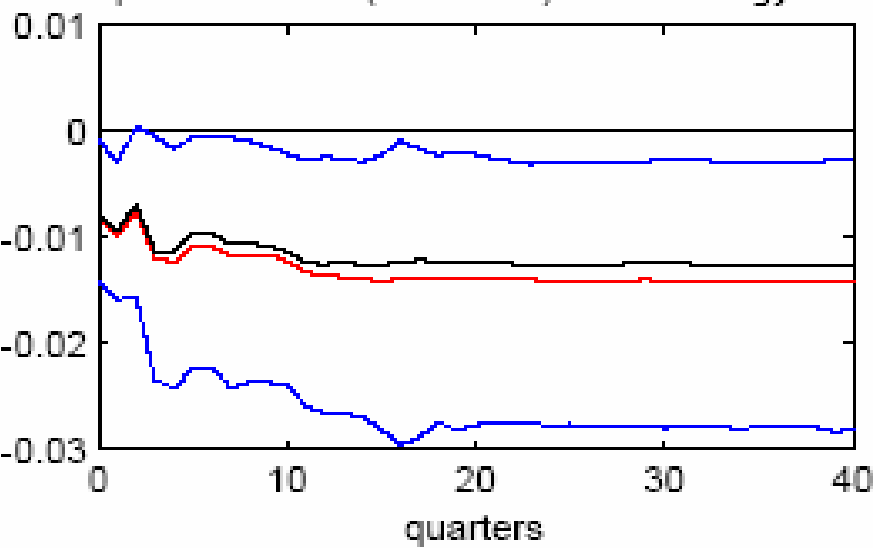




\section{FIGURE 6 - US LEVEL SPECIFICATION}

Response of labor productivity to technology shock
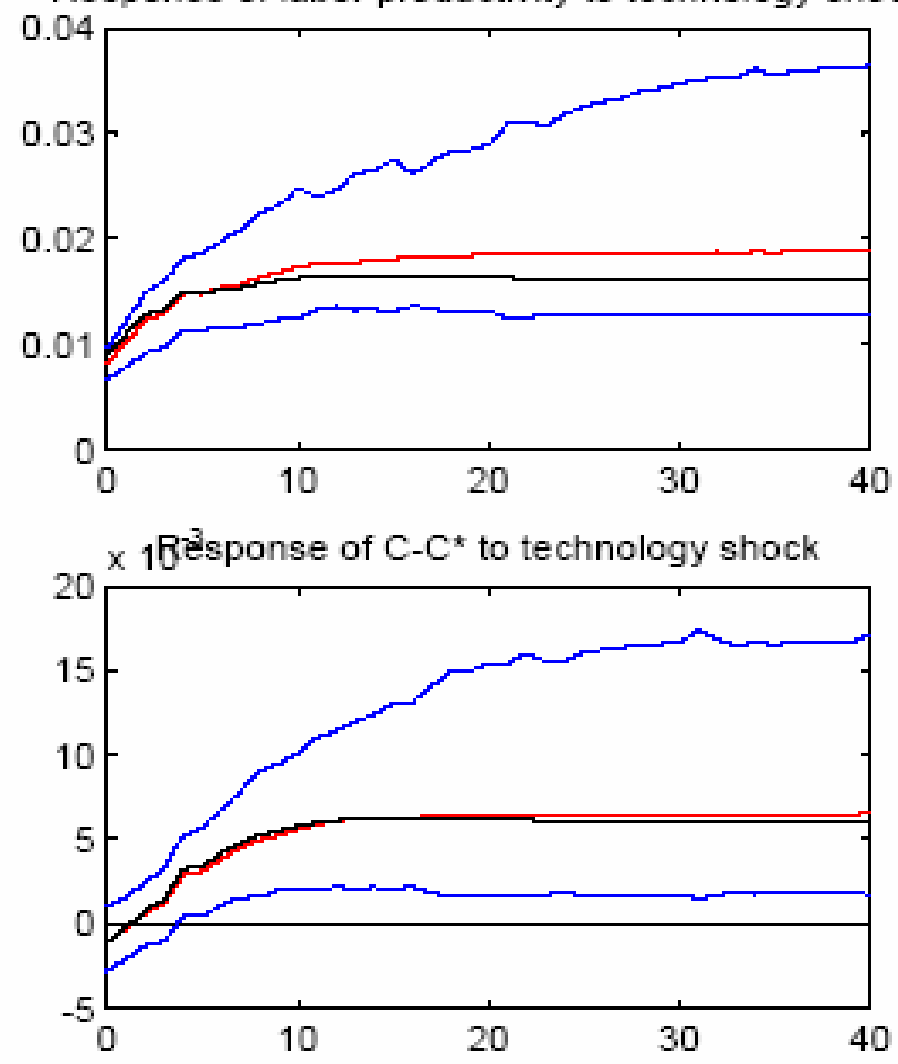

Response of PPI/CPI to technology shock

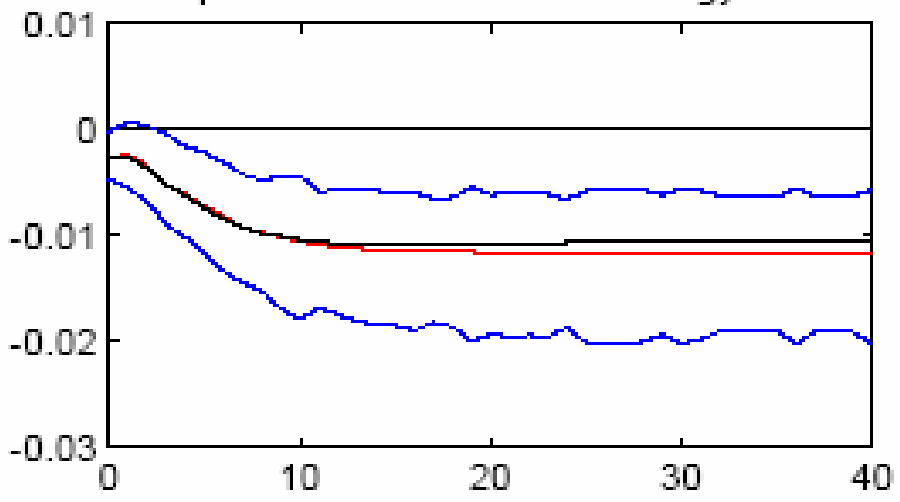

Response of RER (PPI) to technology shock

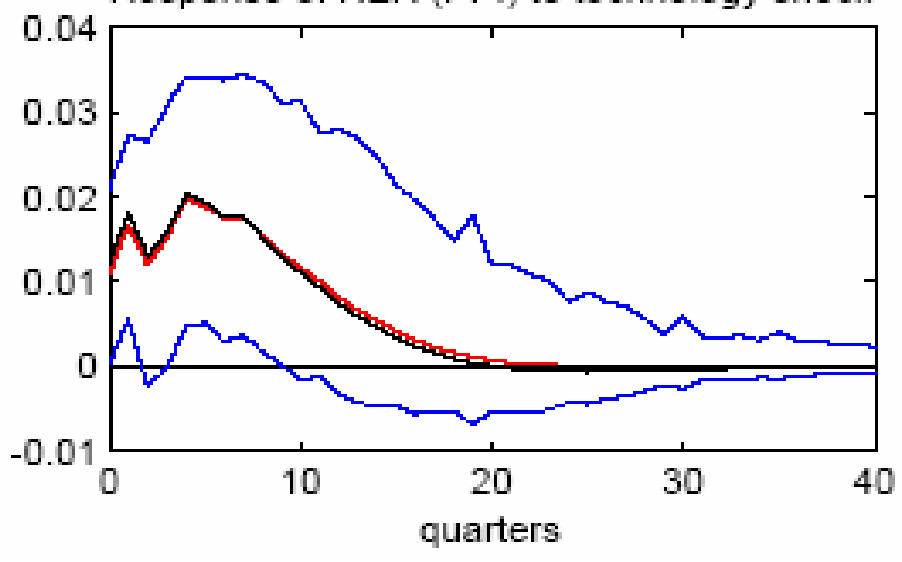

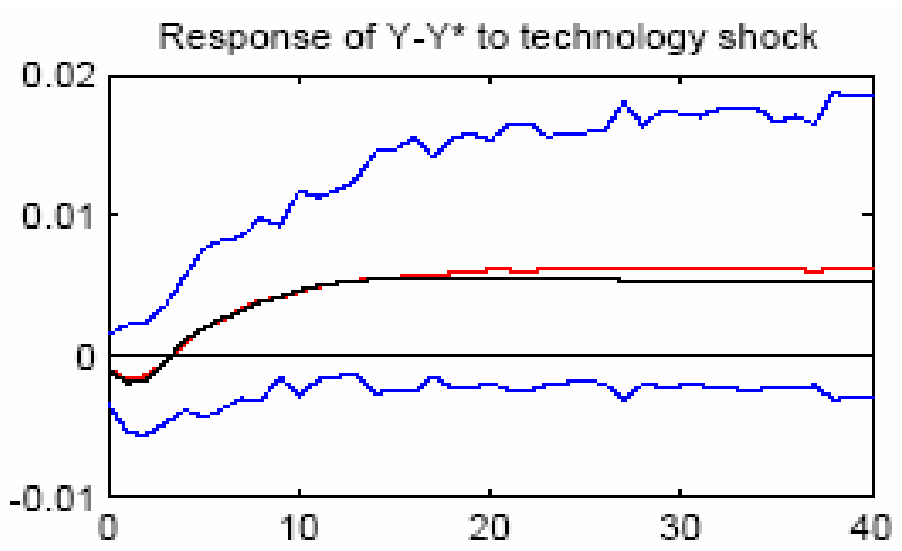

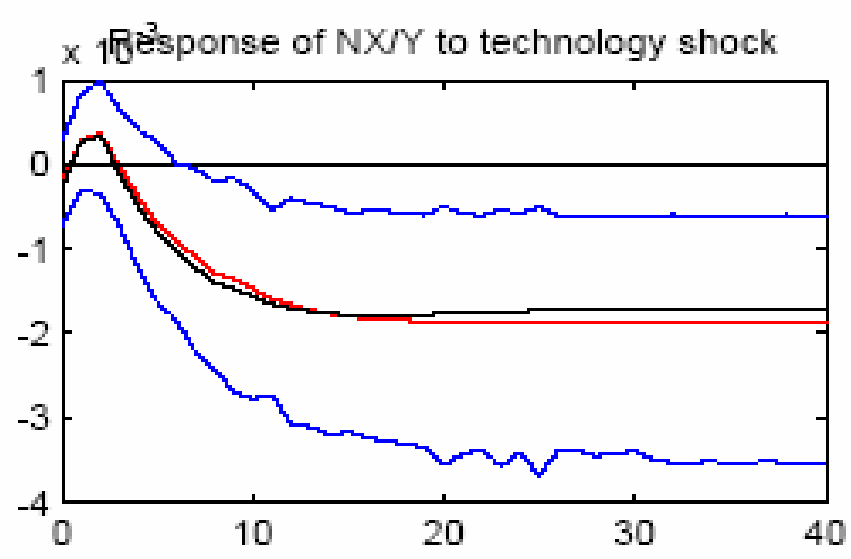

Response of RER to technology shock

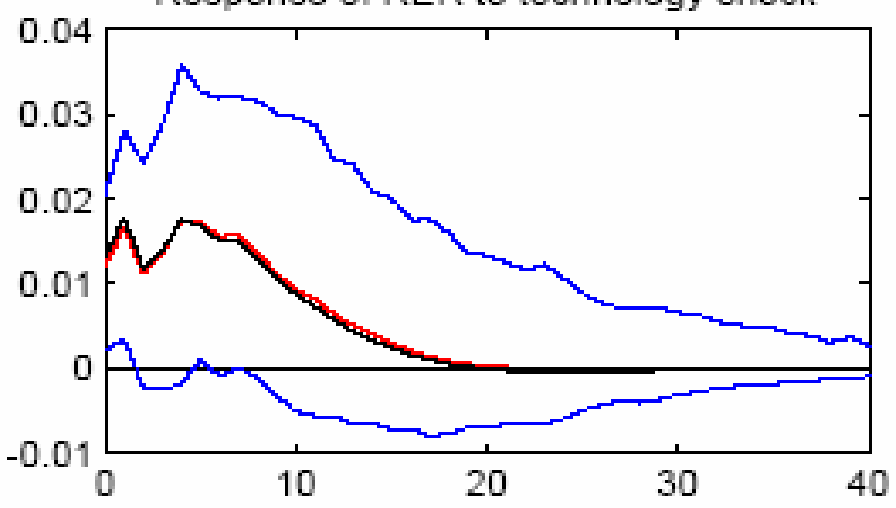

Response of RER (EXP DEF) to technology shock

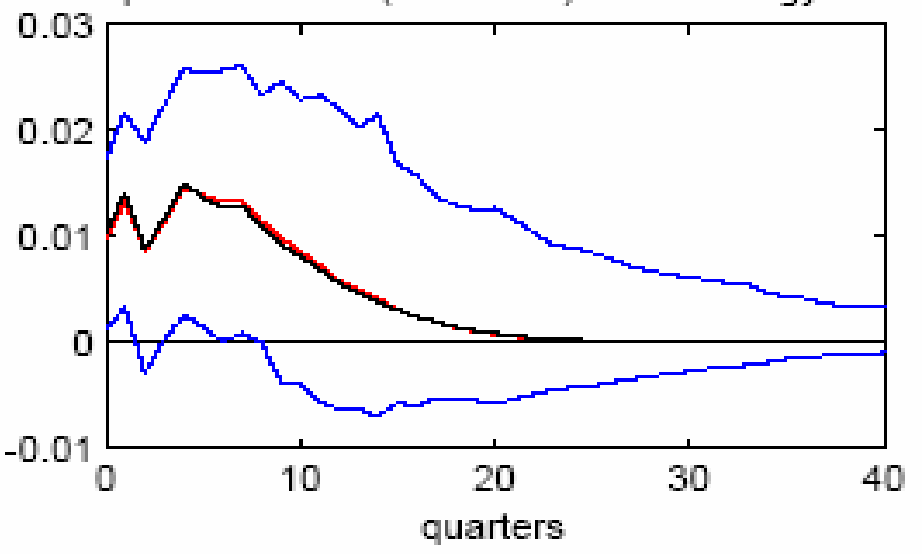




\section{FIGURE 7 - JAPAN LEVEL SPECIFICATION}

Response of labor productivity to technology shock
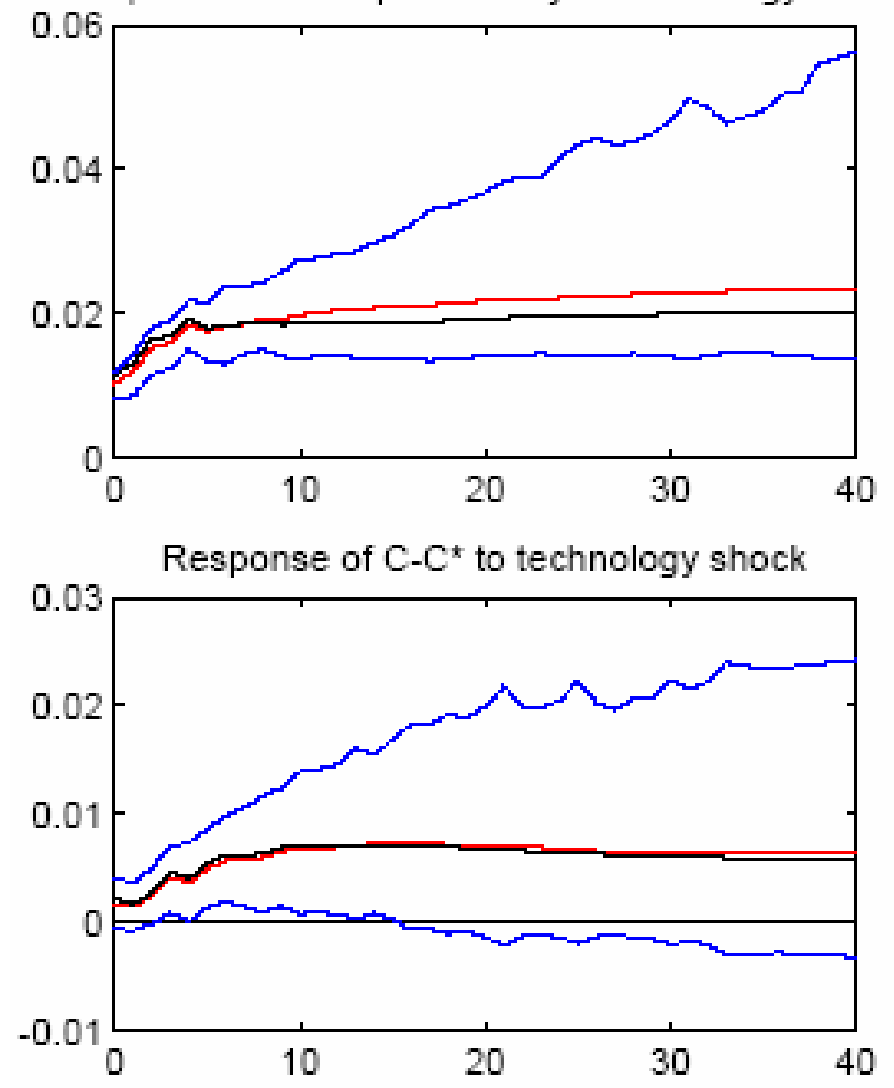

Response of PPI/CPI to technology shock
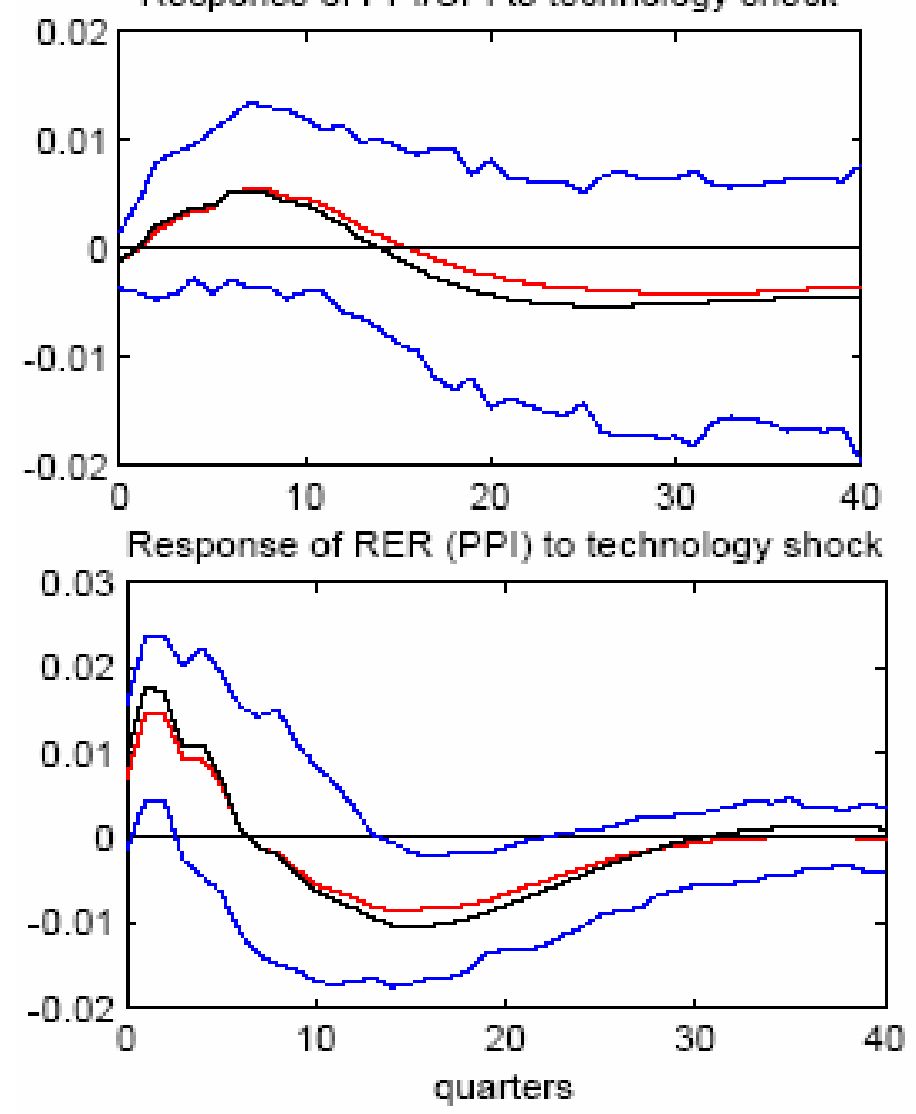
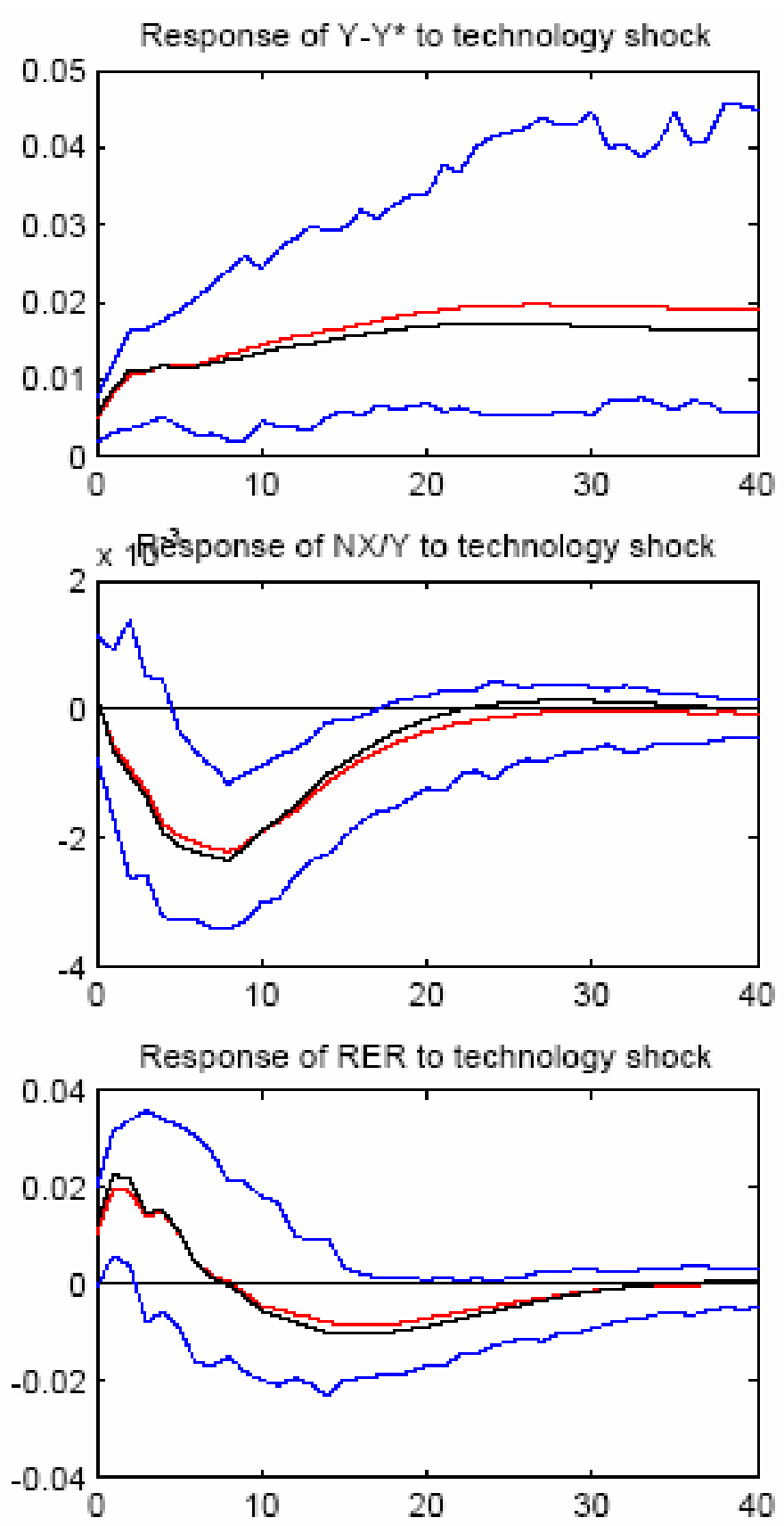

Response of RER (EXP DEF) to technology shock

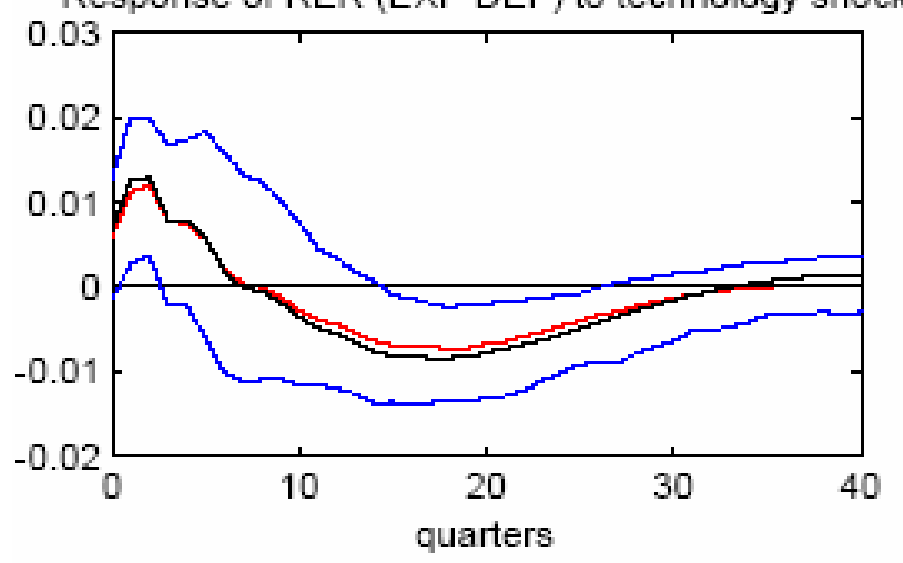




\section{FIGURE 8 - GERMANY LEVEL SPECIFICATION}

Response of labor productivity to technology shock
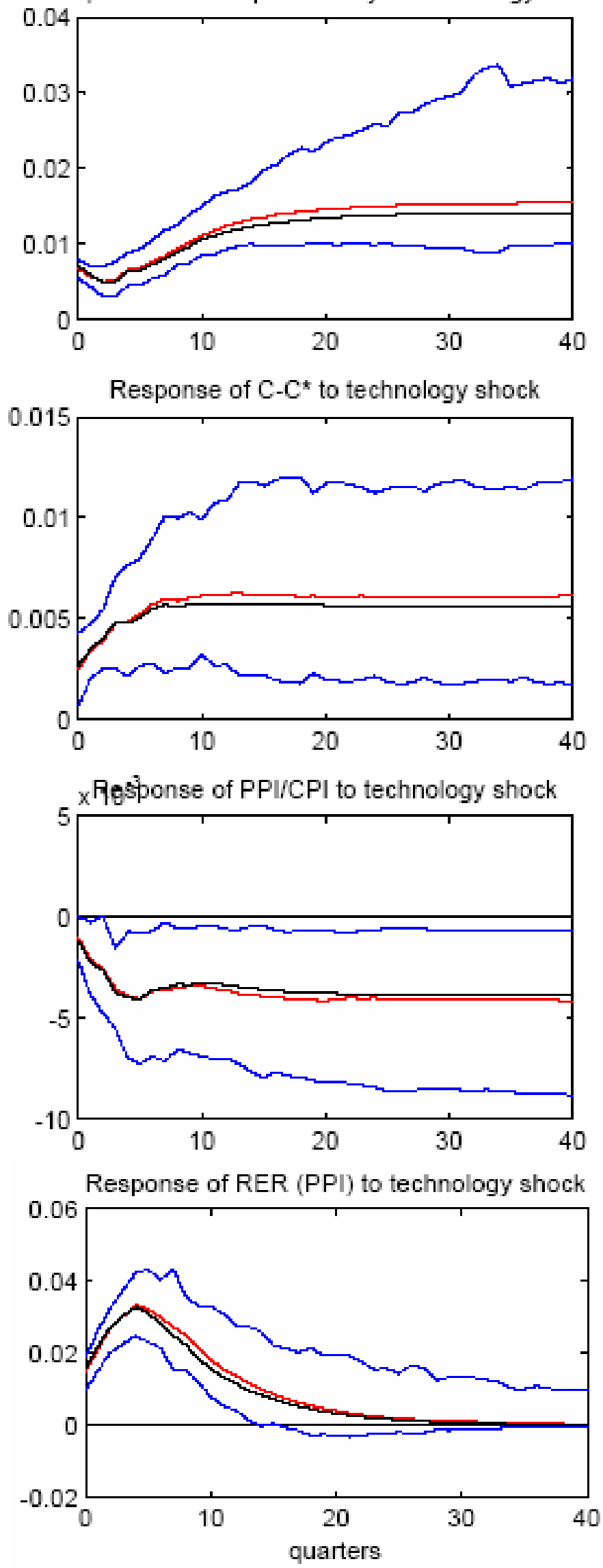
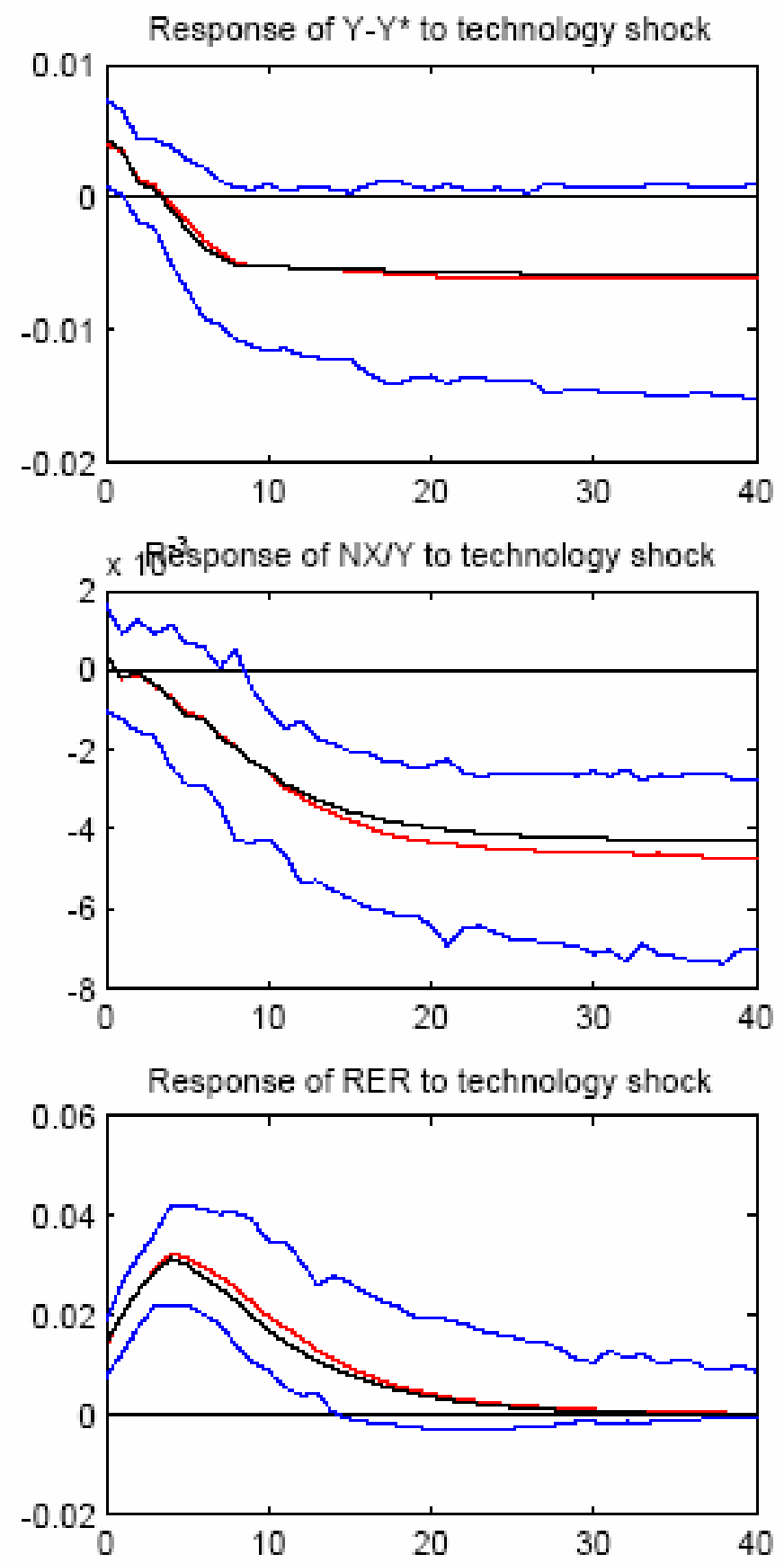

Response of RER (EXP DEF) to technology shock

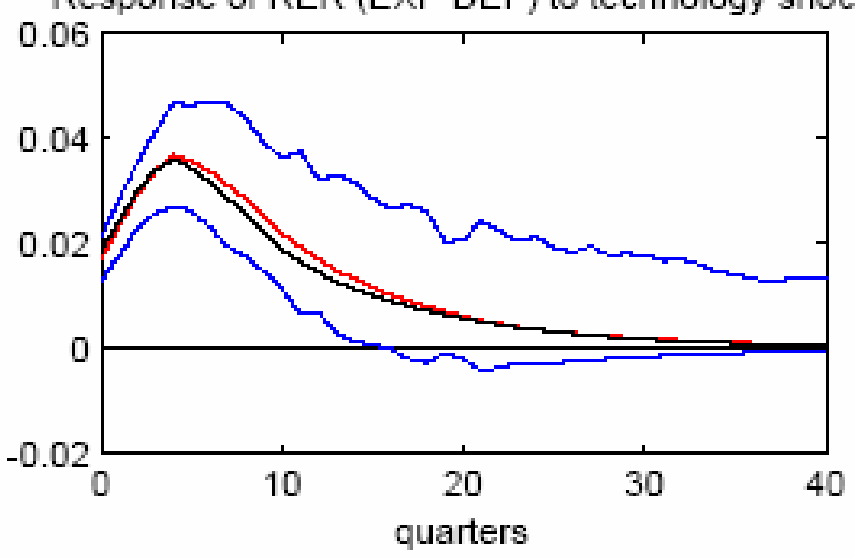




\section{FIGURE 9 - UK LEVEL SPECIFICATION}

Response of labor productivity to technology shock
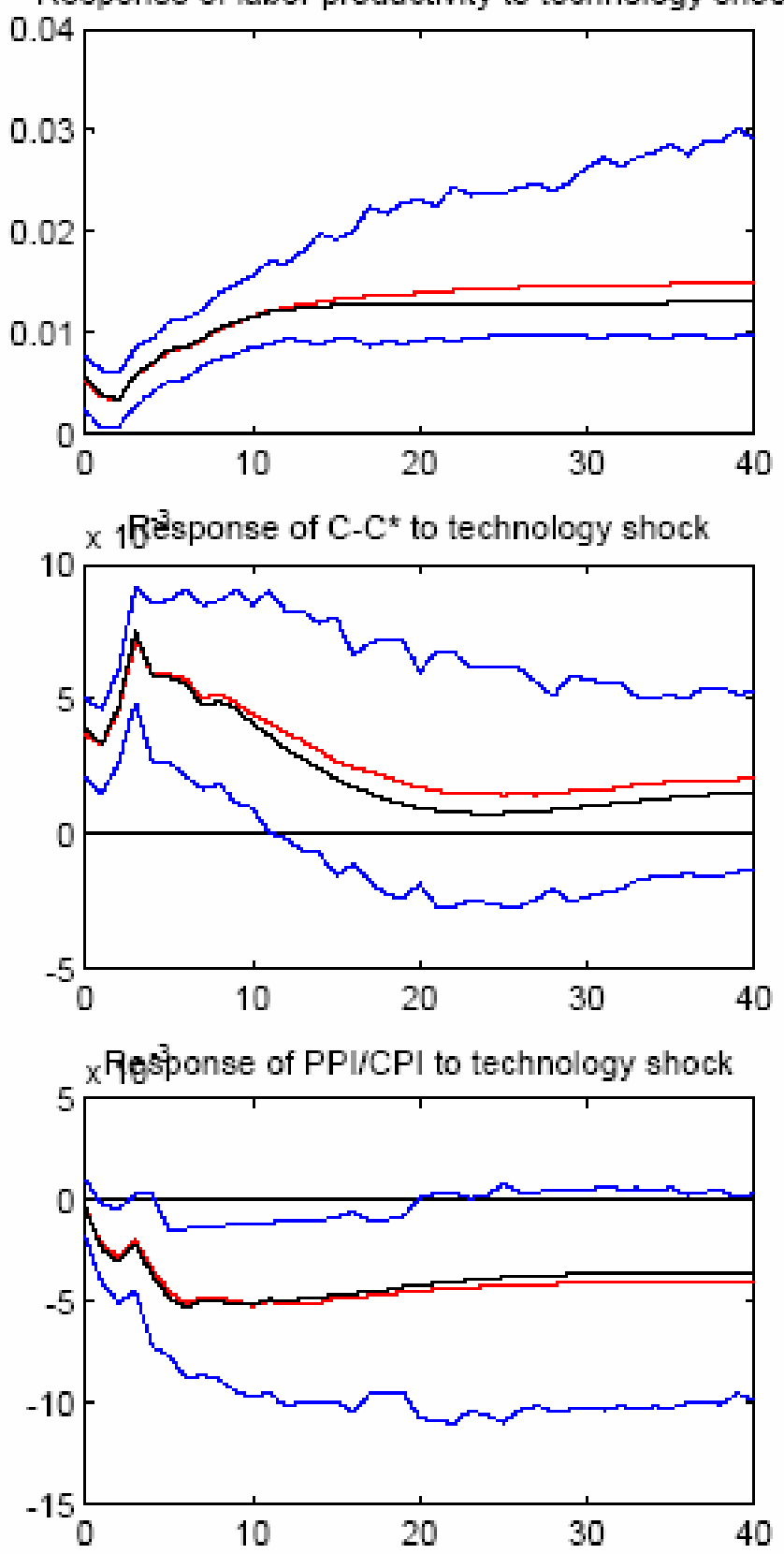

Response of RER (PPI) to technology shock

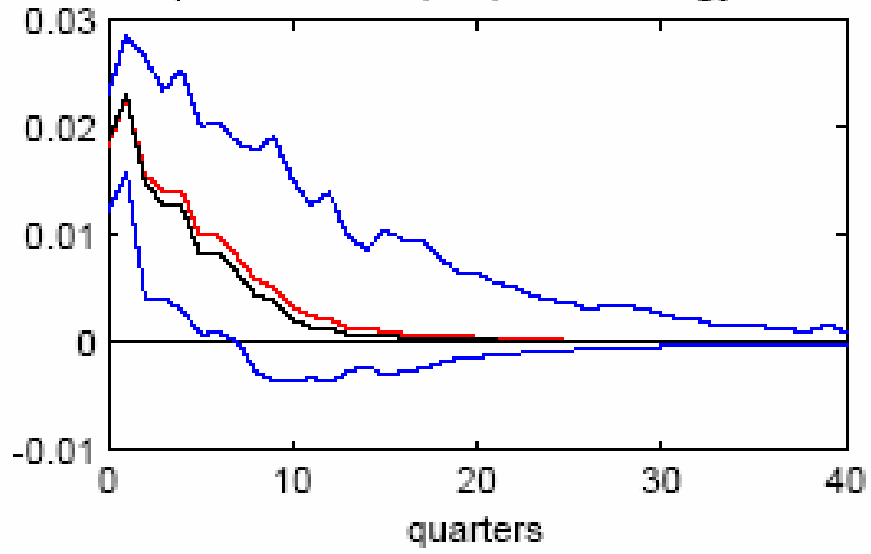

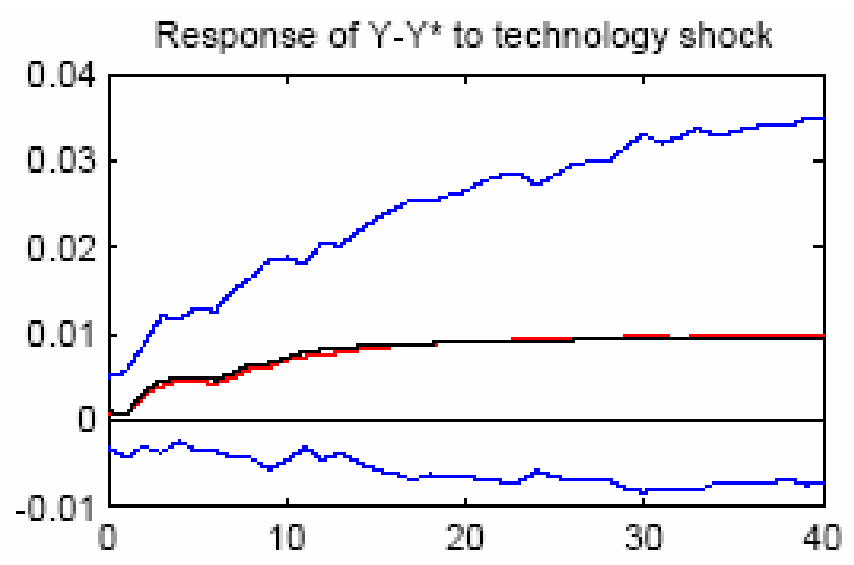
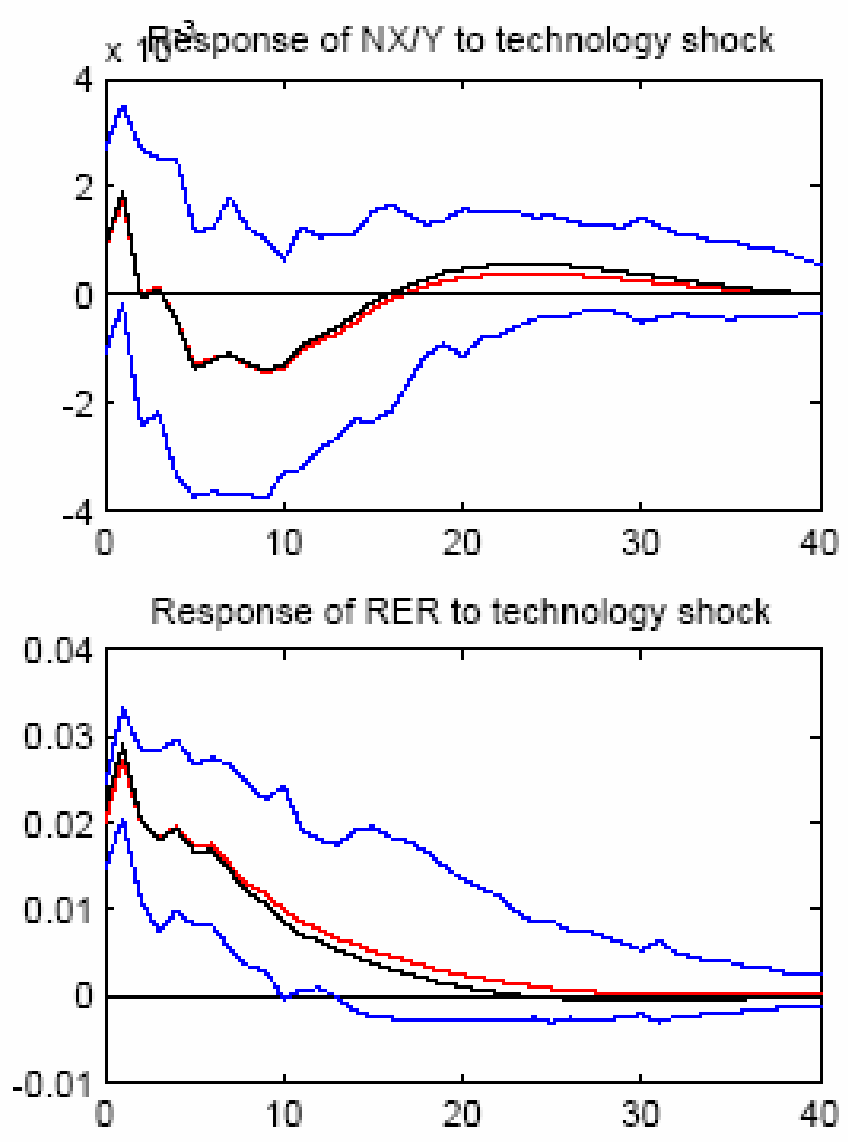

Response of RER (EXP DEF) to technology shock

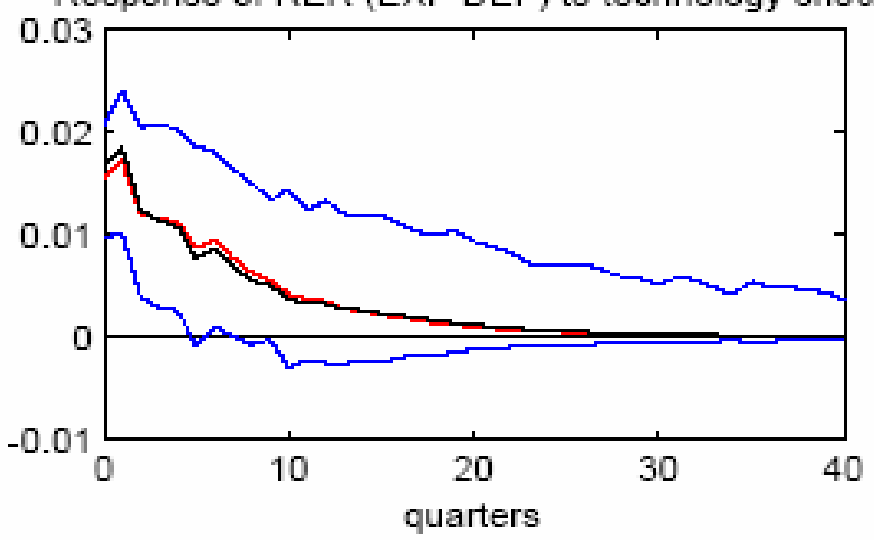




\section{FIGURE 10 - ITALY LEVEL SPECIFICATION}

Response of labor productivity to technology shock
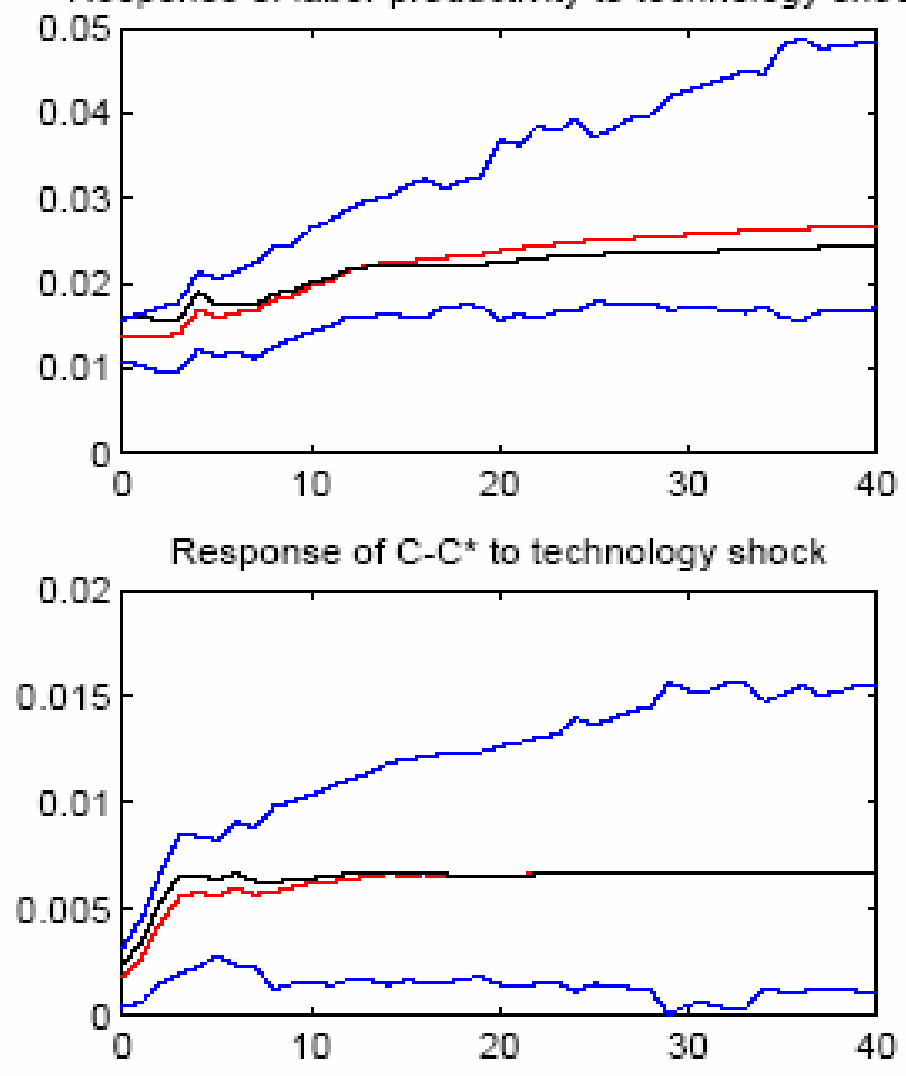

Response of PPI/CPI to technology shock
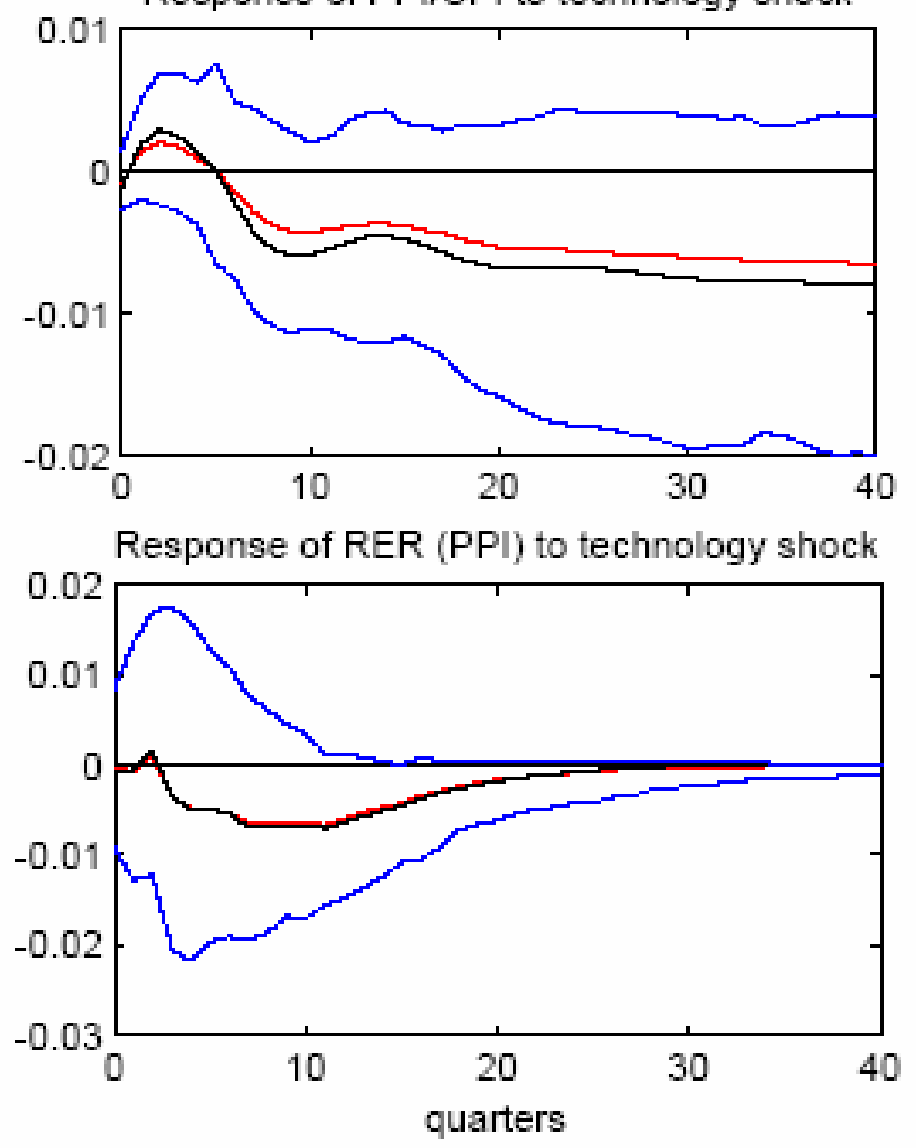
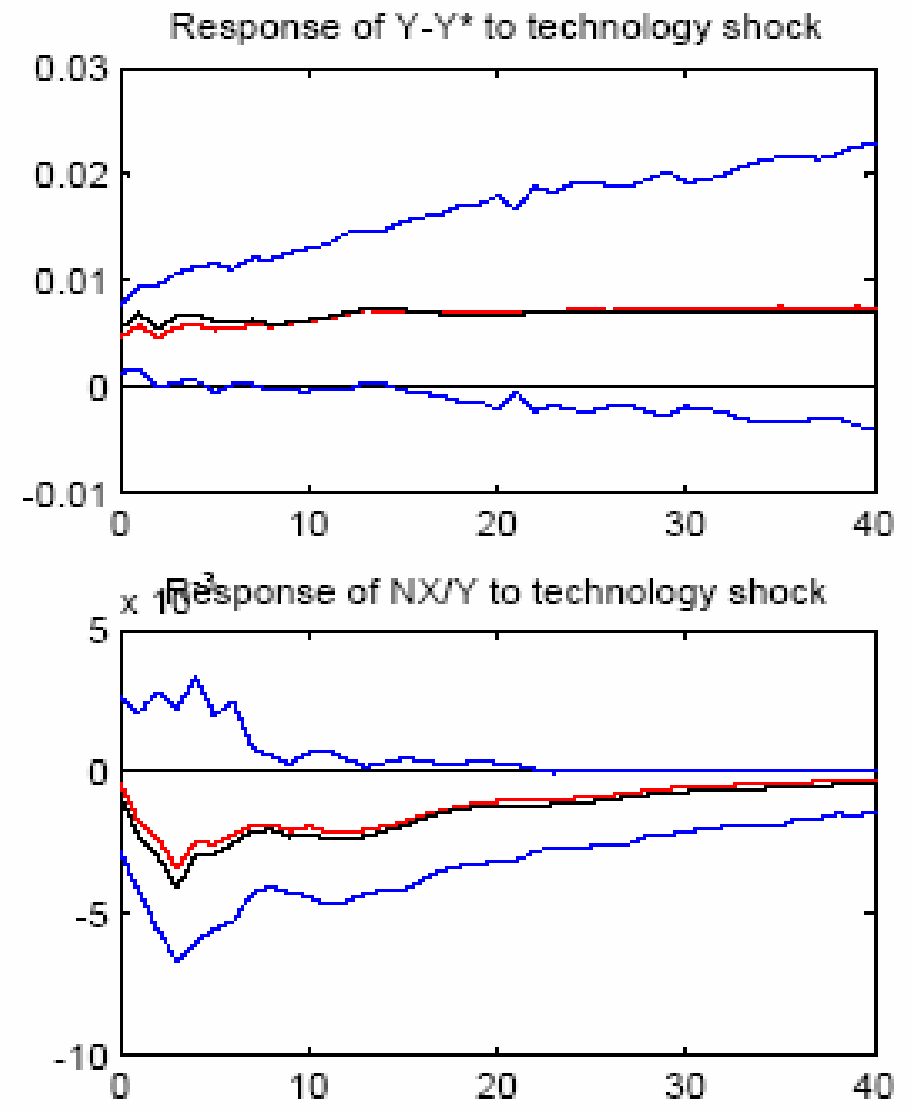

Response of RER to technology shock

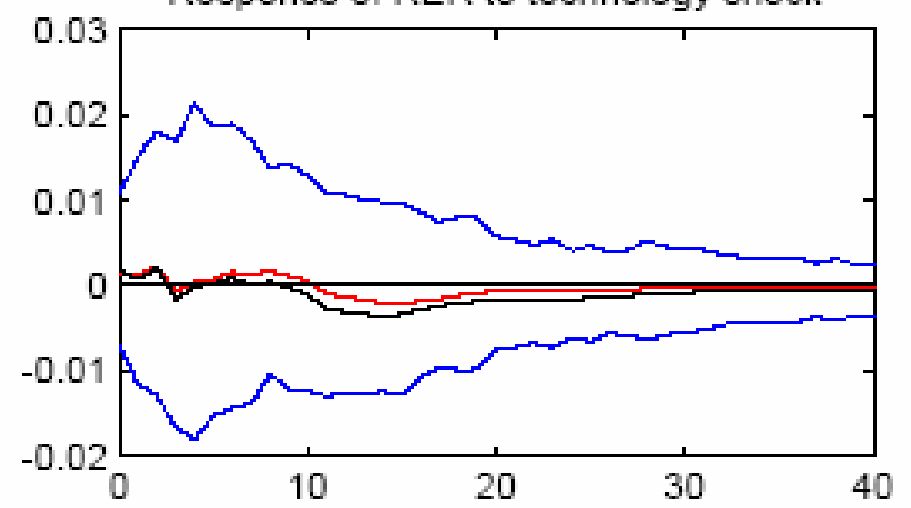

Response of RER (EXP DEF) to technology shock

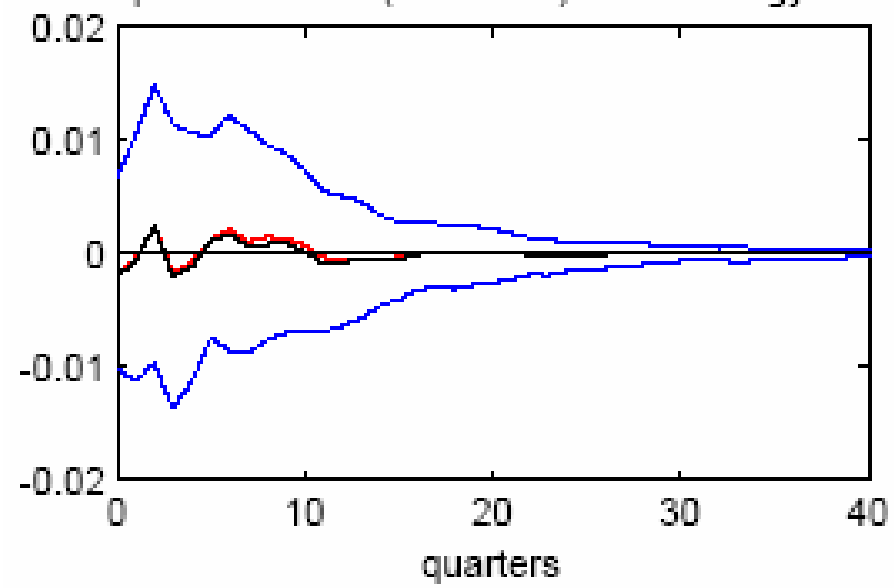




\section{FIGURE 11 - US SUBSAMPLE ANALYSIS}

\section{PANEL A - US SUBSAMPLE 1973-1998}
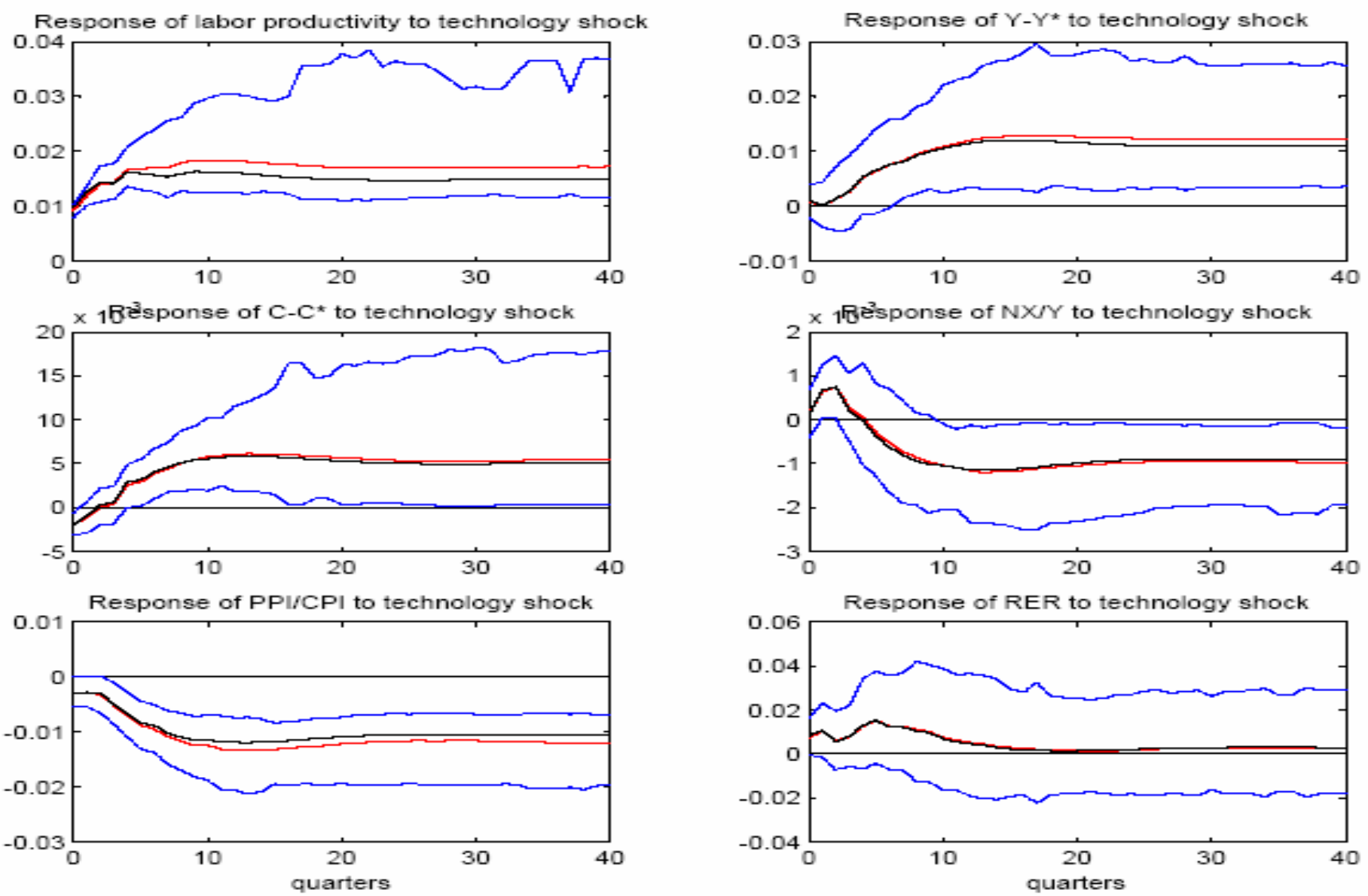

PANEL B - US SUBSAMPLE 1979-2004
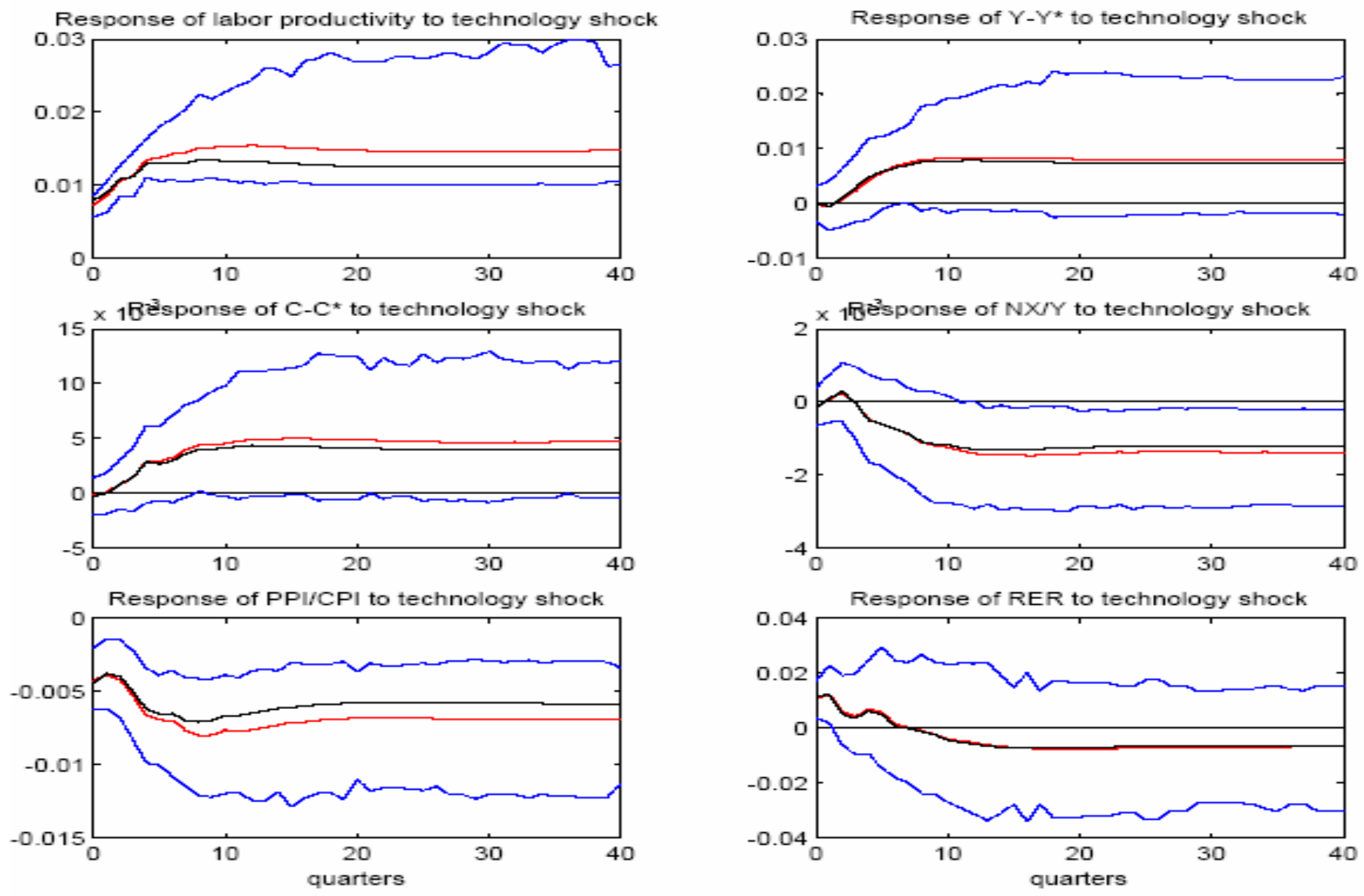


\section{FIGURE 12 - US ABSOLUTE SPECIFICATION}

Response of labor productivity to technology shock

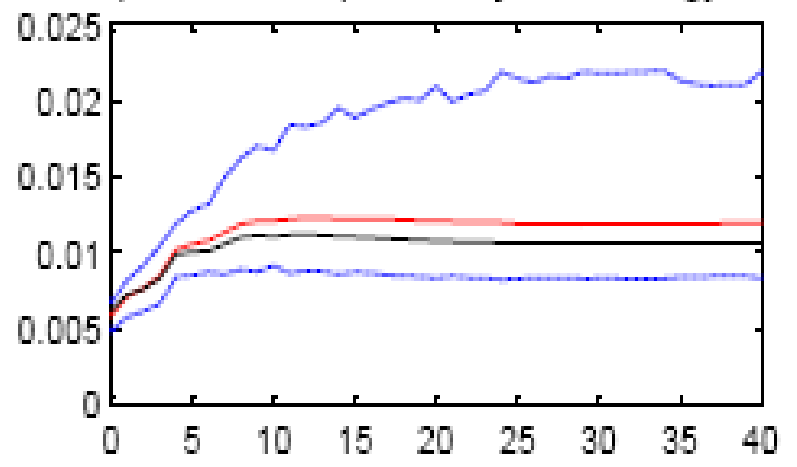

Response of $\mathrm{C}-\mathrm{C}^{x}$ to technology shock

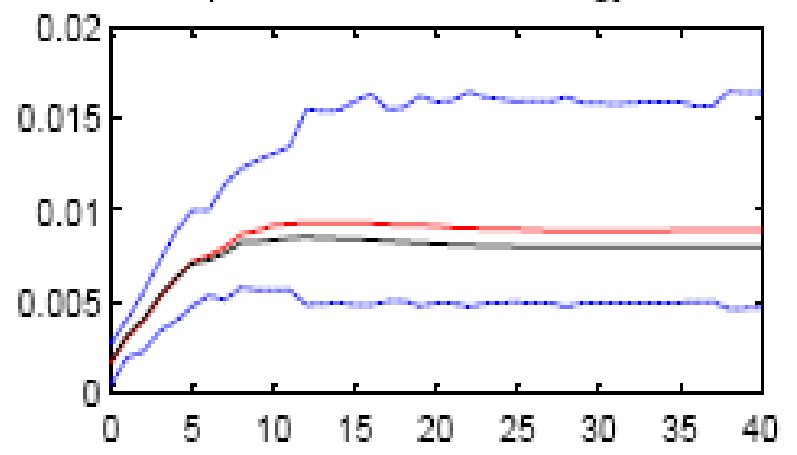

Response of PPICPI to technology shock

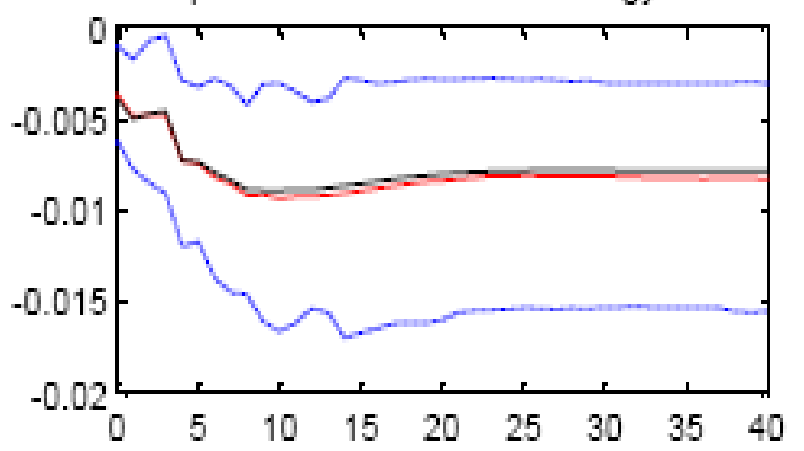

Response of RER (PPI) to technology shock

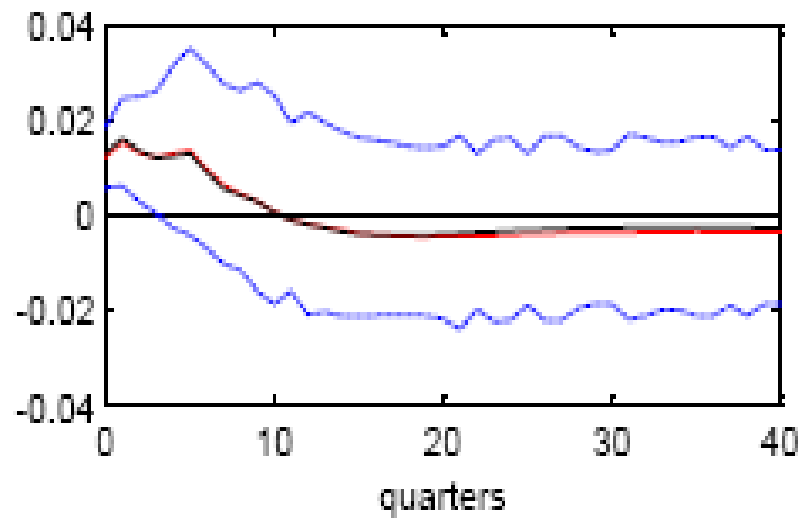

Response of $Y-Y^{x}$ to technology shock
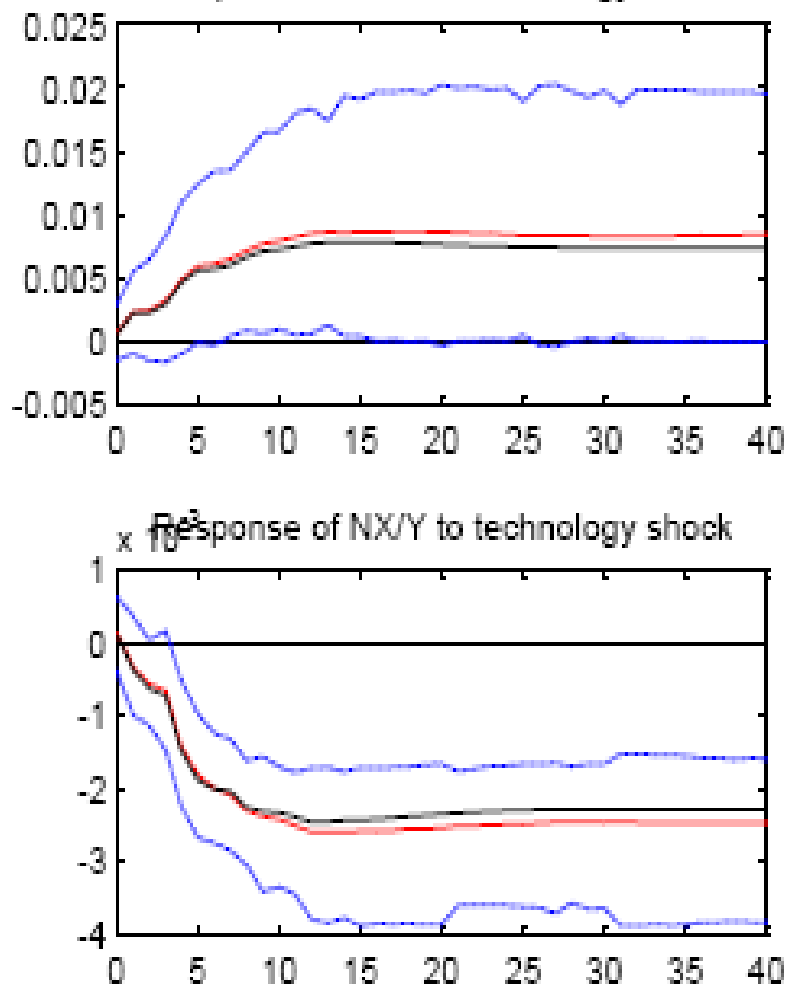

Response of RER to technology shock

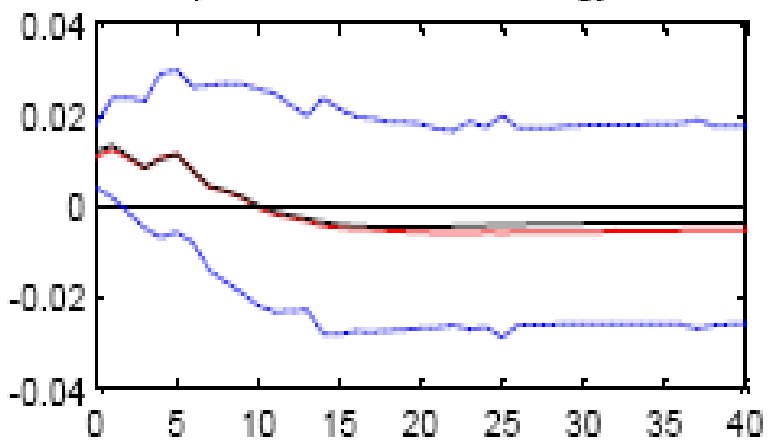

Response of RER (EXP DEF) to technology shock

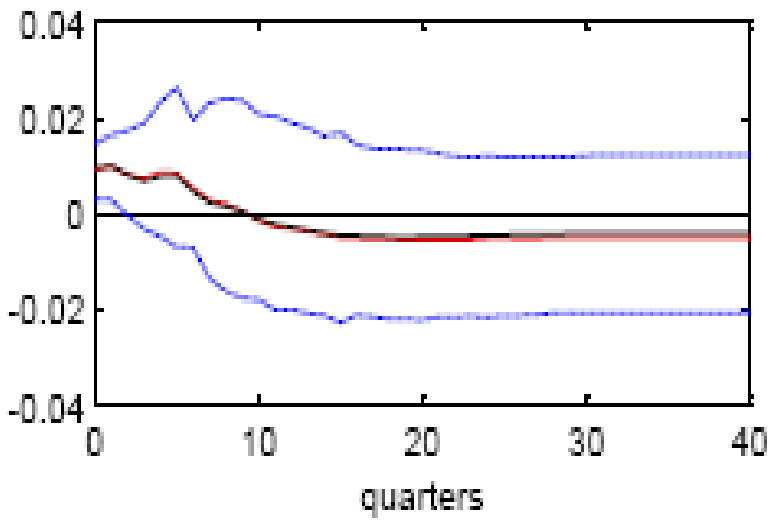


Figure 13: Theoretical and VAR Impulse Responses: High Trade Elasticity
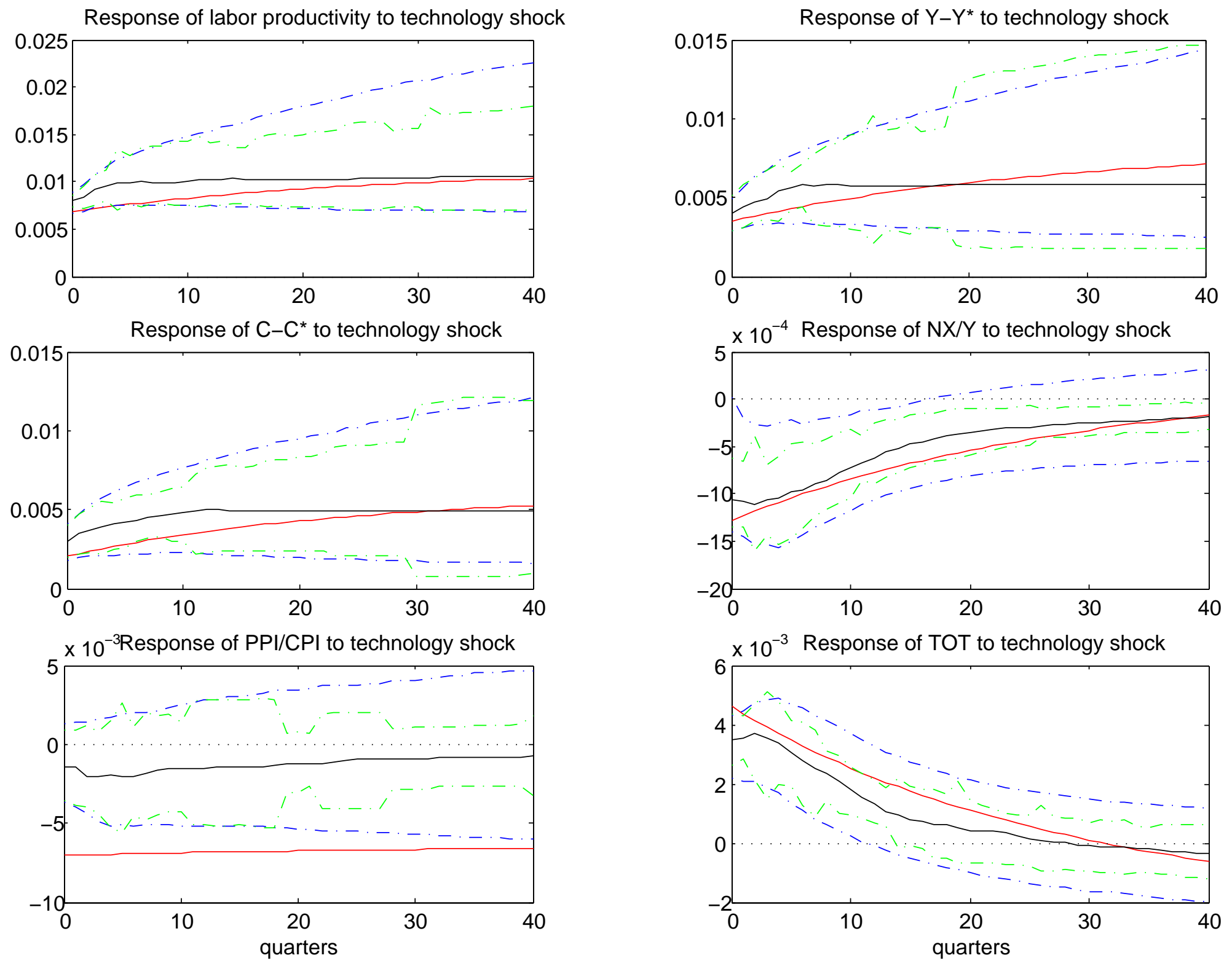
Figure 14: Theoretical and VAR Impulse Responses: Unitary Trade Elasticity
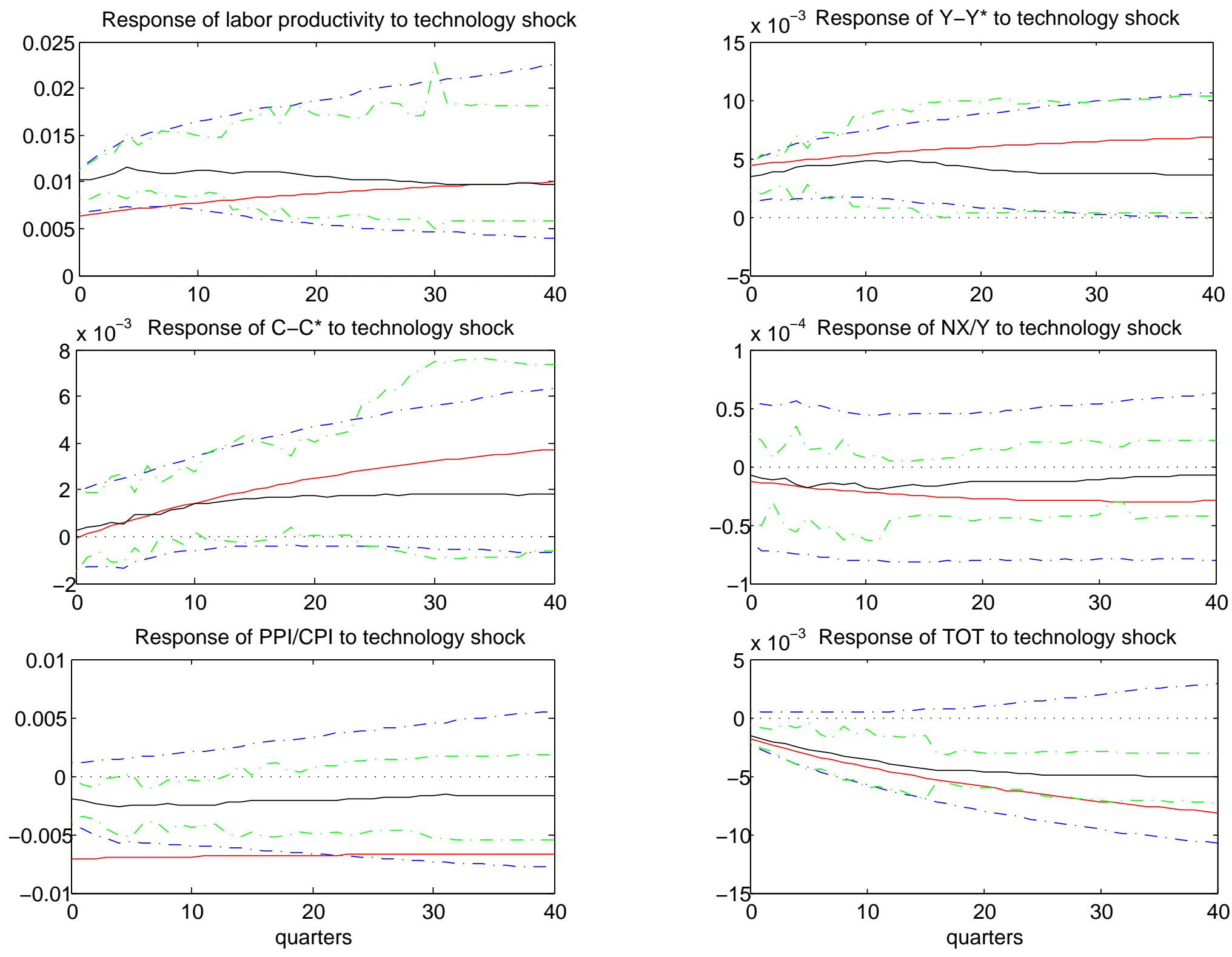
FIGURE A1 - US VAR DATA

LP-LP*

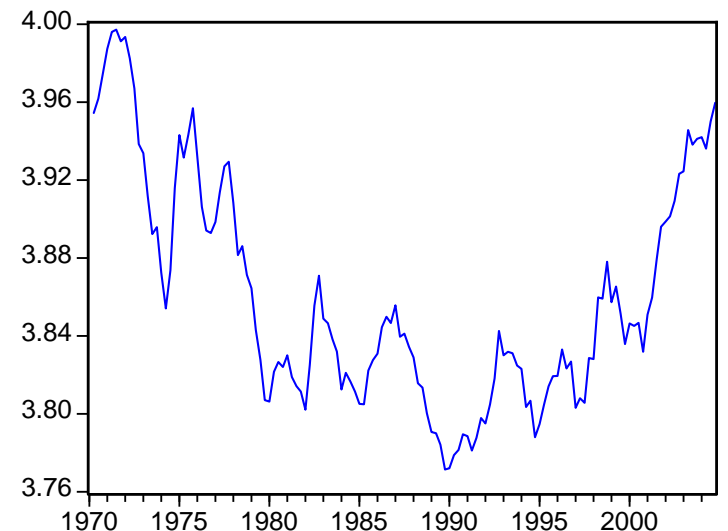

$Y-Y^{*}$

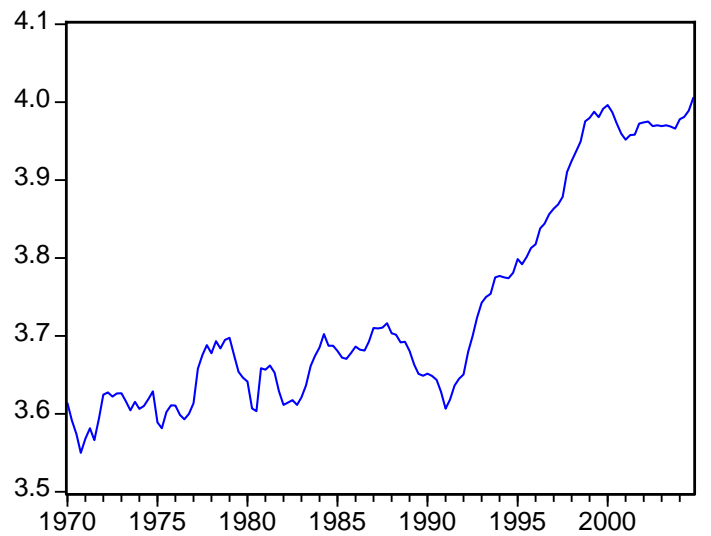

C-C*

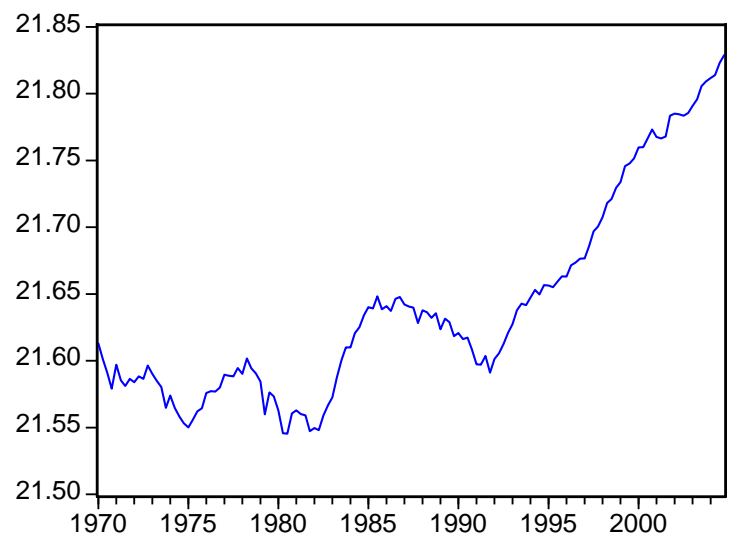

$N X / Y$

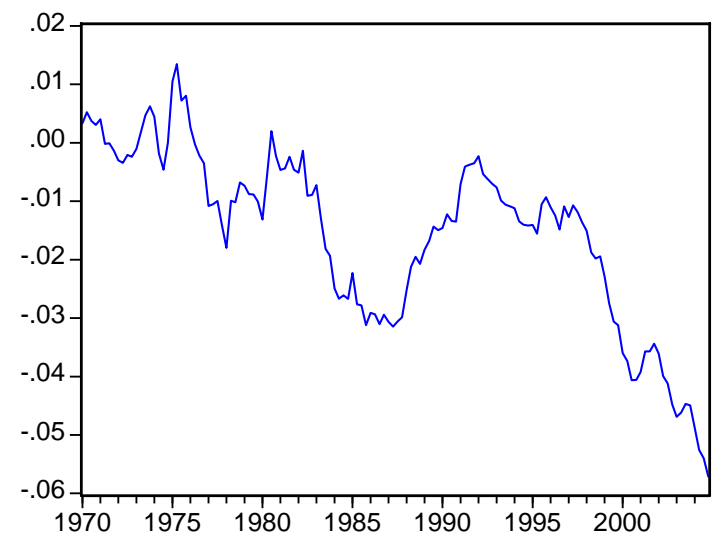

PPI/CPI SERVICES

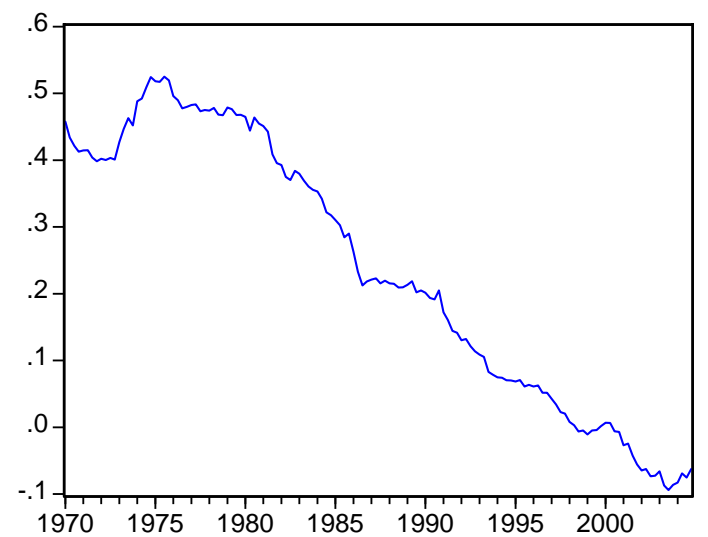

RER (CPI BASED)

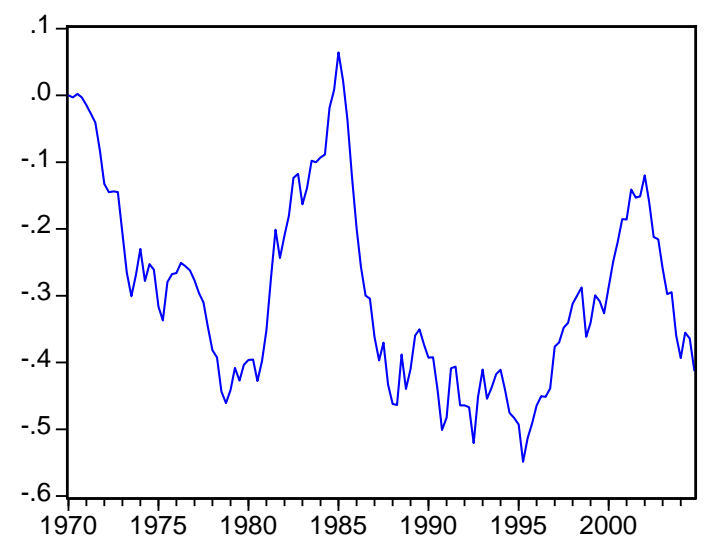

RER (PPI BASED)

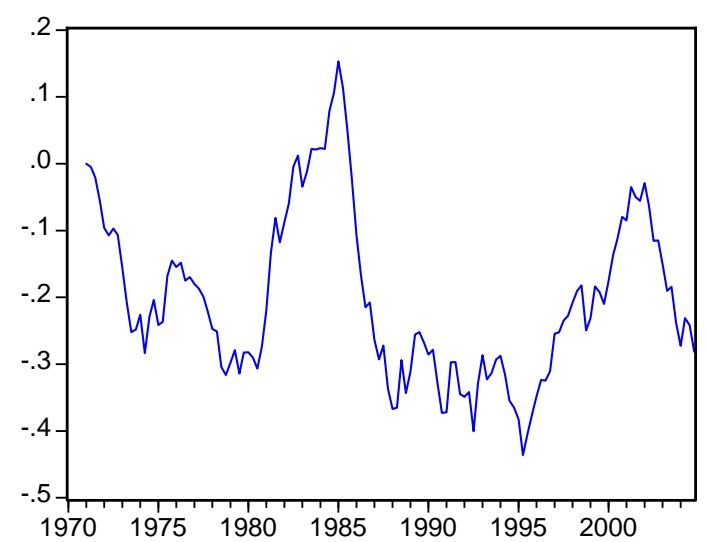

RER (EXP DEFLATOR)

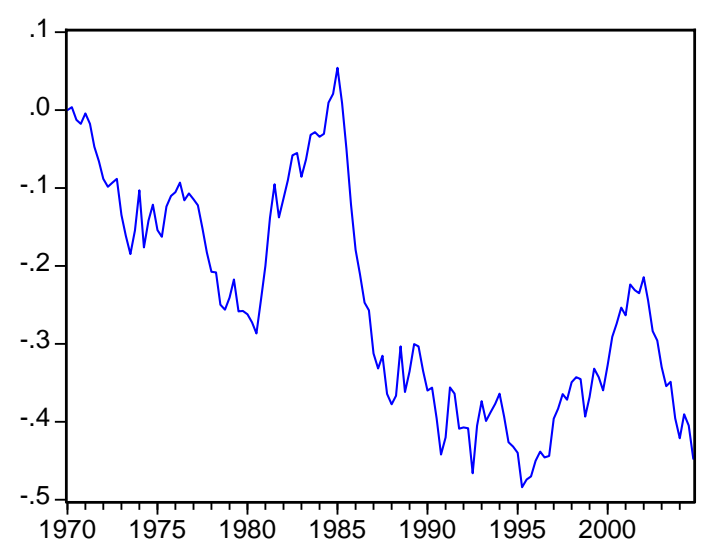


FIGURE A2 - JAPAN VAR DATA

LP-LP*
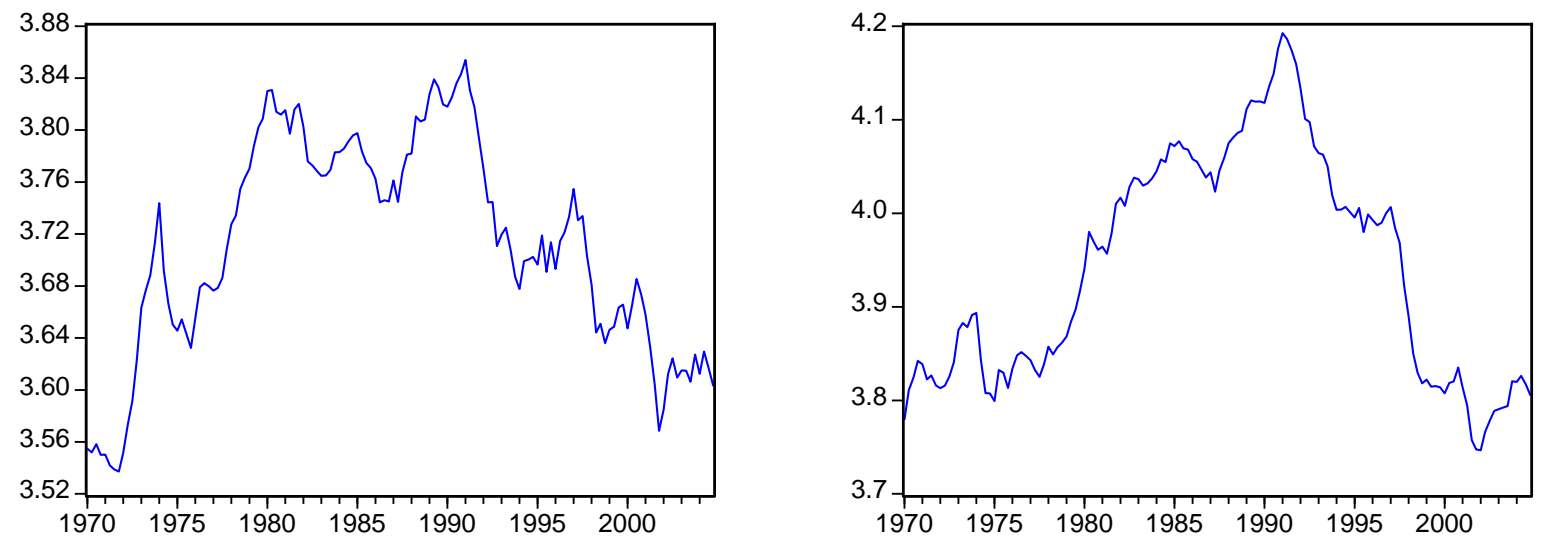

$C-C^{*}$

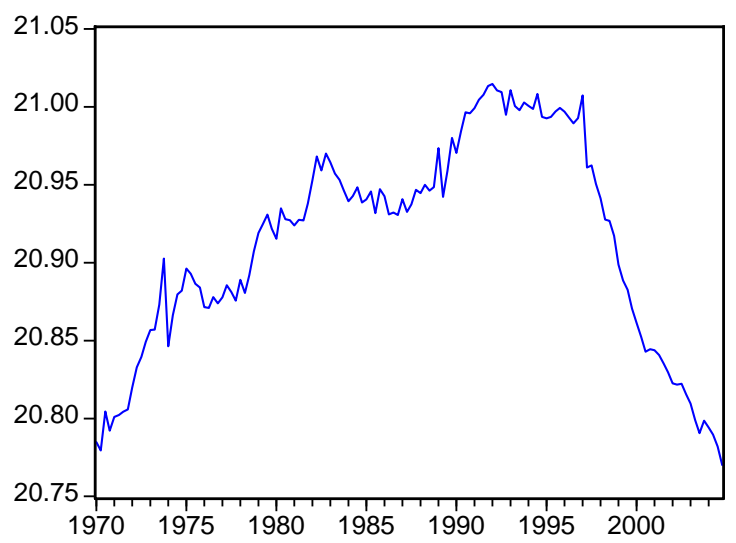

PPI/CPI SERVICES

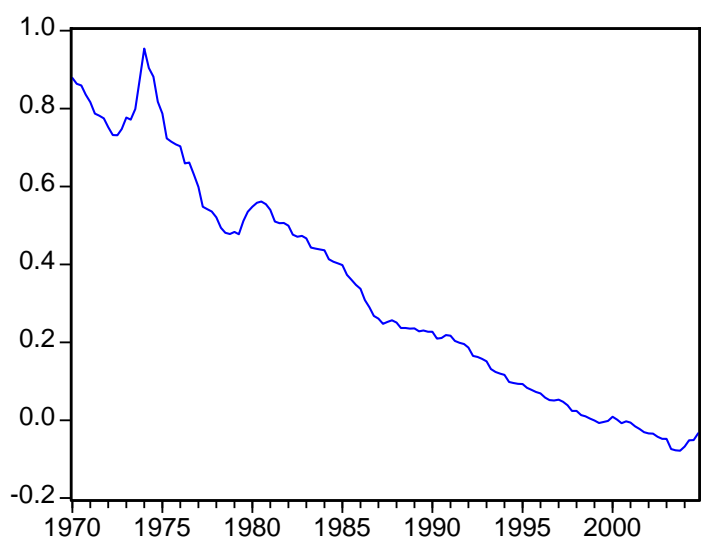

RER (CPI BASED)

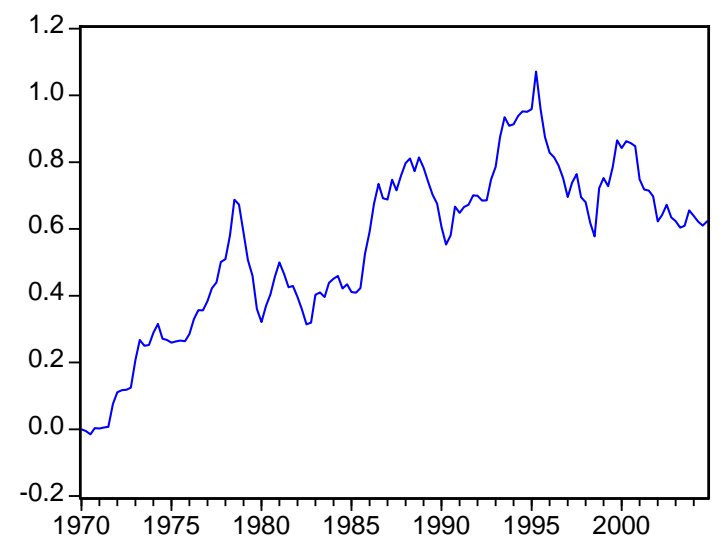

RER (PPI BASED)

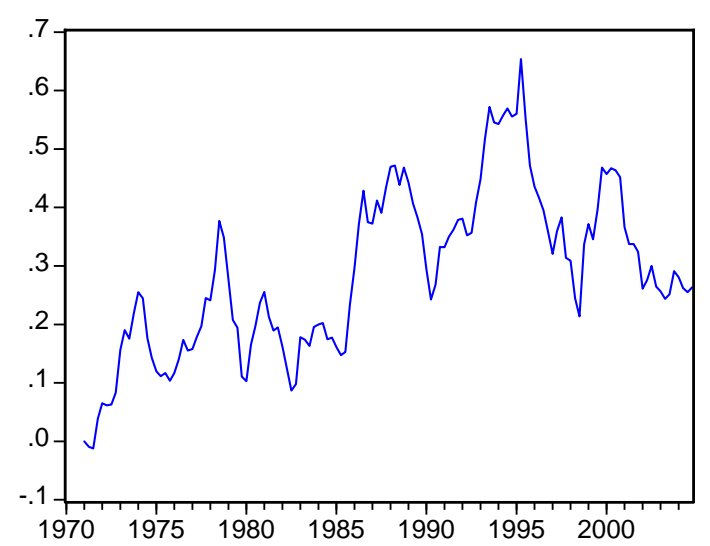

RER (EXP DEFLATOR)

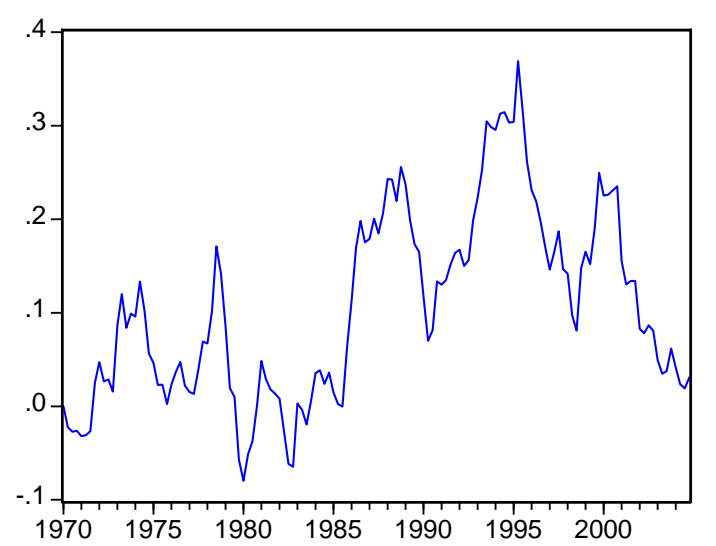


FIGURE A3 - GERMANY VAR DATA

LP-LP*
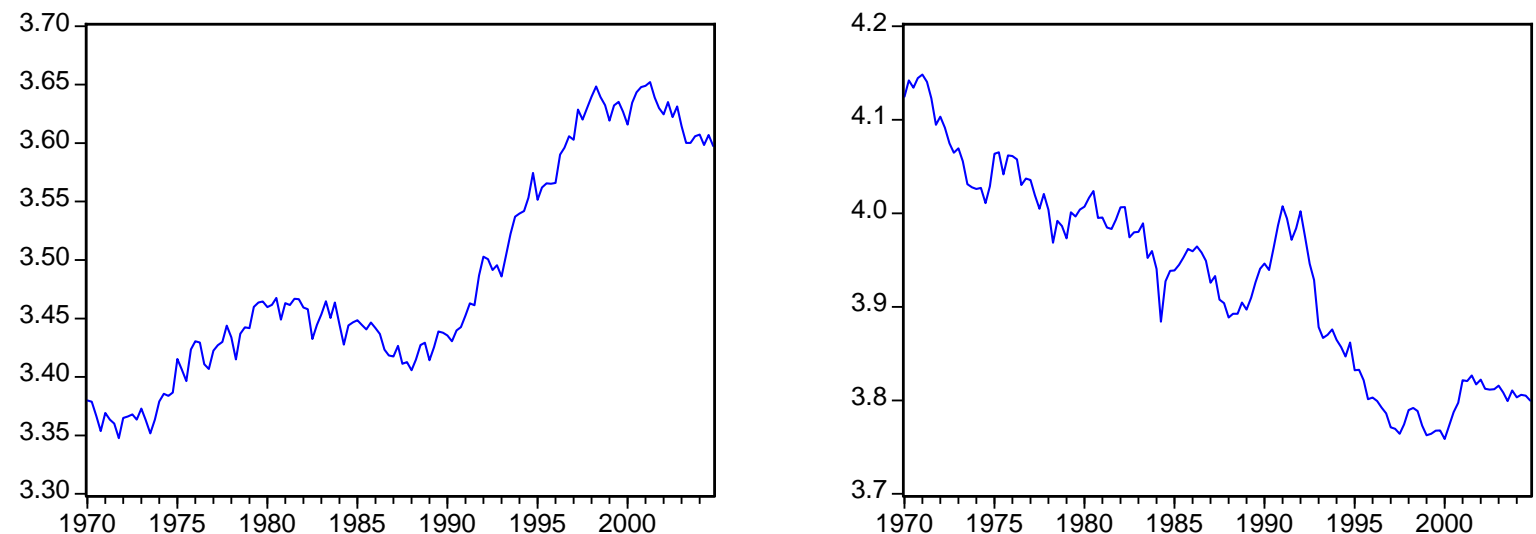

$C-C^{*}$

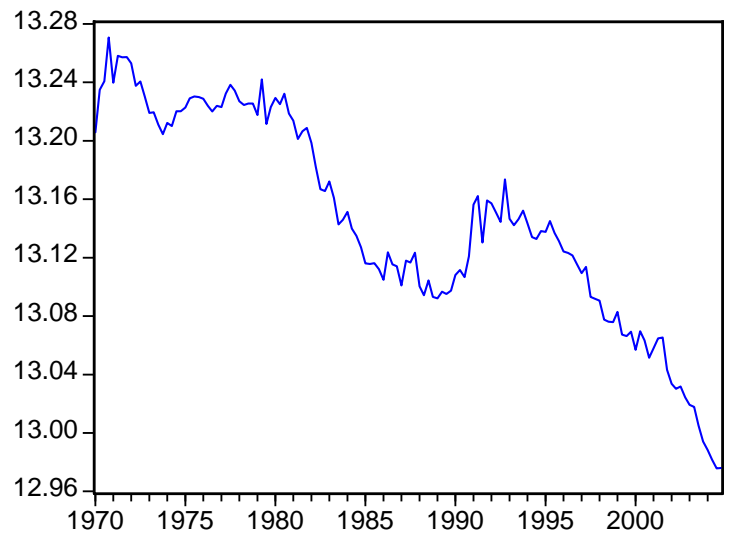

$N X / Y$

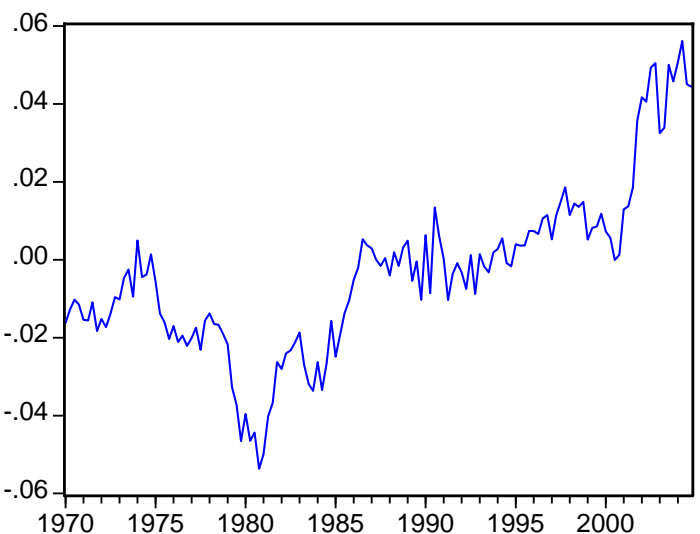

$\mathrm{PPI} / \mathrm{CPI}$

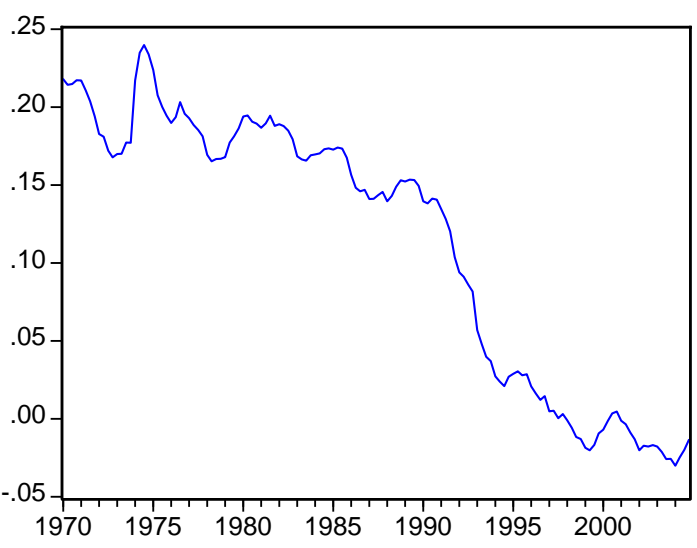

RER (CPI BASED)

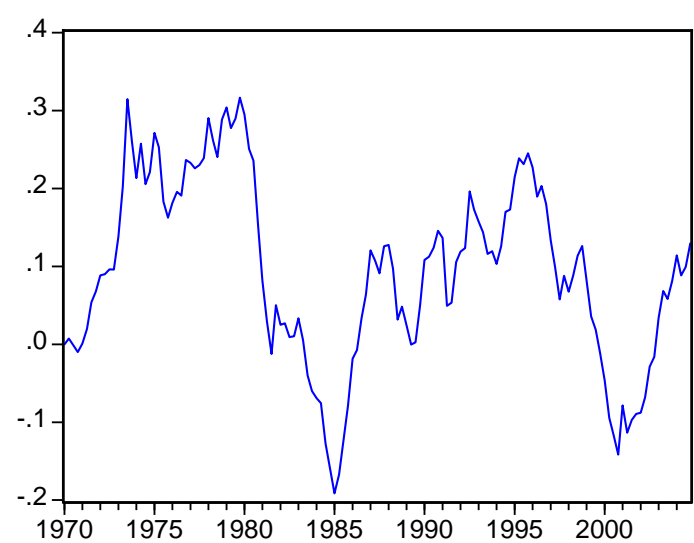

RER (PPI BASED)

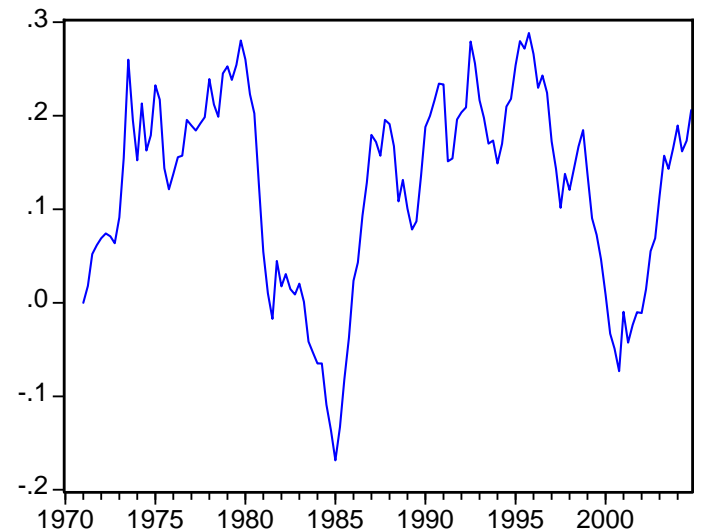

RER (EXP DEFLATOR)

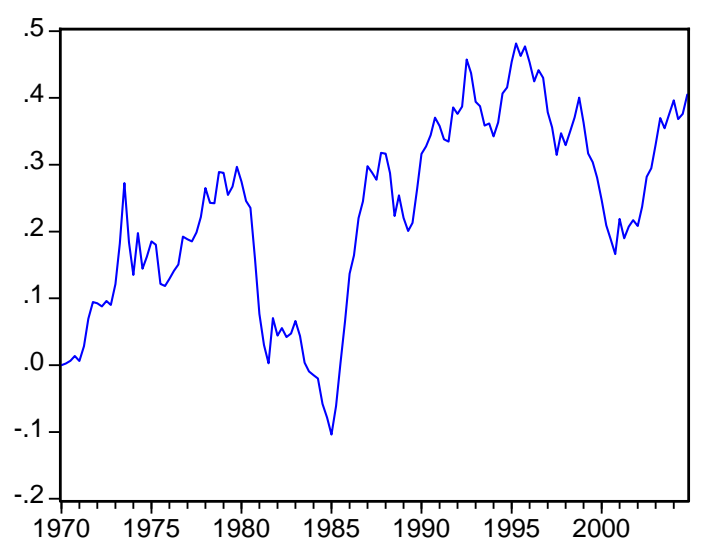


FIGURE A4 - UK VAR DATA

LP-LP*
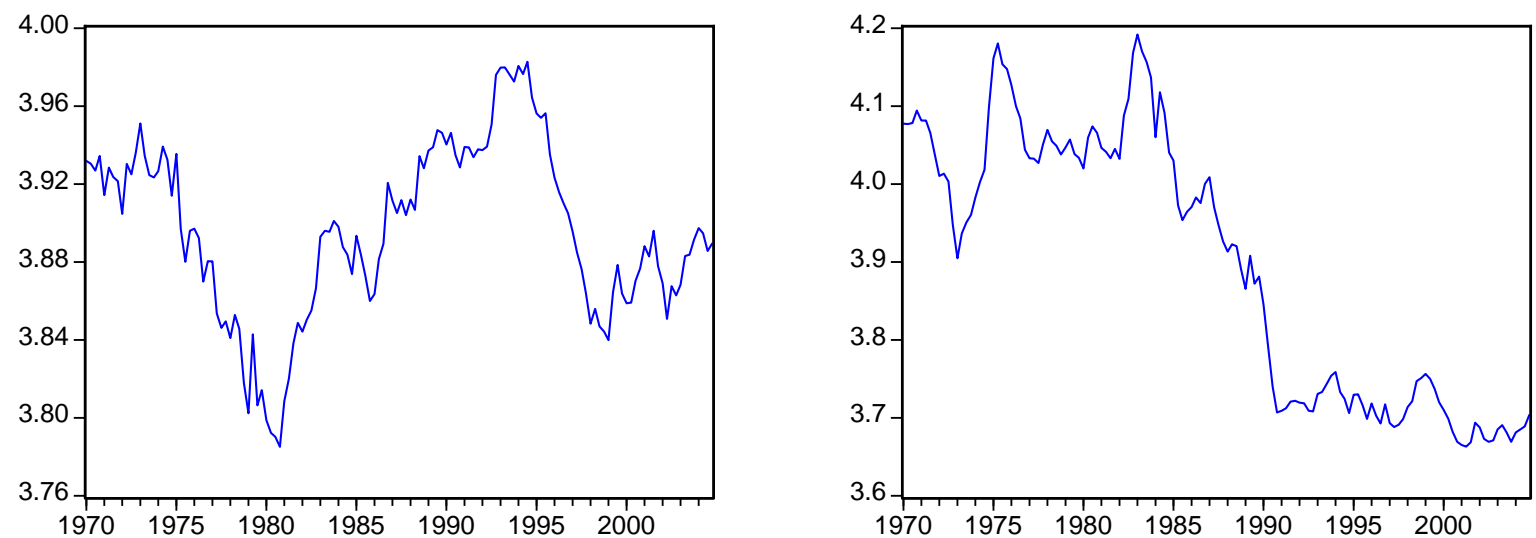

C-C*

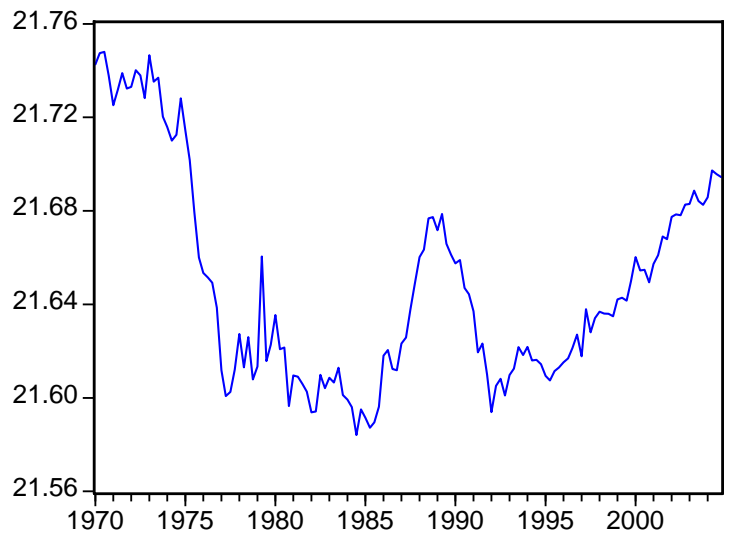

$N X / Y$

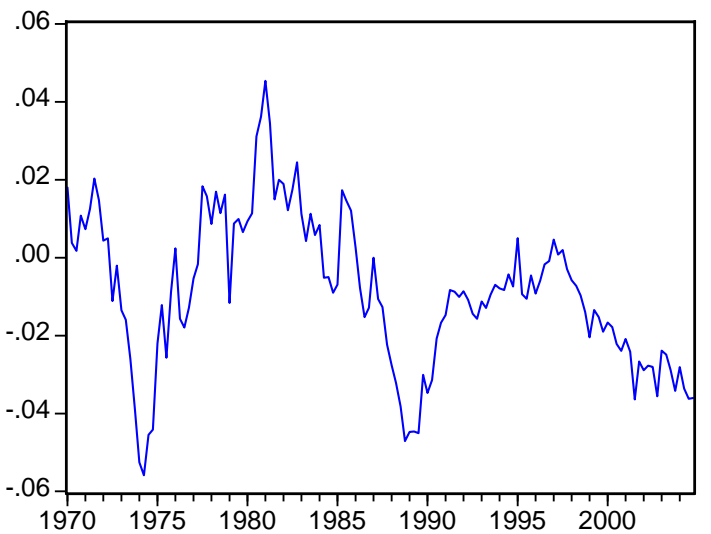

$\mathrm{PPI} / \mathrm{CPI}$

RER (CPI BASED)
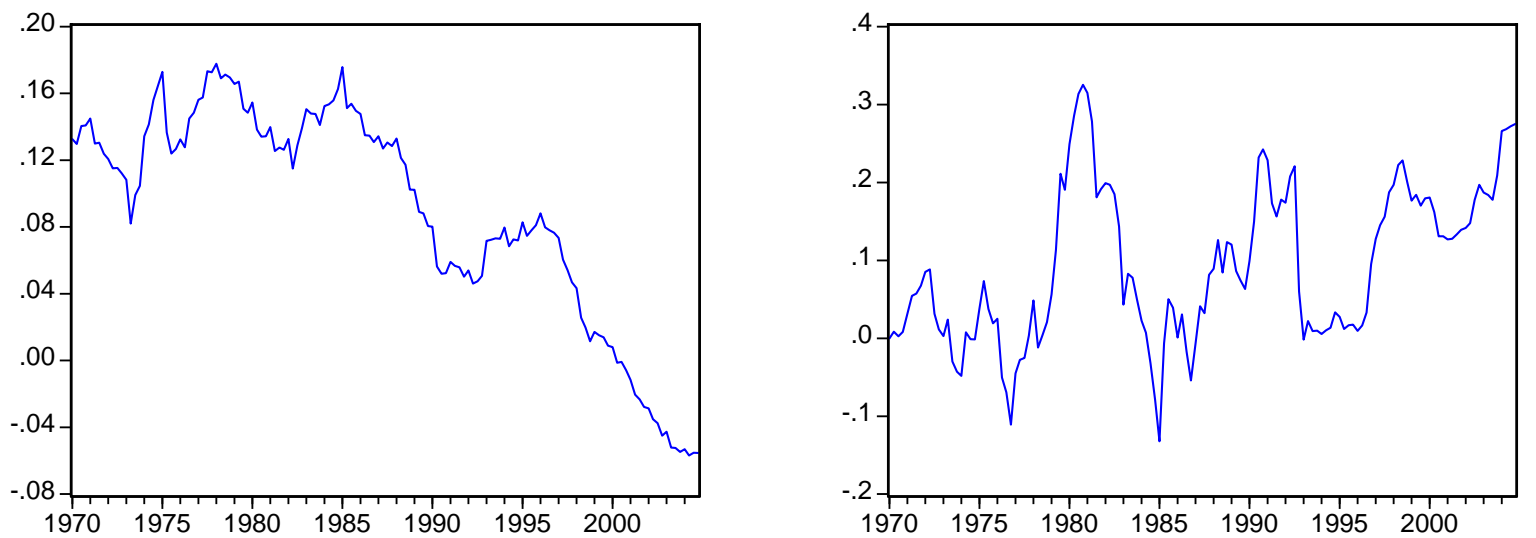

RER (PPI BASED)

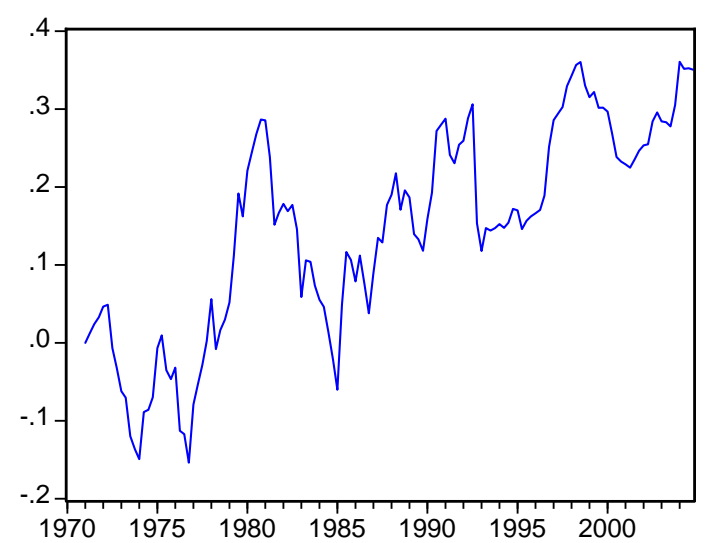

RER (EXP DEFLAT

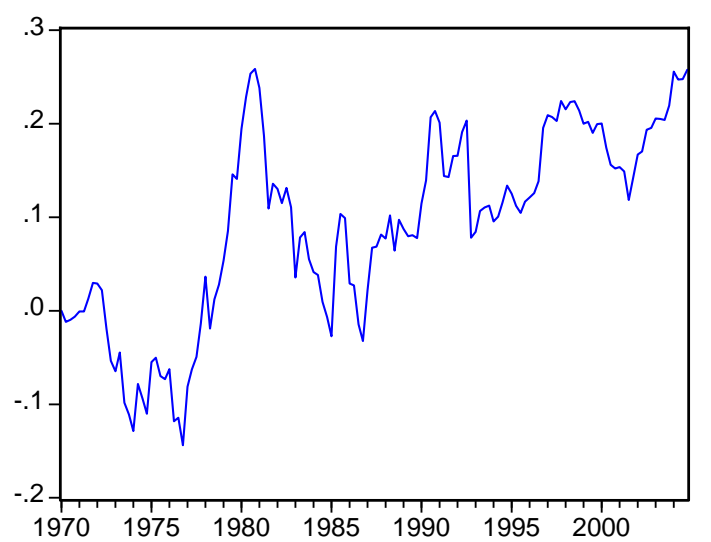


FIGURE A5 - ITALY VAR DATA

LP-LP*
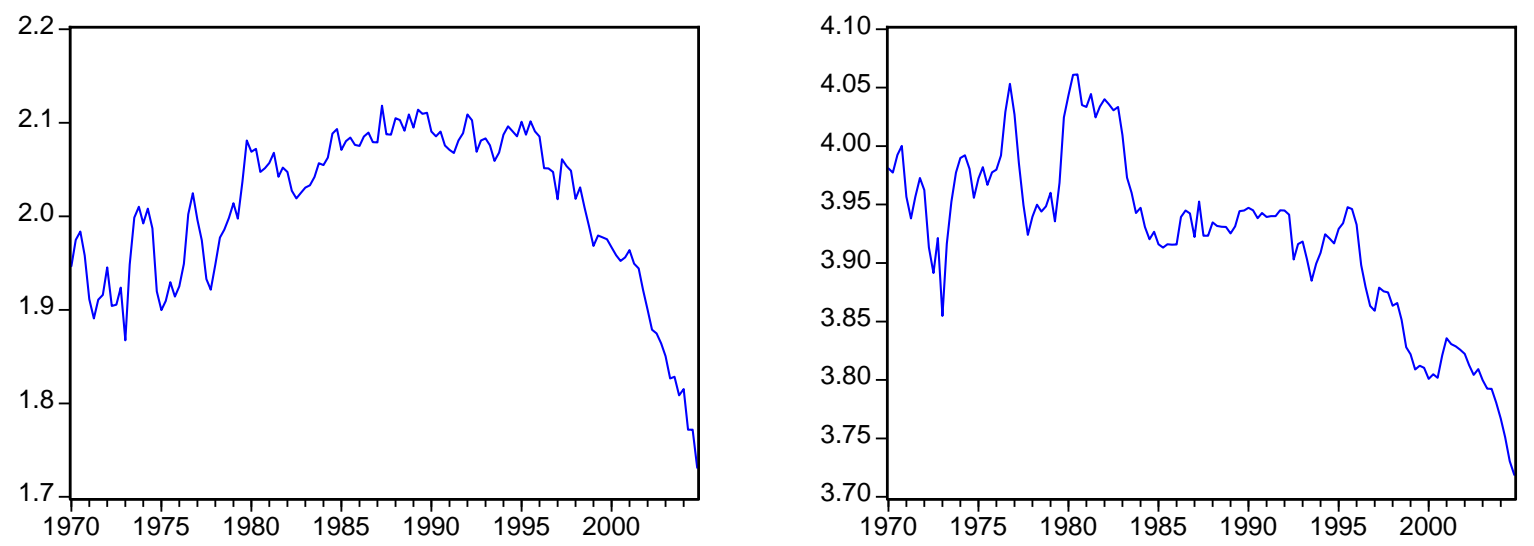

C-C*

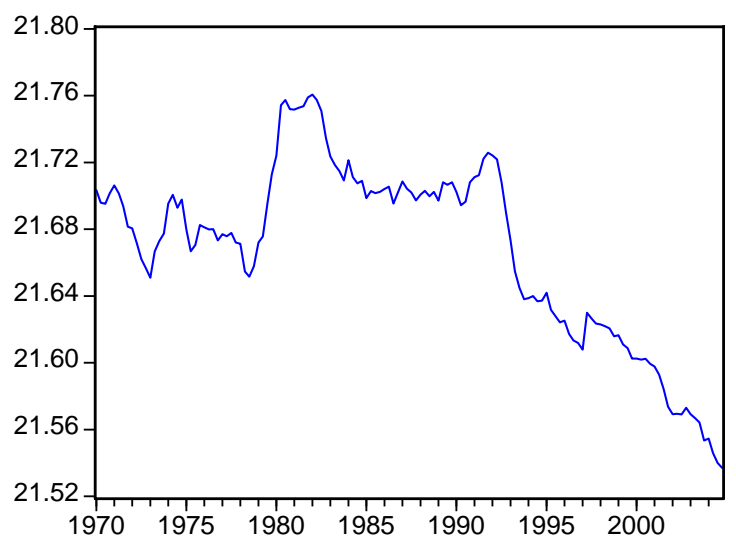

PPI/CPI SERVICES

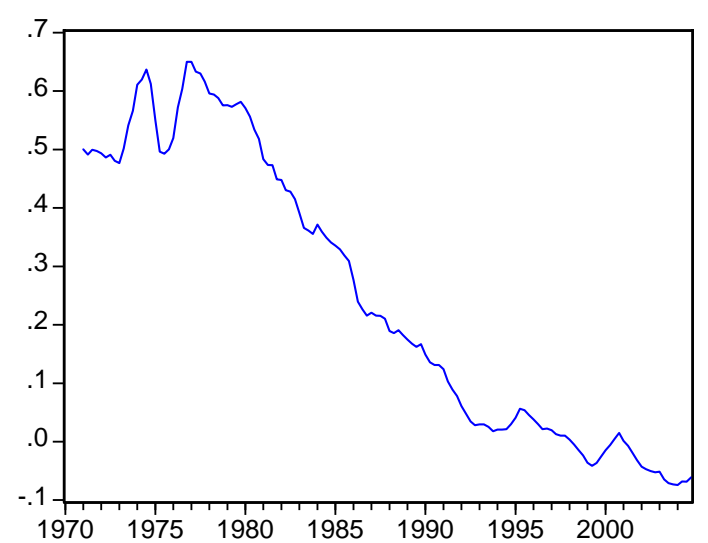

LRER (PPI BASED)

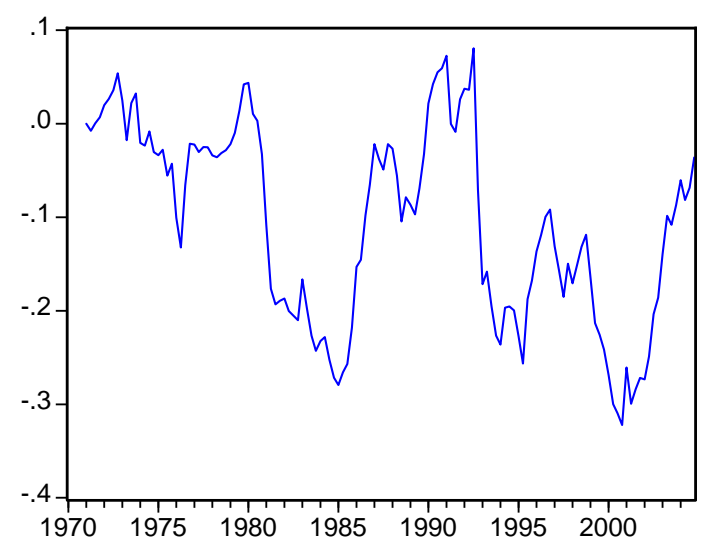

RER (CPI BASED)

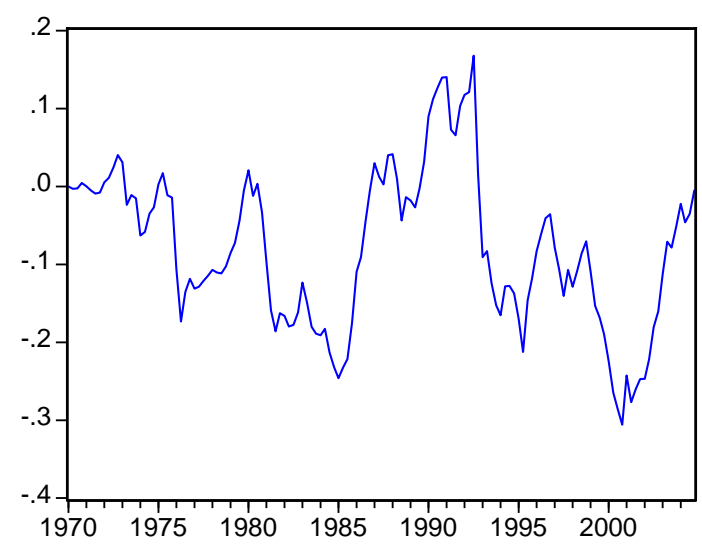

RER (EXP DEFLATOR)

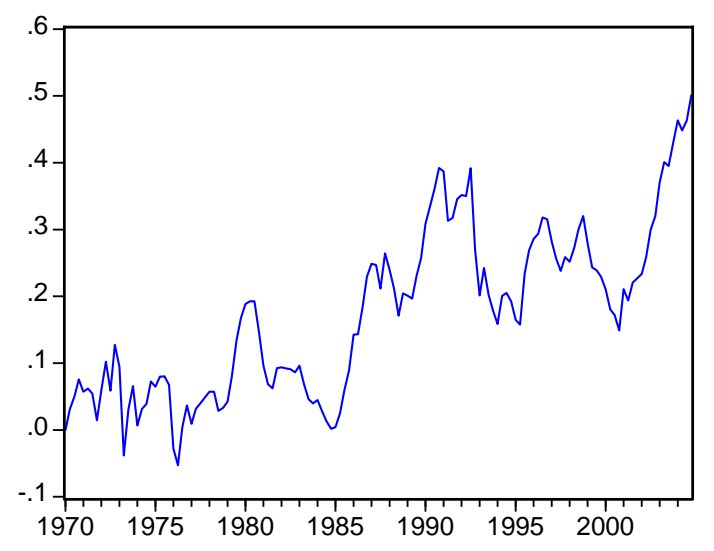


Table A1

Results of unit root tests for USA against ROW

Sample is 1973:1-2004:4

$$
\begin{gathered}
\text { Test specification for differenced series } \\
\text { PP* Test specification for level series } \\
\text { DF-GLS** }
\end{gathered}
$$

\begin{tabular}{|c|c|c|c|c|}
\hline \multirow{2}{*}{\multicolumn{5}{|c|}{ Labor productivity in manufacturing }} \\
\hline & & & & \\
\hline USA & constant & 2.7669 & 1.00 constant, linear trend & 0.008538 pvalue $>0.1$ \\
\hline ROW & constant & -0.7540 & 0.83 constant, linear trend & -2.280369 pvalue $>0.1$ \\
\hline \multirow[t]{2}{*}{ Differential } & constant & -1.6774 & 0.44 constant, linear trend & -0.824595 pvalue $>0.1$ \\
\hline & none & 0.0962 & 0.71 constant & -0.941589 pvalue $>0.1$ \\
\hline \multirow[t]{2}{*}{ Output differential } & constant & 0.1959 & 0.97 constant, linear trend & -1.407352 pvalue $>0.1$ \\
\hline & none & 1.8321 & 0.98 constant & 0.917944 pvalue $>0.1$ \\
\hline \multirow[t]{2}{*}{ Consumption differential } & constant & 1.2960 & 1.00 constant, linear trend & -0.262079 pvalue $>0.1$ \\
\hline & none & 2.0439 & 0.99 constant & 2.798769 pvalue $>0.1$ \\
\hline \multirow[t]{2}{*}{ Net exports over GDP } & none & 0.0842 & 0.73 constant & -0.087946 pvalue $>0.0$ \\
\hline & constant & 1.0842 & 0.93 constant, linear trend & 0.912054 pvalue $>0.1$ \\
\hline \multicolumn{5}{|l|}{$\mathrm{PPI} / \mathrm{CPI}$} \\
\hline CPI SERVICES & constant & 0.674595 & 0.9912 constant, linear trend & 1.064373 pvalue $>0.1$ \\
\hline \multicolumn{5}{|l|}{ Int. relative prices } \\
\hline \multirow[t]{2}{*}{ RER CPI } & none & -0.4388 & 0.52 constant & -1.356705 pvalue $>0.1$ \\
\hline & constant & -2.4182 & 0.14 constant, linear trend & -2.059058 pvalue $>0.1$ \\
\hline \multirow[t]{2}{*}{ RER PPI } & none & -0.8923 & 0.33 constant & -2.142593 pvalue $<0.05$ \\
\hline & constant & -2.3484 & 0.16 constant, linear trend & -2.625866 pvalue $>0.1$ \\
\hline \multirow[t]{2}{*}{ EXP DEF } & none & -0.0055 & 0.68 constant & -0.327176 pvalue $>0.1$ \\
\hline & constant & -1.6585 & 0.45 constant, linear trend & -1.761566 pvalue $>0.1$ \\
\hline
\end{tabular}

Notes

Phillips-Perron test with critical values from MacKinnon (1991, 1996)

**Augmented DF test modified according to Elliot et al . (1996); critical values from MacKinnon (1991, 1996)

${ }^{* * *} \mathrm{~A}$ p-value less than $0.1(0.05)$ means that the null of a unit root is rejected at the 10 (5) percent confidence level 
Table A2

Results of unit root tests for Japan against ROW

Sample is 1973:1-2004:4

Test specification for difference Test specification for level series PP*

\begin{tabular}{|c|c|c|c|c|}
\hline & \multicolumn{2}{|c|}{ test statistic p-value ${ }^{* * *}$} & \multirow[t]{2}{*}{ test statistic p-value*** } \\
\hline & & \multicolumn{2}{|c|}{ Labor productivity in manufacturing } & \\
\hline Japan & constant & -1.581681 & 0.489 constant, linear trend & -1.883897 pvalue $>0.1$ \\
\hline ROW & constant & 1.710243 & 0.9996 constant, linear trend & -0.860656 pvalue $>0.1$ \\
\hline \multirow[t]{2}{*}{ Differential } & constant & -1.536393 & 0.5121 constant, linear trend & -0.871536 pvalue $>0.1$ \\
\hline & none & -0.111406 & 0.6435 constant & -0.890574 pvalue $>0.1$ \\
\hline \multirow[t]{2}{*}{ Output differential } & constant & -0.979977 & 0.759 constant, linear trend & -0.792318 pvalue $>0.1$ \\
\hline & none & -0.1599 & 0.6266 constant & -0.898556 pvalue $>0.1$ \\
\hline \multirow[t]{2}{*}{ Consumption differential } & constant & 0.038817 & 0.9596 constant, linear trend & 0.02179 pvalue $>0.1$ \\
\hline & none & -0.599213 & 0.456 constant & -0.544825 pvalue $>0.1$ \\
\hline \multirow[t]{2}{*}{ Net exports over GDP } & none & -1.86411 & 0.0596 constant & -2.822581 pvalue $<0.01$ \\
\hline & constant & -2.814488 & 0.059 constant, linear trend & -3.035634 pvalue $<0.05$ \\
\hline \multicolumn{5}{|l|}{ PPI/CPI } \\
\hline CPI SERVICES & constant & -1.182787 & 0.6806 constant, linear trend & 1.064373 pvalue $>0.1$ \\
\hline \multicolumn{5}{|l|}{ Int. relative prices } \\
\hline \multirow[t]{2}{*}{ RER CPI } & none & -0.080443 & 0.654 constant & -0.724922 pvalue $>0.1$ \\
\hline & constant & -2.445101 & 0.1316 constant, linear trend & -2.0698 pvalue $>0.1$ \\
\hline \multirow[t]{2}{*}{ RER PPI } & none & -0.659916 & 0.4295 constant & -1.420449 pvalue $>0.1$ \\
\hline & constant & -2.506998 & 0.1162 constant, linear trend & -2.63375 pvalue $>0.1$ \\
\hline \multirow[t]{2}{*}{ EXP DEF } & none & -1.380222 & 0.155 constant & -1.981002 pvalue $<0.05$ \\
\hline & constant & -2.217913 & 0.201 constant, linear trend & -2.431013 pvalue $>0.1$ \\
\hline
\end{tabular}

Notes

Phillips-Perron test with critical values from MacKinnon $(1991,1996)$

**Augmented DF test modified according to Elliot et al . (1996); critical values from MacKinnon $(1991,1996)$

${ }^{* * *}$ A p-value less than $0.1(0.05)$ means that the null of a unit root is rejected at the 10 (5) percent confidence level 
Table A3

Results of unit root tests for Germany against ROW

Sample is 1973:1-2004:4

Test specification for difference Test specification for level series

PP*

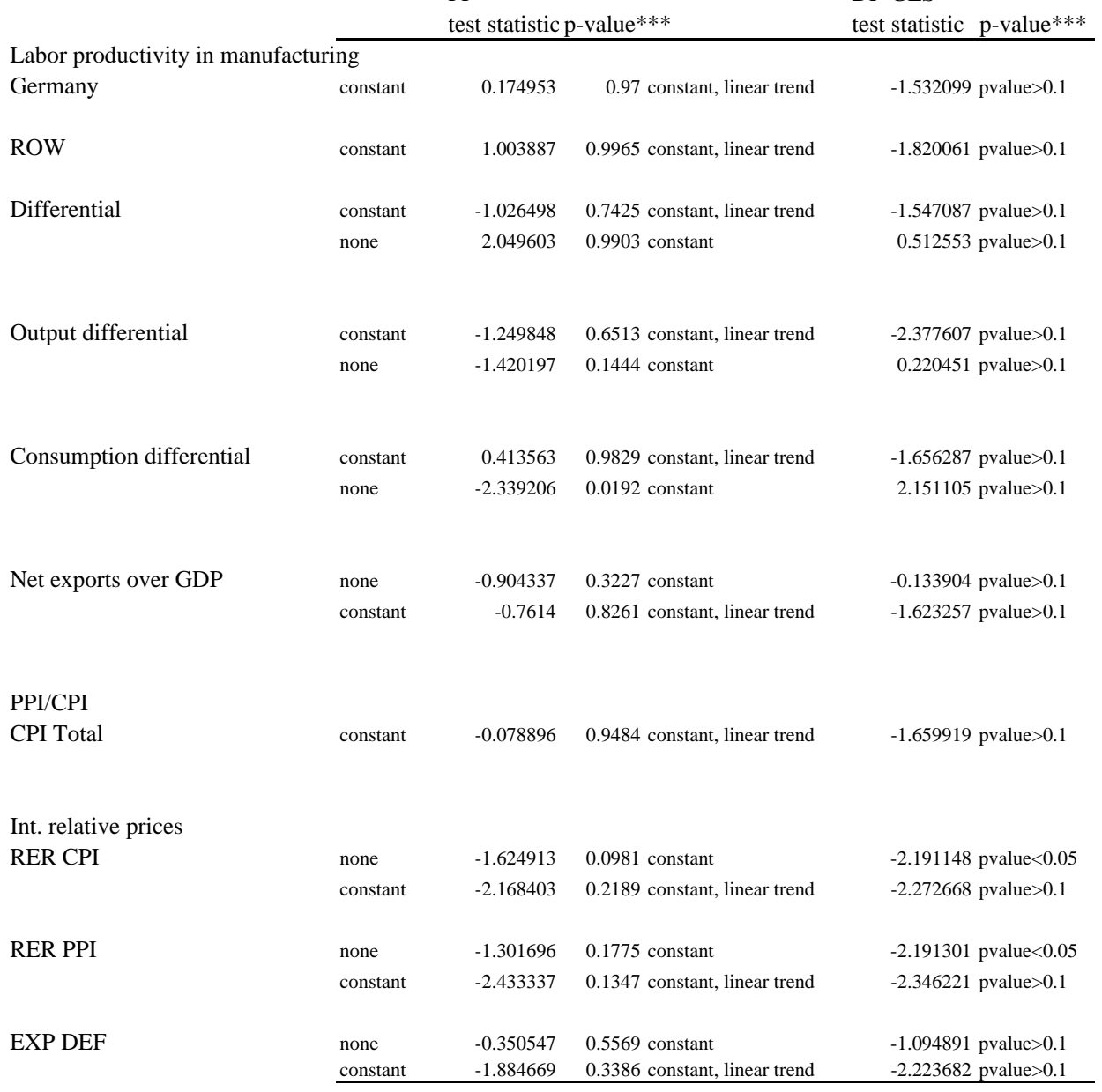

Notes

*Philips-Perron test with critical values from MacKinnon (1991, 1996)

**Augmented DF test modified according to Elliot et al . (1996); critical values from MacKinnon $(1991,1996)$

${ }^{* * *}$ A p-value less than $0.1(0.05)$ means that the null of a unit root is rejected at the $10(5)$ percent confidence leve 
Table A4

Results of unit root tests for UK against ROW

Sample is 1973:1-2004:4

Test specification for differenced series Test specification for level series

test statistic $\mathrm{p}$-value***

test statistic p-value***

\begin{tabular}{|c|c|c|c|c|}
\hline \multicolumn{5}{|c|}{ Labor productivity in manufacturing } \\
\hline UK & constant & 0.630927 & 0.9901 constant, linear trend & -1.485368 pvalue $>0.1$ \\
\hline ROW & constant & 0.762981 & 0.9931 constant, linear trend & -2.917834 pvalue $<0.1$ \\
\hline \multirow[t]{2}{*}{ Differential } & constant & -1.814605 & 0.3721 constant, linear trend & -1.521984 pvalue $>0.1$ \\
\hline & none & -0.334428 & 0.563 constant & -1.30747 pvalue $>0.1$ \\
\hline \multirow[t]{2}{*}{ Output differential } & constant & -0.763321 & 0.8256 constant, linear trend & -2.032963 pvalue $>0.1$ \\
\hline & none & -0.746914 & 0.3911 constant & -0.489868 pvalue $>0.1$ \\
\hline \multirow[t]{2}{*}{ Consumption differential } & constant & -2.1273 & 0.2344 constant, linear trend & -0.927952 pvalue $>0.1$ \\
\hline & none & -0.298068 & 0.5766 constant & -0.873383 pvalue $>0.1$ \\
\hline \multirow[t]{2}{*}{ Net exports over GDP } & none & -1.883786 & 0.0571 constant & -2.182391 pvalue $<0.05$ \\
\hline & constant & -2.300727 & 0.1734 constant, linear trend & -2.567268 pvalue $>0.10$ \\
\hline \multicolumn{5}{|l|}{ PPI/CPI } \\
\hline CPI Total & constant & 0.452297 & 0.9844 constant, linear trend & 1.020843 pvalue $>0.1$ \\
\hline \multicolumn{5}{|l|}{ Int. relative prices } \\
\hline \multirow[t]{2}{*}{ RER CPI } & none & -1.171089 & 0.2197 constant & -2.101924 pvalue $<0.05$ \\
\hline & constant & -2.206316 & 0.2051 constant, linear trend & -2.897819 pvalue $<0.10$ \\
\hline \multirow[t]{2}{*}{ RER PPI } & none & -0.291671 & 0.579 constant & -0.501317 pvalue $>0.1$ \\
\hline & constant & -1.496524 & 0.5323 constant, linear trend & -2.68954 pvalue $>0.1$ \\
\hline \multirow[t]{2}{*}{ EXP DEF } & none & -0.668291 & 0.4258 constant & -0.596741 pvalue $>0.1$ \\
\hline & constant & -1.742741 & 0.4074 constant, linear trend & -2.622335 pvalue $>0.1$ \\
\hline
\end{tabular}

Notes

Phillips-Perron test with critical values from MacKinnon $(1991,1996)$

**Augmented DF test modified according to Elliot et al . (1996); critical values from MacKinnon $(1991,1996)$

${ }^{* * *} \mathrm{~A}$ p-value less than $0.1(0.05)$ means that the null of a unit root is rejected at the 10 (5) percent confidence level 
Table A5

Results of unit root tests for Italy against ROW

Sample is 1973:1-2004:4

Test specification for differenced series _ Test specification for level series

PP* DF-GLS**

\begin{tabular}{|c|c|c|c|c|}
\hline & & test statistic & p-value*** & $\begin{array}{l}\text { DF-GLS stistic } \mathrm{p} \text {-value*** } \\
\text { test stat }\end{array}$ \\
\hline \multicolumn{5}{|c|}{ Labor productivity in manufacturing } \\
\hline Italy & constant & -2.204301 & 0.2059 constant, linear trend & -0.883729 pvalue $>0.1$ \\
\hline ROW & constant & 1.594922 & 0.9995 constant, linear trend & -1.013203 pvalue $>0.1$ \\
\hline \multirow[t]{2}{*}{ Differential } & constant & 0.395478 & 0.9821 constant, linear trend & -0.03336 pvalue $>0.1$ \\
\hline & none & -0.761495 & 0.3846 constant & -0.25524 pvalue $>0.1$ \\
\hline \multirow{2}{*}{ Output differential } & constant & -0.181216 & 0.9367 constant, linear trend & -1.328729 pvalue $>0.1$ \\
\hline & none & -0.93902 & 0.3082 constant & -0.677483 pvalue $>0.1$ \\
\hline \multirow[t]{2}{*}{ Consumption differential } & constant & 0.036218 & 0.9594 constant, linear trend & -1.038549 pvalue $>0.1$ \\
\hline & none & -0.922371 & 0.3151 constant & -0.151934 pvalue $>0.1$ \\
\hline \multirow[t]{2}{*}{ Net exports over GDP } & none & -2.455012 & 0.0142 constant & -2.486968 pvalue $<0.05$ \\
\hline & constant & -2.575099 & 0.1008 constant, linear trend & -2.844862 pvalue $<0.10$ \\
\hline \multicolumn{5}{|l|}{$\mathrm{PPI} / \mathrm{CPI}$} \\
\hline CPI SERVICES & constant & -0.288019 & 0.9224 constant, linear trend & -2.10485 pvalue $>0.1$ \\
\hline \multicolumn{5}{|l|}{ Int. relative prices } \\
\hline \multirow[t]{2}{*}{ RER CPI } & none & -1.911597 & 0.0537 constant & -2.132607 pvalue $<0.05$ \\
\hline & constant & -2.61669 & 0.0922 constant, linear trend & -2.548289 pvalue $>0.10$ \\
\hline \multirow[t]{2}{*}{ RER PPI } & none & -1.574812 & 0.1082 constant & -1.68943 pvalue $<0.1$ \\
\hline & constant & -2.56929 & 0.1021 constant, linear trend & -2.378501 pvalue $>0.1$ \\
\hline \multirow[t]{2}{*}{ EXP DEF } & none & 0.233667 & 0.7525 constant & -0.361994 pvalue $>0.1$ \\
\hline & constant & -0.893053 & 0.7878 constant, linear trend & -3.129265 pvalue $<0.05$ \\
\hline
\end{tabular}

Notes
${ }^{*}$ Phillips-Perron test with critical values from MacKinnon $(1991,1996)$

**Augmented DF test modified according to Elliot et al . (1996); critical values from MacKinnon $(1991,1996)$

A 